\title{
Otimização de risco estrutural baseada em
}

\section{confiabilidade}

Dissertação apresentada à Escola de Engenharia de São Carlos como parte dos requisitos para obtenção do título de Mestre em Engenharia de Estruturas.

Área de Concentração: Engenharia de Estruturas.

Orientador: Prof. Dr. André Teófilo Beck

São Carlos 
AUTORIZO A REPRODUÇÃO E DIVULGAÇÃO TOTAL OU PARCIAL DESTE TRABALHO, POR QUALQUER MEIO CONVENCIONAL OU ELETRÔNICO, PARA FINS DE ESTUDO E PESQUISA, DESDE QUE CITADA A FONTE.

Ficha catalográfica preparada pela Seção de Tratamento da Informação do Serviço de Biblioteca - EESC/USP

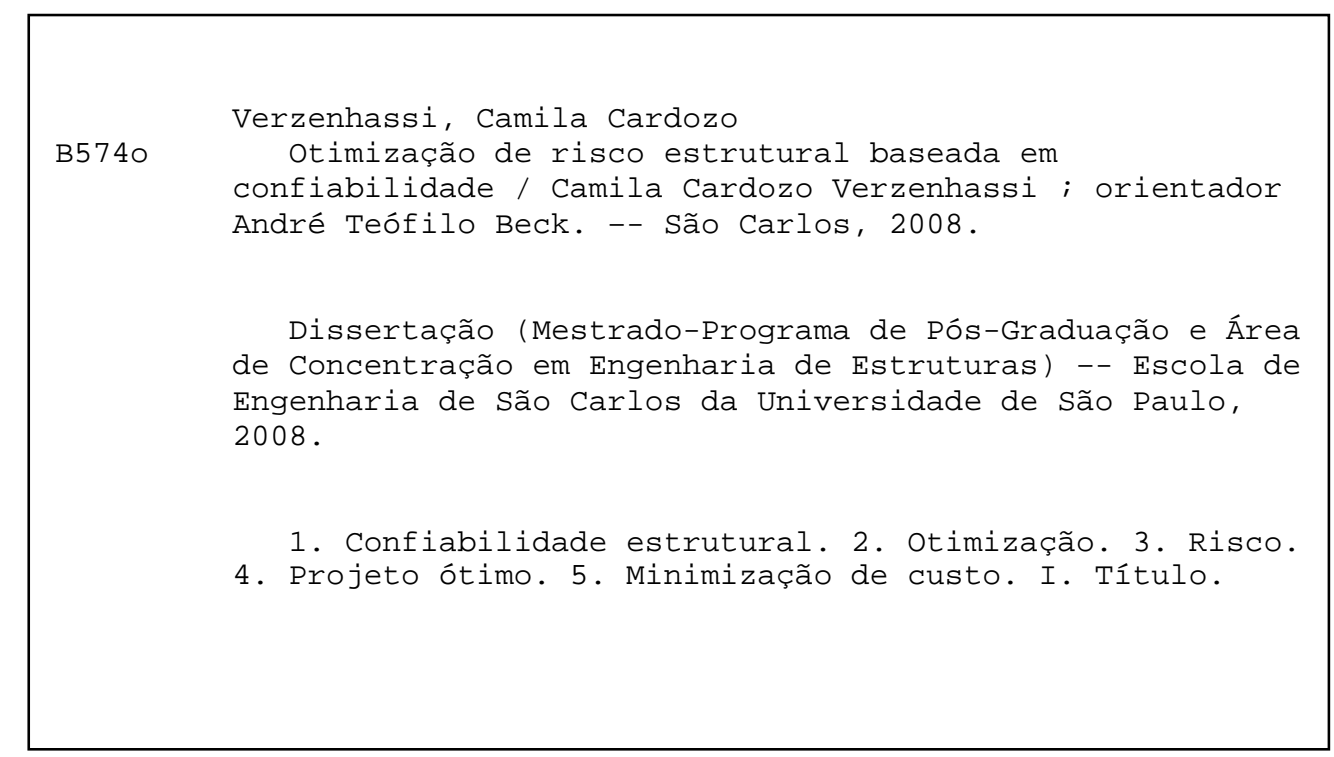


FOLHA DE JULGAMENTO

Candidata: Engenheira CAMILA CARDOZO VERZENHASSI

Dissertação defendida e julgada em 28/03/2008 perante a Comissão Julgadora:

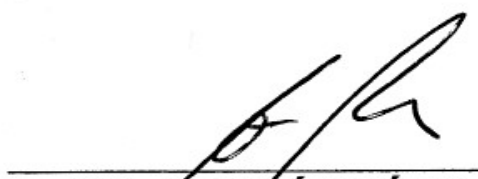

ARROVARO

Prof. Dr/ANDkÉ TEÓFILO BECK (Orientador)

(Escola de Engenharia de São Carlos/USP)

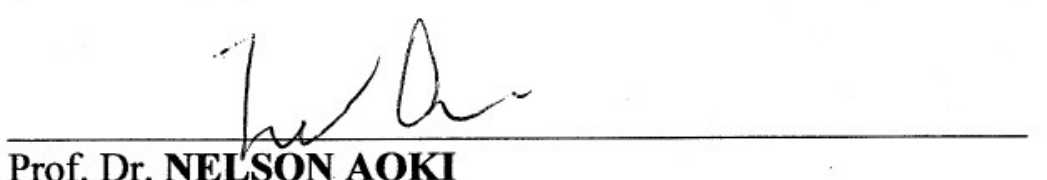

Prof. Dr. NELSON AOKI

(Escola de Engenharia de São Carlos/USP) $\triangle P$ RorDDO

APROVAPO

Prof. Dr. RUY CARLOS RAMOS DE MENEZES

(Universidade Federal do Rio Grande do Sul/UFRGS)
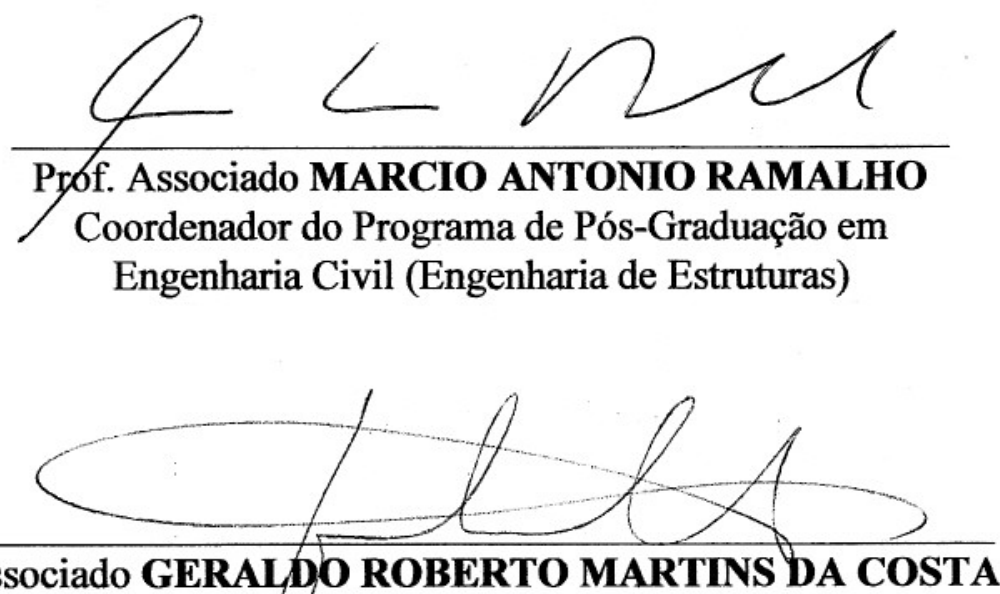
Prof. Associado GERAYDo ROBERTO MARTINS DA COSTA
Presidente da Comissão de Pós-Graduação

* Orof. Ruy Calos Ramos de Menezes paticipar da defera através de video-cofuéncia. 



\section{DEDICATÓRIA}

Aos meus pais, Valentin e Regina, e ao meu irmão Vitor Hugo. 

A Deus, pelo dom da vida, pelas oportunidades e por sempre guiar meus passos.

Aos meus pais, Valentin e Regina, pelos valores que me passaram e pelo incentivo e amor incondicionais. Ao meu irmão Vitor Hugo pela companhia constante mesmo à distância.

Ao meu orientador Prof. Dr. André Teófilo Beck sempre presente, paciente e atencioso.

Aos amigos que fiz em São Carlos, pela convivência e companheirismo e por tornarem o período do mestrado muito mais agradável.

Aos amigos em Curitiba, por continuarem a cultivar nossa amizade e por sempre me incentivarem a perseguir os meus sonhos.

A todos os professores e funcionários do Departamento de Engenharia de Estruturas da EESC/USP que contribuíram para minha formação.

Ao CNPq pela bolsa concedida nos primeiros seis meses do mestrado.

A FAPESP pela bolsa concedida nos últimos 18 meses do mestrado. 

VERZENHASSI, C. C. Otimização de risco estrutural baseada em confiabilidade. 2008. 154 p. Dissertação (Mestrado) - Escola de Engenharia de São Carlos, Universidade de São Paulo, São Carlos - SP, 2008.

Em um ambiente competitivo, sistemas estruturais devem ser projetados levando-se em conta, além da funcionalidade, o custo total de construção e operação da estrutura, bem como a sua capacidade de geração de lucro. Os custos estão diretamente ligados ao risco que a construção e operação da estrutura oferecem. O risco deve ser entendido como o produto de um custo esperado de falha pela probabilidade de que essa falha aconteça. $A$ segurança da estrutura está diretamente relacionada com os coeficientes de segurança adotados em projeto. Verifica-se, portanto, que a minimização do custo total de um sistema estrutural passa, necessariamente, por uma otimização do nível de segurança para o qual o sistema é projetado. Diante desses fatos, neste trabalho realiza-se a busca do coeficiente de segurança parcial ótimo que minimiza o custo esperado total de sistemas estruturais: a chamada otimização de risco baseada em confiabilidade. Para tanto, foi desenvolvido um programa computacional em Fortran que encontra o coeficiente de segurança ótimo. Tal programa está acoplado a um programa de análise de confiabilidade estrutural desenvolvido na EESC/USP e a um programa comercial de elementos finitos. $O$ trabalho inclui alguns estudos de caso, entre eles o de uma torre de telefonia sujeita a cargas de vento e de tornado. Esses estudos mostram que quando parcelas não estruturais dominam o custo, um projeto super-dimensionado não representa grande perda econômica, enquanto um projeto sub-dimensionado pode causar enormes prejuízos. O trabalho aponta que a confiabilidade ótima é altamente dependente das conseqüências e custos de falha. Mostra também que casualidades que possuem grande incerteza e grandes conseqüências de falha tendem a dominar o projeto. O estudo indica que, em situações de projeto diferentes (e.g., carregamentos diferentes), é razoável trabalhar-se com níveis de confiabilidade distintos. Além disso, mostra que a falta de percepção do risco pelas partes envolvidas em um projeto pode levar a contratos inadequados. Finalmente, o estudo revela que para uma estrutura submetida a carregamentos que variam com o tempo, como tornados, o custo e a confiabilidade ótimos são altamente dependentes da vida útil adotada para o projeto.

Palavras-chave: Confiabilidade estrutural. Otimização. Risco. Projeto ótimo. Minimização de custo. 



\section{ABSTRACT}

VERZENHASSI, C. C. Reliability-based structural risk optimization. 2008. 154 p. Dissertation (M. Sc.) - Escola de Engenharia de São Carlos, Universidade de São Paulo, São Carlos - SP, 2008.

In a competitive environment, structural systems must be designed considering not only their function, but also their total costs of construction and operation and their ability to generate profit. The costs are directly linked to the risk resulting from construction and operation of the structure. Risk is defined as the product of failure cost by failure probability. The safety of the structure is directly related to safety coefficients adopted in design. Hence, the minimization of the total cost of a structural system necessarily involves an optimization of the safety level for which the system is designed. Based on these facts, the present study investigates the partial safety factor which minimizes the total expected cost of specific structural systems. This is referred to as reliability-based risk optimization. A Fortran computer code is developed to find the optimum safety factor. This code works together with a structural reliability analysis program developed at EESC/USP and with a commercial finite element program. Some case studies are presented, including the design of a steel frame communications tower, subjected to extreme storm and tornado wind loads. These studies show that when non-structural terms dominate the cost function, it is not too costly to overdesign, but an under-designed project can cause huge money losses. The study shows that optimum reliability is strongly dependant on limit state exceedance consequences. It also shows that events with high uncertainty and high failure consequences generally dominate the design, and that for different design situations (e.g., multiple hazards) it is reasonable to work with different reliability levels. Moreover, it shows that when risk is not properly understood, it is also not properly dealt with by the parties involved, leading to inadequate contracts. Finally, the study shows that for structures under time-varying loads, such as tornados, the optimum reliability is strongly dependent on the selected design life.

Keywords: Structural reliability. Reliability-based risk optimization. Optimum design. Minimum design cost. 



\section{Lista de Figuras}

Figura 2.1: Composição do custo total esperado de um sistema estrutural hipotético 33

Figura 3.1: Variação dos coeficientes de segurança característicos com o nível de confiança. 49

Figura 3.2: Problema fundamental da confiabilidade (interferência entre populações)... 52

Figura 3.3: O índice de confiabilidade $\beta$ e o ponto de projeto, no espaço normal padrão.... 52

Figura 3.4: Diagrama representativo da árvore de falhas 56

Figura 3.5: Interpretação gráfica do problema da confiabilidade estrutural e a transformação para o espaço normal padrão

Figura 4.1: Exemplo de função de uma variável com um mínimo global e dois mínimos locais 64

Figura 4.2: Método da Interpolação Quadrática. 68

Figura 4.3: Situações aceitáveis no método da Interpolação Quadrática 69

Figura 4.4: Fluxograma de uma iteração do Método da Interpolação Quadrática 70

Figura 4.5: Interpretação geométrica do método regula falsi 72

Figura 4.6: Caso particular em que o método regula falsi demora para convergir 73

Figura 4.7: Fluxograma do método Regula Falsi ..... 74

Figura 5.1: Parte da sub-rotina LIMIT_STATE_FUNCTION.F90. 77

Figura 5.2: Trecho do módulo COST_FUNCTIONS.F90 mostrando a criação das funções custo inicial, custos de falha, e da função objetivo COST para um pórtico plano 81

Figura 5.3: Fluxograma do RiskOPT 82

Figura 6.1: Barra tracionada. 83

Figura 6.2: Gráfico custo $x \lambda_{k}$ para o problema da barra tracionada 87

Figura 6.3: Coluna tubular metálica simplesmente apoiada carregada verticalmente 88

Figura 6.4: Gráfico custo $\mathrm{x} \lambda_{\mathrm{k}}$ para o problema da barra comprimida. 92

Figura 6.5: Geometria do problema da viga em balanço 92

Figura 6.6: Gráfico custo $\mathrm{x} \lambda_{\mathrm{k}}$ para o problema da viga em balanço 98

Figura 6.7: Variação do $\lambda_{k}$ ótimo com a classe de conseqüência de falha. 98

Figura 6.8: Treliça plana de 6 barras 99 
Figura 6.9: Gráfico custo $\mathrm{x} \lambda_{\mathrm{k}}$ para o problema da treliça plana 106

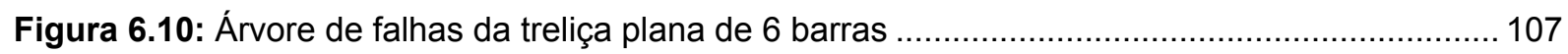

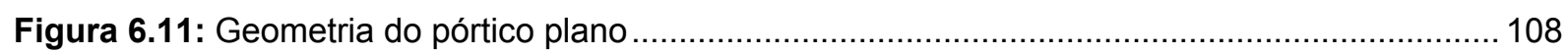

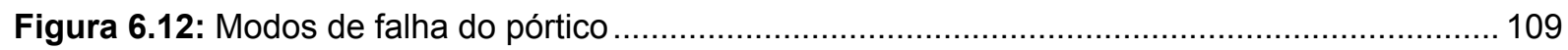

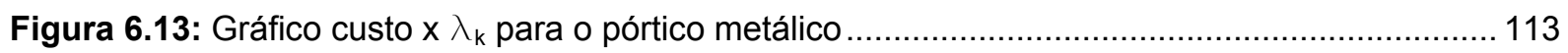

Figura 6.14: Variação do ponto ótimo com a conseqüência de falha ........................................... 113

Figura 6.15: Modelo da torre feito no Ansys e torre verdadeira .................................................. 114

Figura 6.16: Regiões favoráveis à formação de tornado no mundo ……..................................... 117

Figura 6.17: Detalhe das regiões das Américas favoráveis à formação de tornado ........................ 117

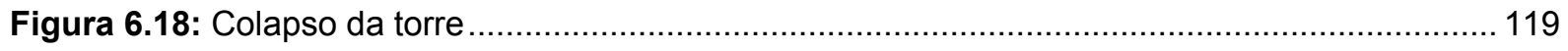

Figura 6.19: Estudo da variação do deslocamento e da carga críticos com o $\lambda_{k} \ldots \ldots \ldots \ldots \ldots \ldots \ldots \ldots \ldots . . . . . . . . . .119$

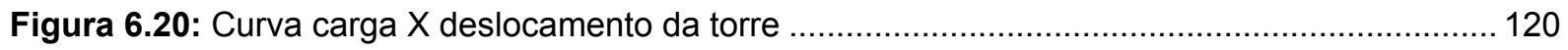

Figura 6.21: Sensibilidade do $\lambda_{k}$ com a vida útil e a conseqüência de falha para o caso da torre

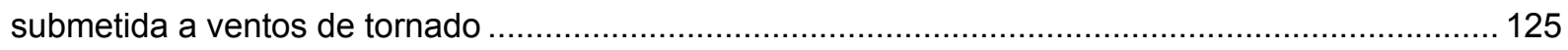

Figura 6.22: Gráfico custo $x \lambda_{k}$ para a estrutura submetida ao vento de 50 anos .......................... 126

Figura 6.23: Gráfico custo $x \lambda_{k}$ para estrutura submetida ao vento de tornado .............................. 127

Figura A.1: Interação entre os módulos de otimização, confiabilidade e mecânico .......................... 139 
Tabela 3.1: Sumário de distribuições contínuas de probabilidades .

Tabela 3.2: Algumas variáveis aletatórias e distribuições comumente utilizadas......

Tabela 3.3: Valores alvo para o índice de confiabilidade $\beta$ e probabilidades de falha associadas, relacionados a estados limites últimos. 53

Tabela 6.1: Variáveis aleatórias do problema da barra tracionada 84

Tabela 6.2: Resultados do RiskOPT para o problema da barra tracionada 87

Tabela 6.3: Variáveis aleatórias do problema da barra comprimida 88

Tabela 6.4: Variáveis determinísticas do problema da barra comprimida 89

Tabela 6.5: Resultados do RiskOPT para o problema da barra comprimida. 91

Tabela 6.6: Variáveis aleatórias para o problema da viga em balanço. 93

Tabela 6.7: Custo dos materiais de construção 96

Tabela 6.8: Resultado do RiskOPT para o problema da viga em balanço 97

Tabela 6.9: Variáveis aleatórias para o problema da treliça plana 100

Tabela 6.10: Perfis adotados para o projeto de referência da treliça plana. 103

Tabela 6.11: Resultado do RiskOPT para o problema da treliça plana 105

Tabela 6.12: Perfis comerciais adotados para o projeto otimizado. 105

Tabela 6.13: Variáveis aleatórias para o problema do pórtico plano 108

Tabela 6.14: Resultados do RiskOPT para o problema do pórtico plano 112

Tabela 6.15: Dimensões do pórtico otimizado 112

Tabela 6.16: Escala Fujita de classificação de tornados 115

Tabela 6.17: Dados adotados para tornados na região Sul do Brasil. 117

Tabela 6.18: Dados para o problema da torre. 118

Tabela 6.19: Custos para o problema da torre submetida ao vento de norma e a tornados. 123

Tabela 6.20: $\lambda_{\mathrm{k}}$ e $\beta$ ótimos obtidos para a torre 123 



\section{Lista de Siglas}

\begin{tabular}{|c|c|}
\hline AASHTO & American Association of State Highway and Transportation Officials \\
\hline CET & Custo Esperado Total \\
\hline CF & Custo de Falha \\
\hline CFS & Custo esperado de Falha de Serviço \\
\hline CFU & Custo esperado de Falha Última \\
\hline $\mathbf{C l}$ & Custo Inicial \\
\hline CM & Custo de Material \\
\hline CMO & Custo de Mão de Obra \\
\hline EEL & Equação de Estado Limite \\
\hline EESC & Escola de Engenharia de São Carlos \\
\hline FDA & Função de Distribuição Acumulada de Probabilidades \\
\hline FDP & Função Densidade de Probabilidade \\
\hline FORM & First Order Reliability Method - método de aproximação de primeira ordem \\
\hline JCSS & Joint Committee on Structural Safety \\
\hline MSR & Método das Superfícies de Resposta \\
\hline MSRI & $\begin{array}{l}\text { Método da Superfície de Resposta utilizando Monte Carlo com amostragem } \\
\text { por Importância }\end{array}$ \\
\hline MSRS & Método da Superfície de Resposta utilizando Monte Carlo simples \\
\hline SMCI & Simulação de Monte Carlo com amostragem por Importância \\
\hline SMCS & Simulação de Monte Carlo Simples \\
\hline SORM & Second Order Reliability Method - método de aproximação de segunda ordem \\
\hline StRAnD & $\begin{array}{l}\text { Structural Reliability Analysis and Design - Programa de confiabilidade } \\
\text { estrutural }\end{array}$ \\
\hline USP & Universidade de São Paulo \\
\hline VA & Variável Aleatória \\
\hline
\end{tabular}





\begin{tabular}{|c|c|}
\hline$A$ & área da seção transversal \\
\hline$b$ & base da seção transversal \\
\hline c.o.v. & coeficiente de variação \\
\hline E & módulo de elasticidade do material \\
\hline$f_{c k}$ & resistência característica do concreto à compressão \\
\hline$f_{c}$ & variável aleatória resistência do concreto à compressão \\
\hline$f_{s k}$ & resistência característica do aço à tração \\
\hline$f_{s}$ & variável aleatória resistência do aço à tração \\
\hline$g(x)$ & equação de estado limite do problema \\
\hline$h$ & altura da seção transversal \\
\hline$I$ & momento de inércia da seção transversal \\
\hline$P_{f}$ & probabilidade de falha \\
\hline$P_{f S}$ & probabilidade de falha do estado limite de serviço \\
\hline$P_{f U}$ & probabilidade de falha do estado limite último \\
\hline$p_{k}$ & nível de confiança \\
\hline$R$ & resistência \\
\hline$r_{k}$ & resistência característica \\
\hline$S$ & solicitação \\
\hline$s_{k}$ & solicitação característica \\
\hline$V$ & volume da peça \\
\hline$x$ & vetor das VA's \\
\hline
\end{tabular}


variável aleatória, definida por sua FDP e por seus momentos

$Z_{x}$

módulo plástico da seção transversal

$\beta$

índice de confiabilidade

$\gamma_{k}$

coeficiente característico de majoração da solicitação

$\phi$

coeficiente característico de minoração da resistência

$\lambda_{0}$

coeficiente de segurança central

$\lambda_{k}$

coeficiente de segurança global ou característico

$\mu_{X}$

valor médio da variável aleatória $X$

$\rho$

taxa entre o custo esperado total e o custo de construção - indica a classe de consequência da estrutura

$v$

coeficiente de Poisson

$\sigma$

desvio-padrão da variável aleatória

$\sigma_{y}$

tensão de escoamento do material 


\section{SUMÁRIO}

Capítulo 1: INTRODUÇÃO 25

1.1 Considerações Iniciais 25

1.2 Objetivo 26

1.3 Justificativa 26

1.4 Metodologia 28

1.5 Organização da Dissertação 29

Capítulo 2: REVISÃO BIBLIOGRÁFICA 31

2.1 Composição do Custo Esperado Total de um Sistema Estrutural 31

2.2 Problema de Otimização: Minimização do Custo Total Esperado 33

2.3 Confiabilidade Estrutural 35

2.4 Otimização Estrutural Baseada em Confiabilidade 37

Capítulo 3: CONFIABILIDADE ESTRUTURAL 41

3.1 Variáveis Aleatórias 41

3.1.1 Função de Distribuição Acumulada de Probabilidades (FDA) 41

3.1.2 Função de densidade de probabilidades (FDP) ___ 42

3.1.3 Média e variância de uma VA contínua ___ 43

3.2 Modelos Probabilísticos 45

3.3 Estados Limites 45

3.3.1 Equações de estado limite 46

3.3.2 Coeficientes de segurança___ 47

3.4 Violação de Estados Limites: A Probabilidade de Falha___ 50

3.4.1 Classes de Conseqüência ___ 53

3.5 Confiabilidade de Componente e Confiabilidade de Sistemas___ 54

3.5.1 Árvore de Falhas _ـ 55

3.6 Cálculo da Probabilidade de Falha __ 56

3.6.1 Métodos assintóticos aproximados _ـ 57 
3.6.2 Métodos de Simulação

3.6.3 Superfícies de Resposta

4.1 Introdução

4.2 Formulação do Problema de Otimização

4.3 Propriedades dos Pontos de Mínimo

4.3.1 Ponto de Mínimo Global

4.3.2 Ponto de Mínimo Local 63

4.4 Algoritmos Utilizados 65

4.4.1 Interpolação Quadrática

4.4.2 Regula Falsi

5.1 Structural Reliability Analysis and Design: o StRAnD 75

5.2 Acoplamento StRAnD/Ansys 77

5.3 O módulo de otimização RiskOPT 79

5.4 Fluxograma 81

Capítulo 6: EXEMPLOS RESOLVIDOS

6.1 Barra tracionada 83

6.2 Barra comprimida 88

6.3 Viga em balanço 92

6.4 Treliça Plana 99

6.5 Pórtico Plano 108

6.6 Torre Tridimensional 114

Capítulo 7: CONCLUSÕES 129

7.1 Sugestões para trabalhos futuros 131 REFERÊNCIAS 133

Apêndice A: RiskOPT - MANUAL DE UTILIZAÇÃO 139

A.1 Estrutura do programa 139 
A.2 Entrada de dados do StRAnD

A.3 Equações de Estado Limite 142

A.4 Funções Custo 144

A.5 Utilização do Módulo Mecânico: entrada de dados do Ansys 146

A.6 Saída de dados do StRAnD 149

A.7 Saída de dados do RiskOPT 154

A.8 Resumo das etapas de utilização do RiskOPT 154 


\section{Capítulo 1: INTRODUÇÃO}

\subsection{Considerações Iniciais}

Durante os últimos 30 anos, técnicas muito efetivas para a estimativa da confiabilidade foram desenvolvidas, tais como First Order Reliability Method (FORM), Second Order Reliability Method (SORM) e técnicas de simulação. No mesmo período, vários métodos para a resolução de problemas de otimização também foram desenvolvidos (ENEVOLDSEN; SORENSEN; 1994).

$\mathrm{Na}$ engenharia de estruturas, projetar sistemas com confiabilidade satisfatória e ao menor custo possível constitui o objetivo principal. Esses requisitos contraditórios são geralmente cumpridos utilizando procedimentos determinísticos, baseados em normas técnicas. Em problemas determinísticos de otimização estrutural a função objetivo geralmente é o volume ou o peso da estrutura, e as restrições estão relacionadas aos requisitos normativos quanto a tensões e deslocamentos. Na otimização de risco estrutural baseada em confiabilidade o custo esperado total relacionado à estrutura (custo inicial, de manutenção e de falha) pode ser usado como função objetivo. As restrições são níveis mínimos de confiabilidade relacionados aos possíveis modos de falha da estrutura. Tipicamente essas restrições impõem que a probabilidade de falha deve ser menor que $10^{-3}$ $-10^{-5}$

A otimização estrutural baseada em confiabilidade tem aplicações mais gerais que o projeto de sistemas estruturais, por exemplo a inspeção ótima e o planejamento de manutenção para pontes, estruturas offshore, e outras (ENEVOLDSEN; SORENSEN; 1994). Também na calibração de coeficientes parciais de segurança de normas técnicas, princípios de otimização baseada em confiabilidade são utilizados (ELLINGWOOD; GALAMBOS; 1982). 


\subsection{Objetivo}

Neste trabalho estuda-se o coeficiente de segurança característico ótimo a ser utilizado em projeto, buscando a minimização do custo esperado total de um sistema estrutural e a otimização do nível de segurança para o qual o sistema é projetado. Para tanto, foi desenvolvido um programa computacional em Fortran 95 que encontra tal coeficiente de segurança ótimo, minimizando assim o risco estrutural. O programa está acoplado ao programa de análise de confiabilidade Structural Risk Analysis and Design (StRAnD), desenvolvido no Departamento de Engenharia de Estruturas da Escola de Engenharia de São Carlos (EESC) da Universidade de São Paulo (USP), e ao programa de elementos finitos Ansys, que faz a análise numérica do modelo mecânico. Através do acoplamento, os mais diversos problemas de aplicação poderão ser estudados. A presente dissertação enfoca especificamente o desenvolvimento do programa de otimização, os estudos de caso realizados, e as conclusões aferidas desses estudos.

\subsection{Justificativa}

O objetivo principal de um projeto estrutural é assegurar que a estrutura será capaz de cumprir as funções dela requeridas satisfatoriamente durante sua vida útil, tais como proteger seus ocupantes de intempéries e suportar carregamentos, e atingir esses objetivos a um custo razoável. A segurança e o desempenho de um sistema estrutural são, invariavelmente, os principais objetivos técnicos de um projeto de engenharia. Devido a tais preocupações com a segurança, a confiabilidade estrutural está rapidamente crescendo em importância na engenharia de projetos. Normas técnicas européias e norte-americanas, nas ultimas 3 ou 4 décadas, buscam determinar coeficientes parciais de segurança baseados em fatores probabilísticos (MRÁZIK; KRIZMA, 1997) abandonando o antigo modelo de coeficientes de segurança baseados na experiência dos engenheiros civis. 
Problemas de segurança e confiabilidade das estruturas surgem devido a incertezas no projeto. A quantificação e análise destas incertezas são, portanto, aspectos centrais na avaliação da confiabilidade e no conseqüente desenvolvimento de projetos baseados em confiabilidade. Uma medida apropriada da confiabilidade ou segurança somente pode ser determinada no contexto da probabilidade. De fato, níveis consistentes de segurança e confiabilidade só podem ser atingidos se os critérios de projeto são baseados em tais medidas probabilísticas da confiabilidade, e métodos apropriados para a avaliação da confiabilidade são necessários. Além disso, em um ambiente competitivo, não é suficiente que sistemas estruturais sejam projetados levando-se em conta apenas a sua função estrutural. É importante levar em consideração o custo total de construção e operação da estrutura, bem como a capacidade de geração de lucro da mesma. Em obras de infraestrutura como pontes e viadutos, o usufruto é do público, e, portanto, é o custo total da estrutura que deve ser considerado. Para estruturas dedicadas diretamente à atividade produtiva, como uma aeronave comercial, é a capacidade de geração de lucro da estrutura que deve ser observada.

Tanto o custo total (construção + operação) da estrutura quanto sua capacidade de geração de lucro estão diretamente ligados ao risco que a construção e operação da mesma oferecem. O risco deve ser entendido como o produto de um custo de falha pela probabilidade de que esta falha aconteça. A falha pode ser tanto uma falha de serviço (que afeta o desempenho do sistema estrutural) como uma falha catastrófica. Em ambos os casos, a segurança da estrutura está diretamente relacionada com os coeficientes de segurança adotados em projeto, bem como ao nível de controle e manutenção praticados na operação da estrutura. É sabido que coeficientes de segurança excessivos levam a estruturas pesadas, de alto custo, e para as quais a capacidade de geração de lucro fica comprometida. Por outro lado, coeficientes de segurança insuficientes ou manutenção inadequada produzem sistemas estruturais para os quais tanto o custo total, como a 
capacidade de geração de lucro, ficam comprometidos pela falta de segurança ou excessivo risco de falha.

Verifica-se, portanto, que a minimização do custo total de um sistema estrutural ou a maximização de sua capacidade de geração de lucro passam, necessariamente, por uma otimização do nível de segurança para a qual o sistema é projetado. Para tanto, é necessária uma medida quantificável da segurança do sistema, que pode ser obtida através da confiabilidade estrutural. Utilizando a teoria de confiabilidade estrutural, pode-se determinar a probabilidade de falha e, portanto, o risco associado a cada modo de falha do sistema. Assim, é possível verificar se os coeficientes de segurança e os níveis de controle e manutenção adotados são adequados. A partir da determinação da função custo esperado total da estrutura em função dos coeficientes de segurança, e com base na teoria de confiabilidade, pode-se encontrar os níveis de segurança ótimos, minimizando custos.

\subsection{Metodologia}

Em uma primeira etapa, foi feita uma revisão bibliográfica sobre os temas envolvidos na pesquisa, tais como composição do custo esperado total de sistemas estruturais, otimização, confiabilidade estrutural e otimização baseada em confiabilidade.

A implementação dos algoritmos de otimização matemática foi feita em Fortran 95, utilizando modernas técnicas de orientação a objetos. Desta forma, desenvolveu-se um programa que pode ser utilizado na análise de diferentes problemas de aplicação, e que faz uso de outros dois programas, o StRAnD, para análise de confiabilidade, e o Ansys, para análise numérica. No desenvolvimento das rotinas de otimização o problema foi equacionado considerando a função de custo esperado total.

A seguir, vários estudos de caso foram realizados, partindo-se de estruturas simples, como uma barra comprimida, até estruturas complexas, como uma torre metálica tridimensional. 


\subsection{Organização da Dissertação}

O trabalho engloba conceitos de confiabilidade e otimização estruturais. A dissertação está dividida em seis capítulos, sendo dois capítulos dedicados aos conceitos supracitados.

O segundo capítulo traz uma revisão bibliográfica sobre os temas envolvidos no trabalho. São apresentados trabalhos relevantes para a dissertação, que discutem a composição do custo esperado total de sistemas estruturais, a otimização estrutural, a confiabilidade estrutural e a otimização baseada em confiabilidade.

O terceiro capítulo aborda a confiabilidade estrutural de uma maneira geral. São apresentados os principais conceitos envolvidos na teoria de confiabilidade.

O quarto capítulo trata da otimização matemática. Conceitos gerais, propriedades dos pontos de mínimo e métodos de programação linear utilizados no trabalho são descritos.

O quinto capítulo é dedicado à descrição do programa computacional desenvolvido.

No sexto capítulo exemplos analisados com o programa são discutidos, ilustrando as possibilidades de aplicação da otimização de risco estrutural baseada em confiabilidade.

Finalmente, no sétimo e último capítulo são apresentadas as conclusões obtidas, além de sugestões para trabalhos futuros.

Como apêndice à dissertação apresenta-se o manual de utilização do código computacional desenvolvido. 


\section{Capítulo 2: REVISÃO BIBLIOGRÁFICA}

Esta revisão bibliográfica apresenta alguns conceitos mais gerais que são importantes no desenvolvimento da dissertação. Foi realizado um apanhado dos trabalhos mais relevantes sobre os temas em questão.

\subsection{Composição do Custo Esperado Total de um Sistema Estrutural}

Seja $\boldsymbol{X}$ um vetor de parâmetros que caracterizam determinado sistema estrutural. Este vetor inclui características geométricas, propriedades de resistência de materiais e de membros estruturais, solicitações atuantes, coeficientes de majoração de cargas e de minoração de resistências, coeficientes parciais de segurança, parâmetros de programas de manutenção e inspeção periódica, etc. Dentre estes parâmetros, propriedades de resistência são modeladas como variáveis aleatórias, e carregamentos são representados como variáveis aleatórias ou processos estocásticos.

O custo total esperado deste sistema estrutural, que apresenta risco de falha, pode ser decomposto em:

- custo inicial ou de construção da estrutura;

- custo de operação e manutenção;

- custo esperado de falha.

O custo esperado de falha, que está diretamente associado ao risco de falha, vem a ser o produto do custo de falha pela probabilidade de falha $\left(P_{f}(\boldsymbol{X})\right)$ :

custo esperado de falha $\left(\boldsymbol{X}, P_{f}\right)=$ custo de falha $(\boldsymbol{X}) \cdot P_{f}(\boldsymbol{X})$

O custo de falha inclui custos de reparo ou de substituição dos componentes danificados, custo de reconstrução completa do sistema, custo de indenizações pagas a 
funcionários e à terceiros em decorrência da falha, e outros. Para determinar o custo esperado de falha, é necessário quantificar o custo de falha, em termos monetários, bem como determinar a probabilidade de falha. A probabilidade de falha é avaliada utilizando-se a teoria de confiabilidade estrutural.

Para cada modo de falha do sistema ou de componentes do mesmo haverá um componente de custo esperado de falha. O custo esperado total do sistema é dado pela soma de todos os termos parciais de custo:

$$
\begin{aligned}
\text { custo esperado total }\left(\boldsymbol{X}, P_{f}\right) & =\text { custo inicial }(\boldsymbol{X})+\text { custo operação }(\boldsymbol{X}) \\
& +\sum_{i=1}^{\text {\#modos de falha }} \text { custo esperado de falha } \\
\mathrm{i} & \left(\boldsymbol{X}, P_{f}\right)
\end{aligned}
$$

O custo inicial e o custo de operação aumentam diretamente com o nível de controle ou de segurança utilizados. O custo inicial ou de construção depende diretamente dos coeficientes de segurança adotados em projeto. O custo de operação aumenta com o nível de controle porque o aumento da segurança exige mais equipamentos de segurança, maior redundância de equipamentos críticos, maior conservadorismo na utilização do sistema e maiores gastos em manutenção.

O custo esperado de falha, obviamente, diminui com o aumento da segurança e do nível de controle do sistema, pois a probabilidade de falha diminui. Esta redução no custo esperado de falha com o aumento da segurança não acontece de maneira proporcional, pois a partir de determinado nível de controle ou segurança o custo esperado de falha não se reduz de maneira significativa. A Figura 2.1 ilustra como estes custos variam em função do nível de controle ou de segurança considerados no projeto e operação de um sistema estrutural hipotético. A decomposição de custos aqui apresentada é ilustrativa, pois outros termos de custo podem existir.

Soltani e Corotis (1988), propuseram uma abordagem sistemática para a análise do custo de falha, baseada na aplicação de pesos para os modos de colapso, mostrando a curva do custo esperado total, na qual a perda esperada diminui com o aumento do custo 
inicial, sendo o custo inicial inversamente proporcional ao custo de falha. Os autores apresentaram formulações simples e multi-objetivas com custo inicial e de falha como funções objetivo. Consideraram como variáveis de projeto o momento de plastificação médio dos membros estruturais, seguindo a teoria da plasticidade para estruturas de aço. Eles definiram o custo de falha como o custo de reposição da estrutura e o custo de compensação por possíveis danos causados pela falha e admitiram que a avaliação desta última parcela do custo é extremamente difícil, especialmente se vidas humanas estão em perigo.

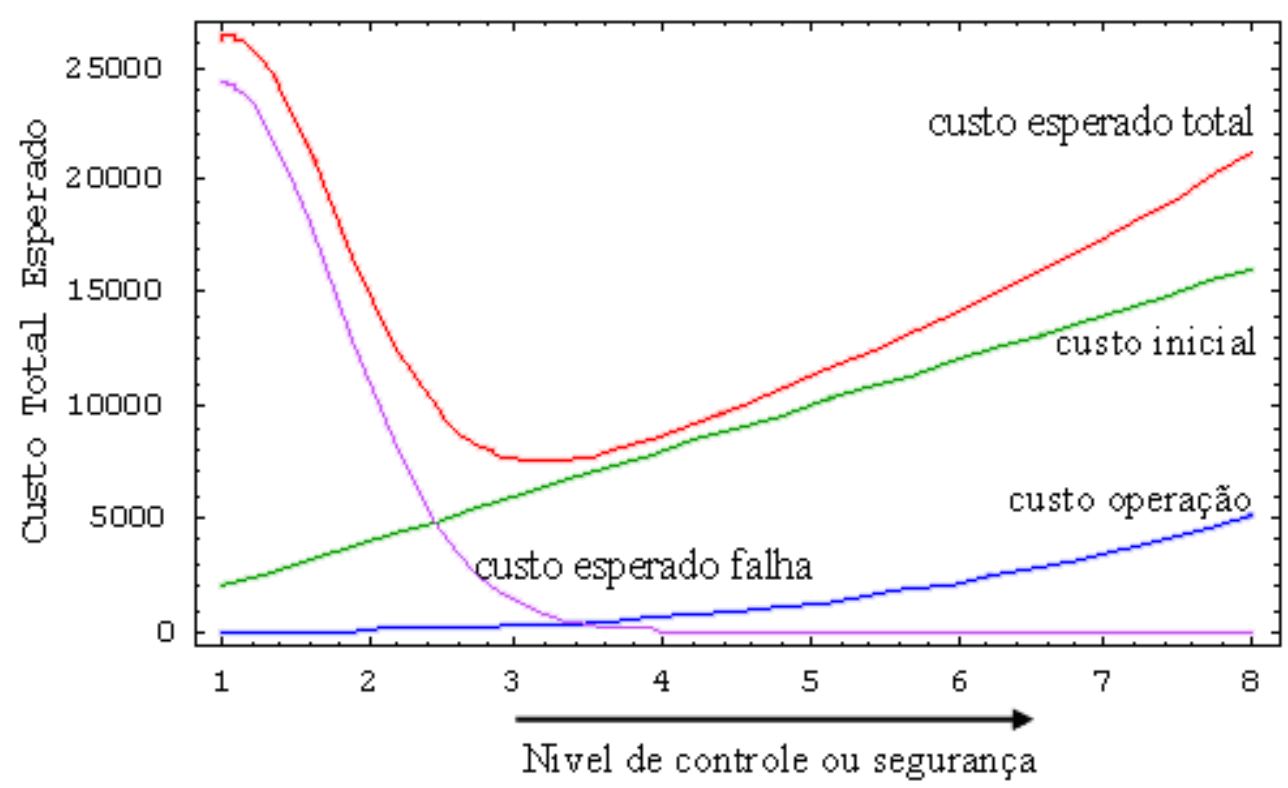

Figura 2.1: Composição do custo total esperado de um sistema estrutural hipotético

\subsection{Problema de Otimização: Minimização do Custo Total Esperado}

O comportamento das funções custo apresentadas acima é típico de sistemas estruturais. Com o aumento do nível de segurança, de controle e de manutenção adotados, o custo esperado de falha diminui, enquanto os custos inicial e de operação aumentam, de forma que a função custo esperado total apresenta um valor mínimo, que corresponde ao nível de controle e de segurança ideal para determinado sistema estrutural. Em outras palavras, o 
nível de segurança ideal é aquele que minimiza o custo esperado total, ou maximiza o lucro obtido com a utilização do sistema.

Esta formulação dá origem a um problema de otimização sem restrições:

$$
\text { Minimizar: custo esperado } \operatorname{total}\left(\boldsymbol{X}, P_{f}\right)
$$

Se a falha do sistema em questão envolve conseqüências sem mensuração monetária, como a morte de pessoas, então um limite inferior para a probabilidade de falha pode ser imposto no problema:

$$
\begin{aligned}
& \text { Minimizar: custo esperado } \operatorname{total}\left(\boldsymbol{X}, P_{f}\right) \\
& \text { Sujeito a: } P_{f}(\boldsymbol{X})<P_{f}
\end{aligned}
$$

$\mathrm{Na}$ década de 70 , os primeiros estudos nesta área foram publicados. Mau e Sexsmith (1972), publicaram um dos primeiros artigos referindo-se à otimização de custo estrutural baseada na teoria da confiabilidade. Muitas simplificações foram feitas. Eles apontaram que o critério do mínimo custo esperado total é equivalente à minimização do peso com uma probabilidade de falha admissível. Ravindra e Lind (1973) descreveram o uso da teoria da probabilidade na otimização baseada em normas, com uma tentativa de equilibrar a segurança e o custo, enquanto Moses (1977), introduziu os conceitos gerais da teoria da confiabilidade na otimização estrutural, propondo a minimização do custo estrutural incorporando à função objetivo uma parcela relativa ao custo esperado de falha.

Procedimentos de otimização estrutural baseados em confiabilidade, mais especificamente para pórticos de concreto armado, foram apresentados por Surahman e Rojiani (1983) e por SryVidya e Ranganathan (1994). As análises de confiabilidade foram feitas com o método FORM. O procedimento de obtenção da estrutura ótima referia-se à minimização do custo esperado total, composto pelo custo inicial de construção e pelo custo da perda da estrutura devido à falha.

Kim e Wen (1990) desenvolveram um método para a minimização do custo esperado total de estruturas sujeitas a múltiplos carregamento estocásticos, baseado na teoria da 
confiabilidade. Os carregamentos foram modelados por processos aleatórios e métodos de combinações de carregamentos foram utilizados. Concluíram que a imposição de restrições para a confiabilidade de membros é mais efetiva e fácil de implementar do que a restrição para a confiabilidade do sistema estrutural, e que a utilização de ambas as restrições é mais consistente. Sarma e Adeli $(1998,2000,2002)$ em seus recentes trabalhos fizeram uma revisão dos trabalhos publicados referentes à otimização do custo de estruturas de concreto armado e de aço, incluindo os que se baseiam na confiabilidade estrutural. Também realizaram um estudo da otimização do custo do ciclo de vida de estruturas de aço, baseado em lógica fuzzy.

\subsection{Confiabilidade Estrutural}

O termo confiabilidade está associado ao grau de confiança que se tem em algo. Segundo Thoft-Christensen e Murotsu (1986), "A confiabilidade de uma estrutura é a capacidade que ela tem de cumprir seu propósito de projeto por um determinado período de referência".

Portanto, confiabilidade é uma probabilidade, ou seja, uma medida que reflete a segurança do componente ou sistema. A maioria das estruturas tem vários possíveis modos de falha. Logo, ao determinar a confiabilidade de uma estrutura esse fato deve ser levado em consideração. O primeiro passo normalmente será estimar a confiabilidade estrutural com relação a cada modo de falha, isto é, a probabilidade de que a estrutura não irá atingir cada modo de falha (último ou de serviço) durante um período de referência especificado. $\mathrm{O}$ próximo passo, estimar a confiabilidade da estrutura como um todo, leva em conta correlações entre os modos de falha.

A confiabilidade do sistema é uma função das confiabilidades de seus componentes. Por isso sua determinação deve invariavelmente estar baseada na informação referente à confiabilidade dos componentes. No entanto, projetos de estruturas são realizados a nível de componentes. 
Do ponto de vista da confiabilidade, um sistema é caracterizado por múltiplos modos de falha, nos quais cada um dos potenciais modos de falha é composto por eventos de falha dos componentes associados em série ou em paralelo, ou combinações destes (especialmente para sistemas com redundância). No caso de um sistema redundante, a redundância pode ser do tipo ativa ou passiva. Dependendo do tipo de redundância, a análise da confiabilidade do sistema será diferente.

No caso de sistemas complexos, a identificação dos possíveis modos de falha pode ser bastante complicada, necessitando de um procedimento sistemático de identificação desses modos, como o modelo de árvore de falhas. Também, as potenciais conseqüências da falha de um sistema podem variar, dependendo dos eventos subseqüentes à tal falha. $O$ modelo da árvore de eventos pode ser utilizado para facilitar a identificação sistemática das potenciais conseqüências da falha.

No fim da década de 60, Benjamin (1968) apresentou o uso de conceitos de probabilidade no projeto estrutural. Trabalhos anteriores que avaliavam a confiabilidade das estruturas comumente utilizavam aproximações baseadas na consideração de independência probabilística entre modos de falha ou na sua completa dependência. Vanmarcke (1971) propôs uma formulação matricial para a análise da confiabilidade e para projetos de estruturas baseados em confiabilidade, tornando mais prático o desenvolvimento de códigos computacionais para avaliação da confiabilidade de estruturas maiores. Ele também propôs nesse trabalho um método para o projeto de sistemas estruturais com minimização do peso baseado em restrições na probabilidade de falha.

Dando seqüência à análise da confiabilidade de elementos estruturais, Moses (1977) realizou a avaliação da confiabilidade de estruturas lineares, procurando encontrar os caminhos de falha através da análise seqüencial elástica (incrementos de carga), removendo em cada passo os elementos que atingiam sua capacidade e redistribuindo os esforços, obtendo por fim a confiabilidade do sistema. 
Ang e Ma (1981) ressaltaram as diferenças entre problemas de confiabilidade de sistemas compostos por membros dúcteis ou frágeis, ressaltando que os métodos correntes na época eram muito limitados para se avaliar sistemas dúcteis. A abordagem através de carregamentos incrementais para identificação de modos de falha foi expandida por Moses (1982), empregando-se uma estratégia para identificar e enumerar os modos de falha significantes em estruturas grandes. Exemplos de estruturas frágeis e dúcteis, com resistências correlacionadas foram apresentados.

Mais recentemente, Natarajan e Santhakumar (1995) ressaltaram a necessidade de projetos baseados em confiabilidade após algumas falhas reportadas em linhas de transmissão na Índia, devido a tempestades de ciclones, pois as normas daquele país não levam em conta adequadamente certas incertezas nos carregamentos e nas propriedades dos materiais. Eles também desenvolveram programas para a avaliação da confiabilidade e otimização da estrutura de torres de transmissão.

\subsection{Otimização Estrutural Baseada em Confiabilidade}

Técnicas muito efetivas na teoria de confiabilidade estrutural foram desenvolvidas nos últimos 30 anos, a saber FORM (First Order Reliability Method), SORM (Second Order Reliability Method) e técnicas de simulação, como pode se verificado em Ang e Tang (1984, 2007) e Thoft-Christensen e Murotsu (1986). No mesmo período também foram desenvolvidos métodos eficientes para a solução de problemas de otimização não-linear. Os mais interessantes em conexão com problemas de confiabilidade estrutural são as chamadas técnicas de programação seqüencial quadrática.

Os dois objetivos principais no projeto de sistemas estruturais são a obtenção estruturas com índices de confiabilidade satisfatórios e com o menor custo possível. Estes requisitos contraditórios são satisfeitos geralmente através da utilização de normas e códigos baseados em abordagens determinísticas. 
Em problemas de otimização estrutural determinísticos a função objetivo geralmente é o volume ou o peso da estrutura e as restrições estão relacionadas a requisitos de norma para tensões e/ou deslocamentos admissíveis. Um grande número de procedimentos numéricos foram desenvolvidos para resolver esse tipo de problema, como pode ser visto em Fox (1971) e Vanderplaats (1984). A maioria dos algoritmos utilizados na otimização estrutural determinística são baseados em programação linear seqüencial.

Para a otimização estrutural baseada em confiabilidade o custo total esperado da estrutura (custo inicial, de manutenção e de falha) pode ser usado como função objetivo. Contudo, geralmente o peso é usado como função objetivo devido à maior facilidade de estimá-lo. As restrições são requisitos de confiabilidade conectados com os possíveis modos de falha da estrutura. Tipicamente estas restrições especificam que a probabilidade de falha deve ser menor que $10^{-3}$ a $10^{-5}$. Estas pequenas probabilidades, por sua vez, implicam no fato de que os métodos usuais de otimização estocástica não podem ser usados efetivamente na otimização baseada em confiabilidade. Frangopol (1985) apontou duas razões pelas quais a otimização estrutural baseada em confiabilidade não é popular se comparada à otimização estrutural determinística. Primeiro, a falta de um método de incorporação de incertezas aceito mundialmente, resultando em níveis de confiabilidade não uniformes em situações de projeto semelhantes. Segundo, as opiniões divergentes em muitos assuntos básicos incluindo a própria definição de otimização baseada em teoria da confiabilidade. O autor então propôs uma abordagem multicritério de otimização, com colapso e inutilização como critérios de falha.

Na década de 90 muitos trabalhos sobre o assunto surgiram. Nakib e Frangopol (1990) desenvolveram dois programas computacionais para análise da confiabilidade estrutural e otimização estrutural baseada em confiabilidade. A otimização da estrutura foi realizada buscando-se o seu peso mínimo. Liu e Kiureghian (1991) avaliaram 5 algoritmos para a solução de problemas de análise de confiabilidade estrutural. Concluíram que o método de programação seqüencial quadrática, o método de projeção do gradiente e o 
método HLRF modificado são técnicas robustas para o uso em aplicações de confiabilidade estrutural. Para analises de confiabilidade com elementos finitos não lineares o método de programação seqüencial quadrática e o método HLRF modificado mostraram-se mais eficientes que os demais. Liu e Moses (1992) apresentaram a otimização de treliças com restrição na confiabilidade do sistema, comparando as análises por limites modais e por amostragem por importância de Monte Carlo. Impuseram restrições na confiabilidade tanto do sistema intacto, quanto depois de danificado. Enevoldsen e Sorensen $(1993,1994)$ formularam a otimização para problemas de estruturas formadas pela reunião de subsistemas paralelos em sistemas em série, e combinaram várias técnicas de otimização de risco estrutural com modelos mecânicos de elementos finitos. Também apresentaram avaliações de tempo de inspeção ótimo e planejamento experimental ótimo. Lin e Frangopol (1996) apresentaram uma abordagem prática para a otimização de vigas de concreto armado de pontes rodoviárias. A análise de confiabilidade foi baseada nas normas da AASHTO.

No presente trabalho a otimização estrutural baseada em confiabilidade é realizada utilizando o custo esperado total como função objetivo. Através da majoração do coeficiente de segurança característico $\lambda_{k}$ aumenta-se as dimensões da estrutura. Existe então um $\lambda_{k}$ ótimo que diminui a probabilidade de falha na proporção necessária para minimizar o custo esperado total. 


\section{Capítulo 3: CONFIABILIDADE ESTRUTURAL}

Neste capítulo apresenta-se, de maneira breve e simples, os conceitos fundamentais da confiabilidade estrutural necessários para o desenvolvimento deste trabalho. Para informações mais aprofundadas recomenda-se a consulta das referências indicadas.

\subsection{Variáveis Aleatórias}

É freqüente o interesse em se resumir o resultado de um experimento aleatório através de um número. Pelo fato de o resultado particular do experimento não ser conhecido a priori, o valor resultante da variável também não será conhecido a priori. A variável que associa um número ao resultado de um experimento aleatório é chamada variável aleatória (VA), e a ela é atribuída uma distribuição de probabilidades. Conforme definição de Montgomery e Runger (1999), “Uma variável aleatória é uma função que confere um número real a cada resultado no espaço amostral de um experimento aleatório".

É comum denotar-se uma variável aleatória por uma letra maiúscula e, depois do experimento ser conduzido, o valor medido para a VA ser denotado por uma letra minúscula. Uma variável aleatória discreta é uma variável aleatória com uma faixa finita (ou infinita contável) de possíveis valores, enquanto uma variável aleatória contínua é uma variável aleatória com um intervalo (tanto finito como infinito) de números reais para sua faixa (MONTGOMERY e RUNGER, 1999).

\subsubsection{Função de Distribuição Acumulada de Probabilidades (FDA)}

Conforme definição de Beck (2006):

"A função de distribuição acumulada de probabilidades de uma variável aleatória $X$ é a função:

$$
F_{X}(x)=P[\{X \leq x\}]
$$


definida para qualquer número $x$ no intervalo $(-\infty \leq x \leq+\infty)$."

O número $F_{X}(x)$ corresponde à probabilidade de que a variável aleatória $X$ assuma qualquer valor menor do que $x$.

\subsubsection{Função de densidade de probabilidades (FDP)}

Freqüentemente é de interesse saber a probabilidade de que uma VA assuma um valor particular. A distribuição de probabilidades de uma variável aleatória $X$ é uma descrição das probabilidades associadas com os valores possíveis de $X$. Para uma variável aleatória discreta, a distribuição é, em geral, especificada por apenas uma lista de valores possíveis, juntamente com a probabilidade de cada um.

Uma função densidade de probabilidade $f_{X}(x)$ pode ser usada para descrever a distribuição de probabilidades de uma variável aleatória contínua $X$. A probabilidade de $X$ estar entre um intervalo $a$ e $b$ é determinada pela integral de $f_{X}(x)$ de $a$ a $b$. A FDP fornece uma descrição simples das probabilidades associadas a uma variável aleatória.

Segundo a definição de Montgomery e Runger (1999):

"Para uma VA contínua em $X$, uma função densidade de probabilidade é uma função tal que

1) $f_{X}(x) \geq 0$

2) $\int_{-\infty}^{\infty} f_{X}(x) d x=1$

3) $P[a \leq X \leq b]=\int_{a}^{b} f_{X}(x) d x=$ área $\operatorname{sob} f_{X}(x)$ de $a$ a $b$ para qualquer $a$ e $b$ "

A FDP é a derivada em relação à $x$ da FDA. Como a FDA pode não ter derivadas em todo $x$, faz-se uma distinção entre variáveis aleatórias contínuas e discretas, condizente com o domínio de cada VA. 


\subsubsection{Média e variância de uma VA contínua}

A média de uma VA $X$ usa o modelo de probabilidade para ponderar os valores possíveis de $X$. A média ou o valor esperado de $X$, denotado por $\mu$ ou $E(X)$, é:

$$
\mu=E(X)=\int_{-\infty}^{\infty} x f_{X}(x) d x
$$

A variância de uma VA $X$ é uma medida de dispersão ou espalhamento nos valores possíveis para $X$. A variância de $X$, denotada por $V(X)$ ou $\sigma^{2}$, é:

$$
\sigma^{2}=V(X)=\int_{-\infty}^{\infty}(x-\mu)^{2} f_{X}(x) d x
$$

A constante $\sigma$ é chamada de desvio-padrão e é a raiz quadrada da variância:

$$
\sigma=\sqrt{\sigma^{2}}
$$

A Tabela 3.1 abaixo mostra o sumário de algumas distribuições contínuas de probabilidades. Para mais aprofundamento no assunto veja Ang e Tang (2007), Krishnamoorthy (2006), além das referências já citadas. 
Tabela 3.1: Sumário de distribuições contínuas de probabilidades

\begin{tabular}{|c|c|c|c|c|c|c|c|}
\hline \multirow{2}{*}{ Distribuição } & \multirow{2}{*}{$f_{X}(x)$} & \multicolumn{4}{|c|}{ parâmetros } & \multirow{2}{*}{ Média } & \multirow{2}{*}{ Variância } \\
\hline & & $\mathbf{p}_{1}$ & $\mathbf{p}_{2}$ & $\mathbf{p}_{3}$ & $\mathbf{p}_{4}$ & & \\
\hline Uniforme & 1 & $a$ & $h$ & - & - & $a+b$ & $(b-a)^{2}$ \\
\hline 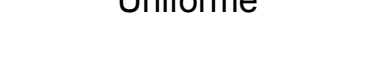 & $\overline{b-a}$ & & & & & 2 & 12 \\
\hline Normal & $\frac{1}{\sigma \sqrt{2 \pi}} \exp \left[-\frac{1}{2}\left(\frac{x-\mu}{\sigma}\right)^{2}\right]$ & $\mu$ & $\sigma$ & - & - & $\mu$ & $\sigma^{2}$ \\
\hline Log-Normal & $\frac{1}{\xi x \sqrt{2 \pi}} \exp \left[-\frac{1}{2}\left(\frac{\ln (x)-\lambda}{\xi}\right)^{2}\right]$ & $\lambda$ & $\xi$ & - & - & $\exp \left[\lambda+0,5 \xi^{2}\right]$ & $\mu^{2}\left[\exp \left(\xi^{2}\right)-1\right]$ \\
\hline Exponencial deslocada & $v \exp [-v(x-\varepsilon)]$ & $v$ & $\varepsilon$ & - & - & $\frac{1}{v}+\varepsilon$ & $\frac{1}{v^{2}}$ \\
\hline Gumbel mínimos & $\beta \exp \left[\beta\left(x-u_{1}\right)-e^{-\beta\left(x-u_{1}\right)}\right]$ & $u_{1}$ & $\beta$ & - & - & $u_{1}-\frac{\gamma}{\beta}$ & $\frac{\pi^{2}}{6 \beta^{2}}$ \\
\hline Gumbel máximos & $\beta \exp \left[\beta\left(x-u_{n}\right)\right.$ & $u_{n}$ & $\beta$ & - & - & $u_{n}-\frac{\gamma}{\beta}$ & $\frac{\pi^{2}}{6 \beta^{2}}$ \\
\hline Frechet mínimos & $\frac{\beta}{u_{1}}\left(\frac{x}{u_{1}}\right)^{\beta+1} \exp \left[-\left(\frac{x}{u_{1}}\right)^{\beta}\right]$ & $u_{1}$ & $\beta$ & - & - & $u_{1} \Gamma\left(1-\frac{1}{\beta}\right)$ & $u_{1}^{2}\left[\Gamma\left(1-\frac{2}{\beta}\right)-\Gamma^{2}\left(1-\frac{1}{\beta}\right)\right]$ \\
\hline Frechet máximos & $\frac{\beta}{u_{n}}\left(\frac{u_{n}}{x}\right)^{\beta+1} \exp \left[-\left(\frac{u_{n}}{x}\right)^{\beta}\right]$ & $u_{n}$ & $\beta$ & - & - & $u_{n} \Gamma\left(1-\frac{1}{\beta}\right)$ & $u_{n}^{2}\left[\Gamma\left(1-\frac{2}{\beta}\right)-\Gamma^{2}\left(1-\frac{1}{\beta}\right)\right]$ \\
\hline Weibull mínimos & $\frac{\beta}{u_{1}-\varepsilon}\left(\frac{x-\varepsilon}{u_{1}-\varepsilon}\right)^{\beta-1} \exp \left[-\left(\frac{x-\varepsilon}{u_{1}-\varepsilon}\right)^{\beta}\right]$ & $u_{1}$ & $\beta$ & $\varepsilon$ & - & $\varepsilon+\left(u_{1}-\varepsilon\right) \Gamma\left(1+\frac{1}{\beta}\right)$ & $\left(u_{1}-\varepsilon\right)^{2}\left[\Gamma\left(1+\frac{2}{\beta}\right)-\Gamma^{2}\left(1+\frac{1}{\beta}\right)\right]$ \\
\hline Weibull máximos & $\frac{\beta}{\varepsilon-u_{n}}\left(\frac{\varepsilon-x}{\varepsilon-u_{n}}\right)^{\beta-1} \exp \left[-\left(\frac{\varepsilon-x}{\varepsilon-u_{n}}\right)^{\beta}\right.$ & $u_{n}$ & $\beta$ & - & $\varepsilon$ & $\varepsilon+\left(\varepsilon-u_{n}\right) \Gamma\left(1+\frac{1}{\beta}\right)$ & $\left(\varepsilon-u_{n}\right)^{2}\left[\Gamma\left(1+\frac{2}{\beta}\right)-\Gamma^{2}\left(1+\frac{1}{\beta}\right)\right]$ \\
\hline
\end{tabular}




\subsection{Modelos Probabilísticos}

Ao se considerar um modo de falha particular, uma modelagem de incerteza deve ser empregada. Essa modelagem é feita com relação às variáveis cuja variabilidade é julgada importante na equação de estado limite correspondente. São as chamadas variáveis aleatórias de projeto. Na Tabela 3.2 abaixo estão relacionados alguns tipos de VA's e a correspondente distribuição probabilística comumente usada, conforme indicado no Probabilistic Model Code (2001) e em Melchers(1999).

Tabela 3.2: Algumas variáveis aletatórias e distribuições comumente utilizadas

\begin{tabular}{cccc} 
& Tipo de Variável Aleatória & Distribuição & c.o.v. \\
\hline \multirow{2}{*}{$\begin{array}{c}\text { VA's de } \\
\text { Resistência }\end{array}$} & Propriedades materiais do concreto & Log-Normal & 0,05 a 0,20 \\
& Propriedades materiais do aço & Log-Normal & $<0,01$ a 0,13 \\
& Parâmetros Geométricos & Normal ou Log-Normal & $<0,01$ a 0,04 \\
\hline \multirow{2}{*}{$\begin{array}{c}\text { VA's de } \\
\text { Solicitação }\end{array}$} & Peso Próprio & Normal & $<0,01$ a 0,10 \\
& Vento (velocidade média) & Gamma & 0,15 a 0,50 \\
& Vento (velocidade máxima) & Gumbel para máximos & 0,10 a 0,30 \\
\hline
\end{tabular}

\subsection{Estados Limites}

O desempenho estrutural de uma estrutura ou parte dela deve ser descrito com referência a um conjunto de estados limite que separam estados desejados de funcionamento da estrutura de estados adversos.

Os estados limites são divididos em duas categorias básicas:

$\checkmark$ estados limites últimos: relativos ao colapso, ou a qualquer outra forma de ruína estrutural, que determine a paralisação do uso da estrutura; 
$\checkmark$ estados limites de serviço: relativos à durabilidade das estruturas, aparência, conforto do usuário e à boa utilização funcional das mesmas, seja em relação aos usuários, seja em relação às maquinas e aos equipamentos utilizados.

\subsubsection{Equações de estado limite}

Para cada estado limite específico as variáveis relevantes devem ser identificadas, isto é, as variáveis que caracterizam ações, propriedades dos materiais e parâmetros geométricos. Algumas dessas variáveis, ou todas elas, podem ser descritas por processos aleatórios e são agrupadas em um vetor que contém as variáveis de projeto do problema: $\boldsymbol{X}=\left\{X_{1}, X_{2}, X_{3}, \ldots\right\}$.

Uma equação de estado limite $g()$ é escrita em função das variáveis de projeto $\boldsymbol{X}$ para cada estado limite da estrutura como

$$
g(X)=g\left(X_{1}, X_{2}, \ldots, X_{n}\right)=0
$$

sendo que

$$
g(X)<0
$$

identifica falha da estrutura.

Em uma análise de componente, onde há um modo de falha dominante, a condição de estado limite normalmente pode ser traçada por uma equação correspondente à (3.4). Em uma análise de sistema, onde mais de um modo de falha pode ser determinante, existem várias equações desta natureza.

Um exemplo simples é um problema envolvendo apenas duas variáveis, a saber, resistência $(R)$ e solicitação $(S)$ :

$$
g(R, S)=R-S=0
$$




\subsubsection{Coeficientes de segurança}

Ao projetar uma estrutura o problema do projetista consiste em dimensionar a estrutura e seus membros de forma que ela atenda aos requisitos de serviço e segurança. Isto geralmente é feito através do procedimento determinístico, que adota os chamados coeficientes de segurança.

\section{Coeficiente de segurança central $\left(\lambda_{0}\right)$}

O coeficiente de segurança central relaciona as médias das variáveis de resistência $(R)$ e solicitação ( $S$ ) (MELCHERS, 1999):

$$
\lambda_{0}=\frac{\mu_{R}}{\mu_{S}}
$$

Este coeficiente não reflete a segurança da estrutura na medida em que não reflete a incerteza existente nas variáveis $R$ e $S$. Não existe confiança em relação aos valores $\mu_{R}$ e $\mu_{S}$ utilizados, pois, na estrutura real, a resistência e a solicitação podem ser tanto maiores quanto menores do que os valores médios. Por tais motivos, não há garantia de que um determinado valor de $\lambda_{0}$ seja suficiente para assegurar a confiabilidade de uma estrutura (ANG; TANG; 2007).

\section{Valores característicos}

A utilização de valores característicos mais significativos é um modo de solucionar o problema acima. Isto pode ser feito através de fatores de segurança, que minoram a resistência e majoram a solicitação, devido à incerteza inerente a essas variáveis.

Os valores característicos são obtidos em termos da inversa da FDA de probabilidades e do nível de confiança $p_{k}$ desejado. Sendo:

$$
p_{k}=P\left[\left\{R>r_{k}\right\}\right] \text { ou } p_{k}=P\left[\left\{S<s_{k}\right\}\right]
$$


onde $r_{k}$ e $s_{k}$ são os valores característicos de resistência e solicitação, respectivamente, tem-se:

$$
\begin{gathered}
r_{k}=F_{R}^{-1}\left(1-p_{k}\right) \\
s_{k}=F_{S}^{-1}\left(p_{k}\right)
\end{gathered}
$$

Dividindo os valores característicos de solicitação e resistência pelos valores médios, obtém-se um coeficiente de minoração da resistência $\phi_{k}$ e um coeficiente de majoração da solicitação $\gamma_{k}$.

$$
\begin{aligned}
& \phi_{k}=\frac{r_{k}}{\mu_{R}}<1 \\
& \gamma_{k}=\frac{s_{k}}{\mu_{S}}>1
\end{aligned}
$$

O nível de confiança desejado $\left(p_{k}\right)$ bem como as distribuições de probabilidades afetam os coeficientes $\phi_{k}$ e $\gamma_{k}$. Logo, valores distintos são obtidos para diferentes distribuições estatísticas.

\section{$\underline{\text { Coeficiente de segurança global (ou característico) }}\left(\lambda_{k}\right)$}

Com a adoção dos coeficientes de segurança parciais $\phi_{k}$ e $\gamma_{k}$, obtidos para uma determinada confiança ( $p_{k}=0,95$ para confiança de $95 \%$, por exemplo), existe segurança em relação aos valores característicos $r_{k}$ e $s_{k}$ a utilizar no projeto. No entanto, a margem criada pelo uso de valores característicos em geral não é suficiente. Portanto, torna-se necessário utilizar ainda o chamado coeficiente de segurança global ou característico, que afasta os valores característicos.

$$
\lambda_{k}=\frac{r_{k}}{s_{k}}=\frac{\phi_{k} \mu_{R}}{\gamma_{k} \mu_{S}}=\frac{\phi_{k}}{\gamma_{k}} \lambda_{0}
$$


Conforme aumenta $p_{k}$ é possível diminuir o coeficiente $\lambda_{k}$. A Figura 3.1 mostra como se comportam os coeficientes parciais de segurança em função do nível de confiança associado aos valores característicos, para um problema exemplo em que a distribuição das variáveis $R$ e $S$, suas médias e desvios-padrão estão fixos. A figura mostra diferentes relações entre os coeficientes parciais que levam à mesma distância entre as médias. Notase que o coeficiente $\lambda_{k}$ pode até se tornar menor que um se $r_{k}<s_{k}$.

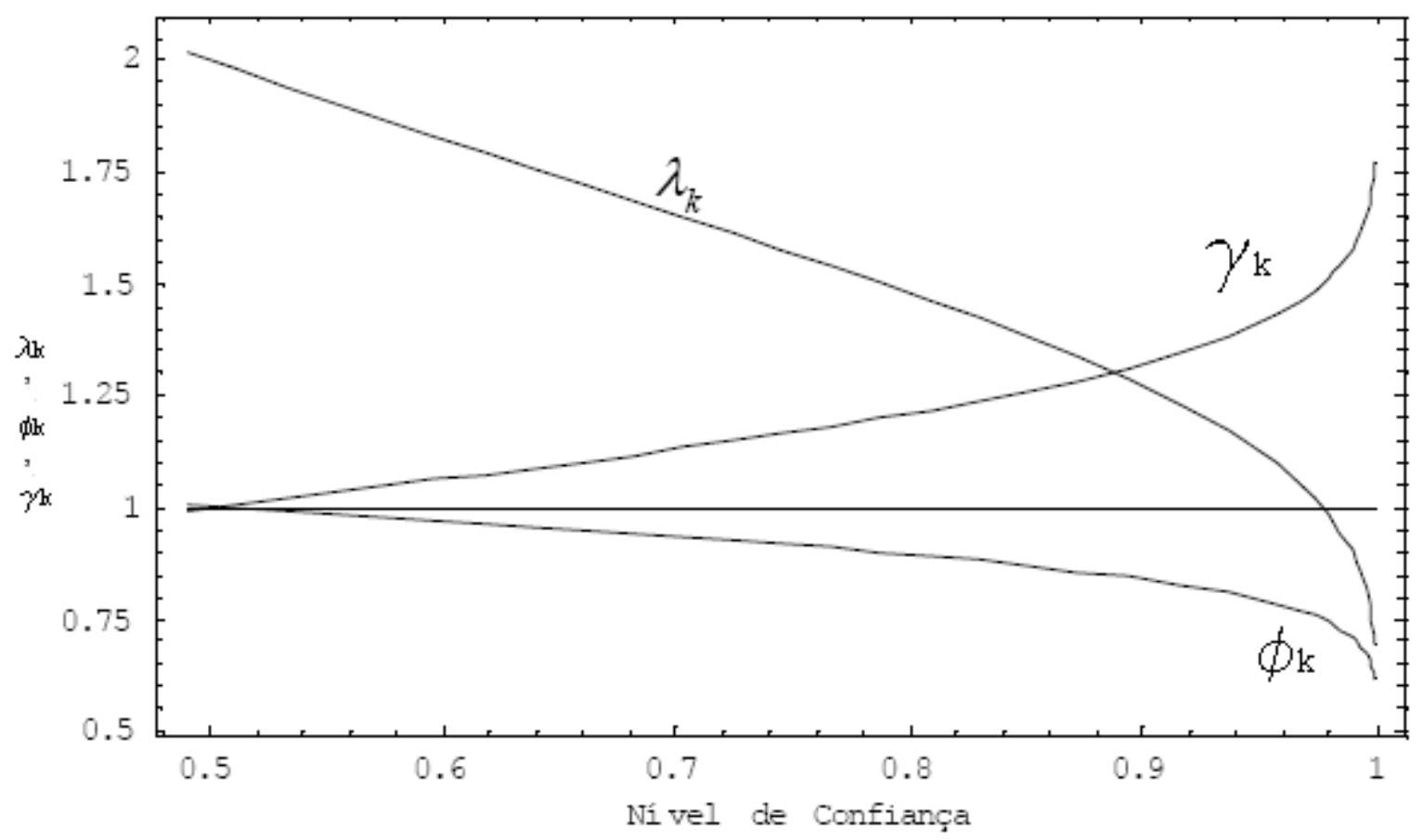

Figura 3.1: Variação dos coeficientes de segurança característicos com o nível de confiança

Os coeficientes $\phi_{k}$ e $\gamma_{k}$ são determinados em função da incerteza das variáveis $R$ e $S$, enquanto o coeficiente parcial $\lambda_{k}$ pode ser utilizado para impor segurança adicional em função do tipo de uso da estrutura, ou em função da gravidade do evento falha.

A escolha do nível de confiança (segurança) e do coeficiente $\lambda_{k}$ é subjetiva, portanto os fatores de segurança parciais não fornecem uma medida de violação de estados limites. Somente a probabilidade de falha pode ser considerada como tal medida. 
A formulação aqui apresentada corresponde ao formato utilizado nas normas técnicas antigas, também conhecido como formato de Tensões Admissíveis. Nos exemplos que seguem, os valores de $\lambda_{k}$ ótimos encontrados podem ser comparados com a coeficientes de segurança globais.

Nas normas técnicas modernas um formato ligeiramente diferente é utilizado. Nestas normas, os coeficientes de majoração de carregamento $\gamma_{S}$ e o coeficiente de redução de resistências $\phi_{R}$ são aplicados aos valores nominais de ações e carregamentos. O coeficiente de segurança global $\lambda_{k}$, conforme formulado neste trabalho, pode ser relacionado aos coeficientes de segurança parciais das normas modernas da seguinte maneira:

$$
\lambda_{k}=\frac{\gamma_{S}}{\phi_{R}}
$$

Para mais detalhes sobre coeficientes de segurança e valores característicos veja Melchers (1999), e Ellingwood e Galambos (1982).

\subsection{Violação de Estados Limites: A Probabilidade de Falha}

A probabilidade de falha é uma medida probabilística de violação de estados limites. Para um problema com duas VA's, a probabilidade de falha é dada por:

$$
P_{f}=P[\{R \leq S\}]=P[\{R-S\} \leq 0]
$$

A avaliação dessa probabilidade dá origem ao chamado problema fundamental da confiabilidade (MELCHERS, 1999). A $P_{f}$ pode ser determinada por:

$$
P_{f}=\int_{-\infty}^{+\infty} \int_{-\infty}^{s} f_{R S}(r, s) d r d s
$$

onde $f_{R S}(r, s)$ é a função conjunta de densidade de probabilidades de $R$ e $S$. 
A probabilidade de falha é proporcional, mas não idêntica, à área de interferência entre as distribuições $R$ e $S$, mostrada na Figura 3.2. Ela pode ser diminuída através da utilização de coeficientes de segurança, que afastam as médias das distribuições de $R$ e $S$, ou através da diminuição dos desvio-padrão das variáveis $R$ e $S$. O desvio-padrão da resistência está relacionado com a variabilidade de propriedades do material, e pode ser diminuído através do uso de materiais mais homogêneos e de melhor qualidade. O desviopadrão da solicitação é mais difícil de ser controlado.

Sendo G a variável aleatória estado limite (proveniente da equação de estado limite (3.4)), o índice de confiabilidade $\boldsymbol{\beta}$ é dado pela razão:

$$
\beta \equiv \frac{\mu_{G}}{\sigma_{G}}
$$

Para variáveis aleatórias independentes com distribuição normal de probabilidades:

$$
\beta=\frac{\mu_{R}-\mu_{S}}{\sqrt{\sigma_{R}{ }^{2}+\sigma_{S}^{2}}}
$$

Esta medida é de extrema importância na confiabilidade estrutural, pois fornece a probabilidade de falha para cada equação de estado limite e permite a resolução de problemas envolvendo um número qualquer de VA's:

$$
P_{f}=\Phi(-\beta)
$$

sendo $\Phi()$ a função de distribuição acumulada da variável normal padrão (média nula e desvio-padrão unitário). Para outros tipos de distribuição, funções normais equivalentes devem ser utilizadas. 


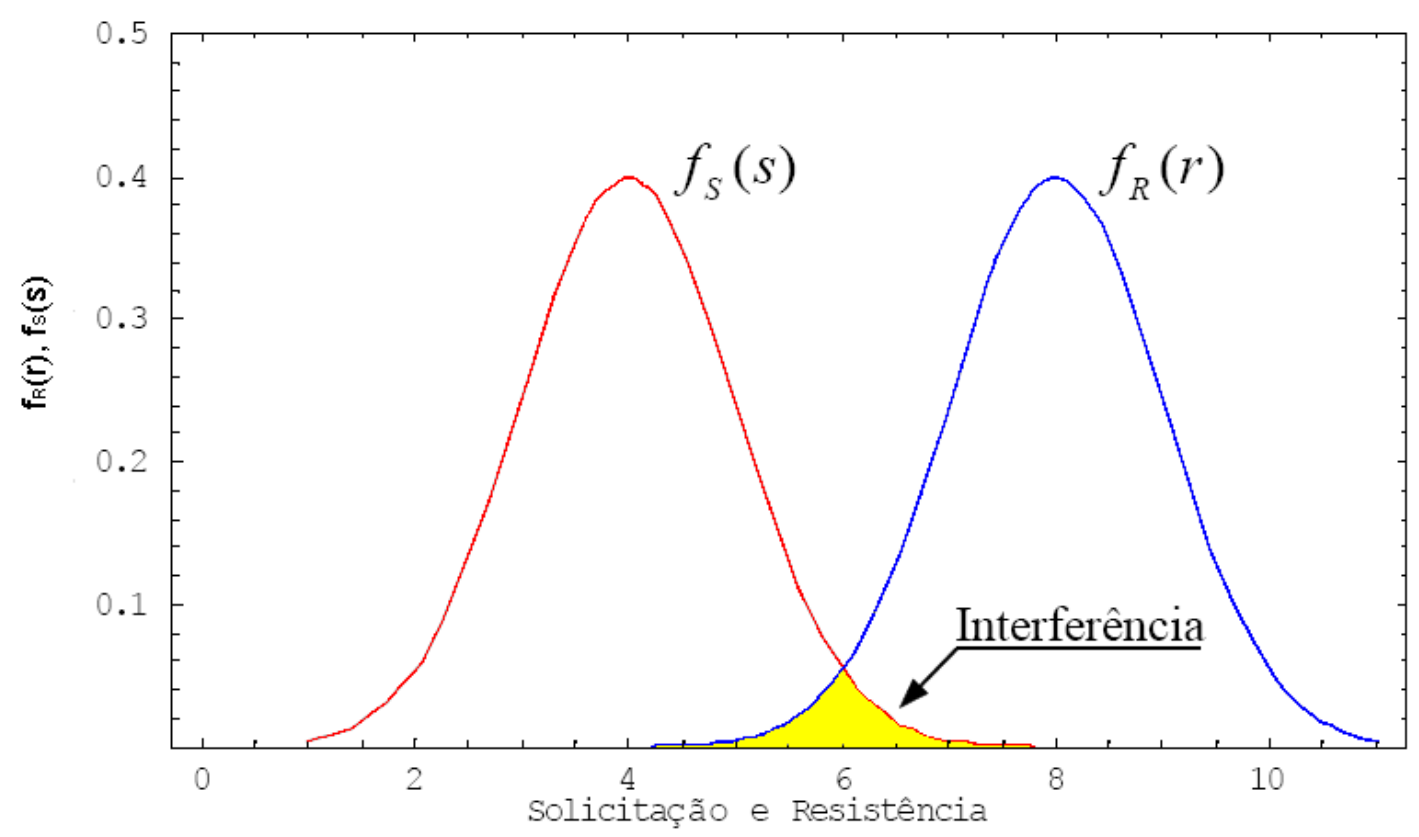

Figura 3.2: Problema fundamental da confiabilidade (interferência entre populações)

O índice $\beta$ é uma medida geométrica que corresponde à distância entre o ponto sobre a EEL $g(\boldsymbol{x})=0$ (ponto de projeto ou ponto mais provável de falha) e a média da distribuição conjunta de probabilidades. No caso mais geral, a definição do ponto de projeto e o cálculo do índice de confiabilidade $\beta$ correspondente demandam a utilização de procedimentos iterativos.

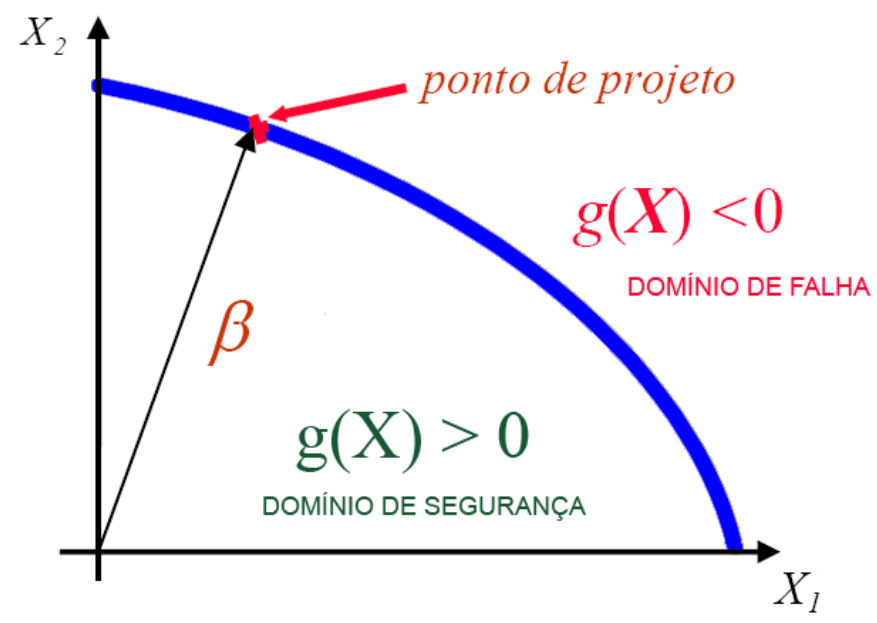

Figura 3.3: O índice de confiabilidade $\beta$ e o ponto de projeto, no espaço normal padrão 
Valores alvo do índice de confiabilidade para estados limites últimos foram propostos pelo JCSS (2001) e são reproduzidos na Tabela 3.3 a seguir.

Tabela 3.3: Valores alvo para o índice de confiabilidade $\beta$ e probabilidades de falha associadas, relacionados a estados limites últimos.

\begin{tabular}{cccc}
\hline $\begin{array}{c}\text { Medida relativa do custo } \\
\text { de segurança }\end{array}$ & $\begin{array}{c}\text { Conseqüencias } \\
\text { leves de falha }\end{array}$ & $\begin{array}{c}\text { Conseqüências } \\
\text { moderadas de falha }\end{array}$ & $\begin{array}{c}\text { Conseqüências } \\
\text { graves de falha }\end{array}$ \\
\hline Grande $(A)$ & $\beta=3,1\left(P_{\mathrm{f}} \approx 10^{-3}\right)$ & $\beta=3,3\left(\mathrm{P}_{\mathrm{f}} \approx 5.10^{-4}\right)$ & $\beta=3,7\left(\mathrm{P}_{\mathrm{f}} \approx 10^{-4}\right)$ \\
Normal (B) & $\beta=3,7\left(\mathrm{P}_{\mathrm{f}} \approx 10^{-4}\right)$ & $\beta=4,2\left(\mathrm{P}_{\mathrm{f}} \approx 10^{-5}\right)$ & $\beta=4,4\left(\mathrm{P}_{\mathrm{f}} \approx 5.10^{-6}\right)$ \\
Pequeno (C) & $\beta=4,2\left(\mathrm{P}_{\mathrm{f}} \approx 10^{-5}\right)$ & $\beta=4,4\left(\mathrm{P}_{\mathrm{f}} \approx 5.10^{-6}\right)$ & $\beta=4,7\left(\mathrm{P}_{\mathrm{f}} \approx 10^{-6}\right)$ \\
\hline
\end{tabular}

\subsubsection{Classes de Conseqüência}

O JCSS (2001) propôs uma classificação das estruturas em classes de conseqüência de falha, baseada na taxa $\rho$ definida como o quociente entre custos totais (i.e. custos de construção mais custos diretos de falha) e custos de construção.

Classe 1 - Conseqüências Leves: $\quad \rho$ é menor que aproximadamente 2.

Risco de vida, dada uma falha, é pequeno ou negligenciável, e as conseqüências econômicas são pequenas ou negligenciáveis (por exemplo: silos e estruturas agrícolas);

Classe 2 - Conseqüências Moderadas: $\quad \rho$ está entre 2 e 5.

Risco de vida, dada uma falha, é médio ou as conseqüências econômicas são consideráveis (por exemplo: construções residenciais, comerciais ou industriais);

Classe 3 - Conseqüências Graves: $\quad \rho$ está entre 5 e 10.

Risco de vida, dada uma falha, é alto, ou as conseqüências econômicas são significantes (por exemplo: pontes, teatros, hospitais, edifícios altos). 
Se $\rho$ é maior que 10 as conseqüências de falha devem ser consideradas extremas e um análise de custo-benefício completa é recomendada. A conclusão poderia ser que a estrutura não deveria ser construída.

As classes e custos de falha podem estar relacionados com a localização da estrutura. Por exemplo, uma estrutura construída em zona rural poderia apresentar conseqüências de falha de leves a moderadas, enquanto essa mesma estrutura construída em zona urbana poderia apresentar conseqüências de falha de graves a extremas.

\subsection{Confiabilidade de Componente e Confiabilidade de Sistemas}

Problemas de engenharia freqüentemente envolvem múltiplos modos de falha; isto é, podem existir vários modos de falha, sendo que a ocorrência de algum deles constituirá falha ou não funcionamento do sistema ou componente.

Confiabilidade de componente é a confiabilidade de um único componente estrutural que tem um modo de falha dominante. Um componente estrutural pode ser entendido como um membro de uma estrutura (sistema estrutural) formada por vários membros. Um componente pode ter um único ou vários modos de falha. Neste ultimo caso, trata-se os múltiplos modos de falha como um sistema em série, como explicado a seguir.

Confiabilidade de sistema é a confiabilidade de um sistema estrutural composto de um número de componentes ou a confiabilidade de um único componente que tem vários modos de falha com aproximadamente a mesma importância. Os sistemas são classificados como:

$\checkmark$ Sistemas Redundantes: a falha de um único componente não resulta diretamente na falha da estrutura. Os componentes, ou parte deles (subsistemas), estão associados em paralelo. 
Sistemas Não-Redundantes: a falha local de um único componente leva rapidamente à falha da estrutura. Os componentes estão associados em série.

A análise probabilística de sistemas deve ser realizada com base em:

$\checkmark$ Redundância (caminhos de distribuição de carregamento alternativos);

$\checkmark$ Estado e a complexidade da estrutura (múltiplos modos de falha).

O cálculo da probabilidade de sobrevivência ou falha de um sistema é geralmente um problema complexo e aproximações são quase sempre necessárias.

\subsection{1 Árvore de Falhas}

Para um sistema, as condições adversas ou falhas que contribuem para a ocorrência dos modos potenciais de falha podem ser muito complexas, fazendo com que sejam necessários meios sistemáticos de identificação das várias falhas e seus efeitos interativos (caso existam) no evento falha. O diagrama conhecido como "árvore de falhas" é utilizado com esse propósito. Essencialmente, uma árvore de falhas é utilizada para decompor um evento principal (geralmente falha do sistema) em combinações de eventos elementares que levam à ocorrência do evento principal. Uma análise da árvore de falhas pode incluir uma avaliação quantitativa das probabilidades de falhas elementares levando ao cálculo da probabilidade de falha principal. Um diagrama geral de uma árvore de falhas é apresentado na Figura 3.4 Na decomposição do evento principal, os eventos elementares são agrupados utilizando-se portas do tipo $E$ ou $O U$, que correspondem a componentes associados em paralelo ou em série. 


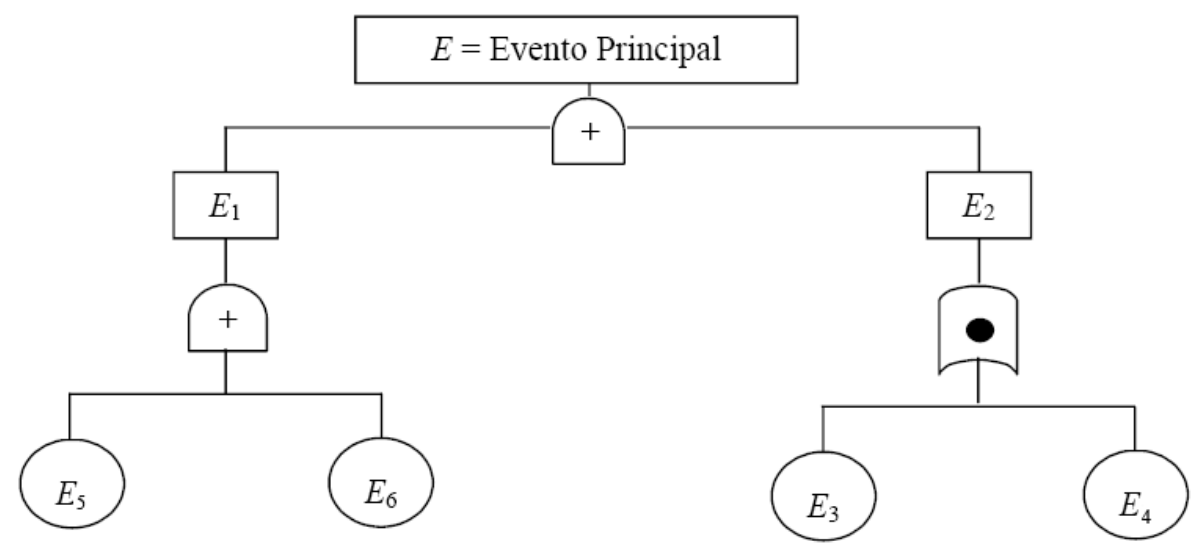

(Evento primário) (Evento

Secundário)

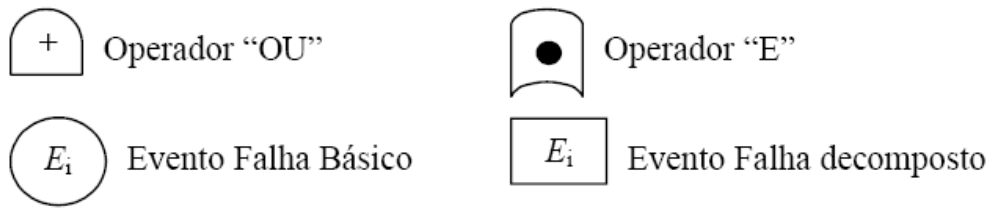

Figura 3.4: Diagrama representativo da árvore de falhas

\subsection{Cálculo da Probabilidade de Falha}

A probabilidade de falha definida na equação (3.12) também pode ser representada como:

$$
P_{f}=\int_{g(X) \leq 0} f_{X}(x) d x
$$

onde $\boldsymbol{X}$ é o vetor de variáveis aleatórias básicas, $g(X)$ é a equação de estado limite para o modo de falha considerado, e $f_{X}(x)$ é a função densidade de probabilidades conjunta de $\boldsymbol{X}$.

Uma categoria importante de estados limites é aquela em que todas as variáveis são consideradas independentes do tempo, tanto ao se negligenciar variações no tempo em casos onde isso é considerado aceitável, como através da transformação de processos dependentes do tempo em variáveis que são independentes do tempo (por exemplo, utilizando distribuições de valores extremos). Os métodos usualmente empregados para o cálculo da $P_{f}$ em tais casos são sumarizados abaixo. 


\subsubsection{Métodos assintóticos aproximados}

Apesar de esses métodos terem surgido com a descrição das variáveis aleatórias através de informações de "segundo momento" (i.e., através da média e do desvio-padrão, mas sem atribuir nenhuma distribuição de probabilidades), atualmente, em muitos casos, é possível ter uma descrição completa do vetor de variáveis aleatórias $\boldsymbol{X}$ (como resultado da coleta de dados e dos estudos de modelos probabilísticos). Em tais situações, a probabilidade de falha pode ser calculada através de métodos de confiabilidade de primeira e segunda ordem, a saber, First Order Reliability Method (FORM) e Second Order Reliability Method (SORM), respectivamente. Sua implementação baseia-se em:

\section{1) Técnicas de transformação:}

$$
\boldsymbol{T}: \boldsymbol{X}=\left(X_{1}, X_{2}, \ldots X_{n}\right) \quad \rightarrow \quad \boldsymbol{U}=\left(U_{1}, U_{2}, \ldots U_{n}\right)
$$

onde $U_{1}, U_{2}, \ldots U_{n}$ são variáveis normais padrão independentes (i.e., com média zero e desvio padrão unitário). Por essa razão, o espaço das variáveis de projeto (incluindo a EEL) é transformado num espaço normal padrão (Figura 3.5). As propriedades especiais do espaço normal padrão levam a vários resultados importantes, discutidos abaixo.

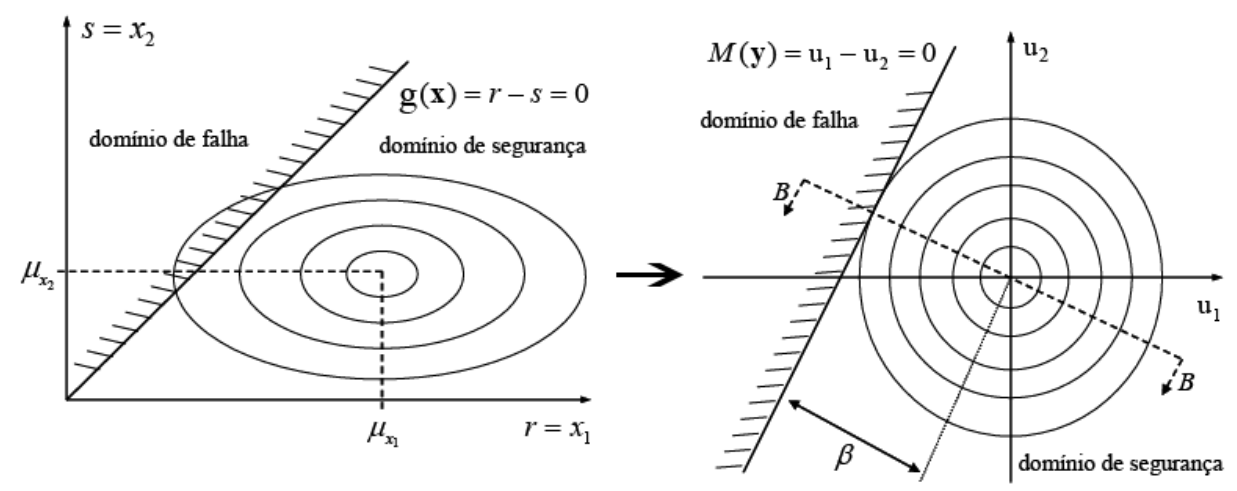

Figura 3.5: Interpretação gráfica do problema da confiabilidade estrutural e a transformação para o espaço normal padrão

2) Técnicas de busca:

No espaço normal padrão, o objetivo é determinar um ponto de parada apropriado, que é o ponto na superfície de estado limite mais próximo da origem, o chamado "ponto de projeto". Nesse espaço rotacionalmente simétrico, ele é o ponto mais provável de falha, isto 
é, suas coordenadas definem a combinação de variáveis que mais provavelmente causarão a falha. Isto ocorre porque a FDP conjunta, cujo pico está diretamente acima da origem (no espaço transformado), diminui exponencialmente conforme a distância para a origem do sistema aumenta. Para determinar esse ponto, um procedimento de busca é necessário. 0 algoritmo de Hasofer, Lind, Rackwitz e Fiessler, ou HLRF, é comumente utilizado (HASOFER; LIND, 1974; RACKWITZ; FIESSLER, 1978).

Denotando as coordenadas do ponto de projeto por

$$
\boldsymbol{u}^{*}=\left(u_{1}^{*}, u_{2}^{*}, \ldots u_{n}^{*}\right)
$$

a distância da origem é igual a

$$
\left(\sum_{i=1}^{n} u_{i} *^{2}\right)^{\frac{1}{2}}
$$

Essa quantidade escalar é conhecida como o índice de confiabilidade de HasoferLind, $\beta_{\mathrm{HL}}$. Note que $\boldsymbol{u}^{*}$ também pode ser escrito como

$$
\boldsymbol{u}^{*}=\beta_{H L} \alpha
$$

onde $\alpha=\left(\alpha_{1}, \alpha_{2}, \ldots \alpha_{n}\right)$ é o vetor unitário normal à superfície de estado limite no ponto $\boldsymbol{u}^{*}$, e, conseqüentemente, $\alpha_{i}(i=1, \ldots n)$ representam os cossenos diretores do ponto de projeto. Eles também são conhecidos como fatores de sensibilidade, já que fornecem uma indicação da importância relativa da incerteza nas variáveis de projeto na confiabilidade calculada. Seu valor absoluto varia entre 0 e 1 e, quanto mais próximo da unidade, mais significante a influência da respectiva VA para a confiabilidade.

\section{3) Técnicas de aproximação:}

Uma vez determinado o ponto de parada do algoritmo, a probabilidade de falha pode ser aproximada utilizando resultados aplicáveis ao espaço normal padrão. Assim, numa 
aproximação de primeira ordem, a superfície de estado limite é aproximada pelo hiperplano tangente ao ponto de projeto. O conteúdo de probabilidade do domínio de falha é dado por:

$$
P_{f F O R M}=\Phi\left(-\beta_{H L}\right)
$$

Em alguns casos, o problema é merecedor de uma aproximação de ordem maior para a superfície de estado limite no ponto de projeto, mesmo que apenas para checar a precisão do FORM. O resultado para a probabilidade de falha assumindo uma aproximação quadrática (segunda ordem) para a superfície de estado limite é assintoticamente dado por

$$
P_{f S O R M}=\Phi\left(-\beta_{H L}\right) \prod_{j=1}^{n-1}\left(1-\beta_{H L} \kappa_{j}\right)^{-1 / 2}
$$

para $\beta_{H L} \rightarrow \infty$, onde $\kappa_{j}$ são as curvaturas principais da superfície de estado limite no ponto de projeto. Uma expressão aplicável a valores finitos de $\beta_{H L}$ também é válida.

\subsubsection{Métodos de Simulação}

Nesta abordagem, uma amostragem aleatória é empregada para simular um número grande de experimentos (geralmente numéricos) e observar o resultado. No contexto da confiabilidade estrutural isto significa, na abordagem mais simples, amostrar o vetor de VA's $\boldsymbol{X}$ para se obter um conjunto de pontos amostrais. A função de estado limite é então avaliada para averiguar se, para esse conjunto, ocorreu falha $(g(x) \leq 0)$. O experimento é repetido muitas vezes e a probabilidade de falha, $P_{f}$, é estimada pela fração de amostras levando à falha dividida pelo número total de amostras. Esse é o chamado Método de Simulação de Monte Carlo Direto, Cru ou Simples (SMCS). Tal método não é indicado para problemas práticos devido ao elevado número de amostras necessárias a fim de se estimar com um certo grau de confiança a probabilidade de falha. Note que o número de tentativas aumenta conforme a probabilidade de falha diminui. 
Deste modo, o objetivo de métodos de simulação mais avançados, comumente utilizados para avaliação da confiabilidade, é reduzir a variância da $P_{f}$ estimada. Um exemplo desses métodos é a Amostragem por Importância, onde o objetivo é concentrar a distribuição dos pontos amostrais na vizinhança dos pontos prováveis de falha, tais como o ponto de projeto obtido da análise com o FORM/SORM. Isso é feito através da introdução de uma função de amostragem, cuja escolha depende de informações disponíveis a priori, tais como as coordenadas do ponto de projeto e/ou quaisquer estimativas da probabilidade de falha. Desta maneira, a taxa de sucesso (definida aqui como a probabilidade de obter um ponto na região de falha) é melhorada, comparado com o Método de Simulação de Monte Carlo Simples. O Método de Simulação de Monte Carlo com Amostragem por Importância $(\mathrm{SMCl})$ é frequentemente usado imediatamente após uma análise inicial pelo FORM/SORM.

\subsubsection{Superfícies de Resposta}

As técnicas de amostragem por importância são capazes de reduzir drasticamente o número de simulações necessárias no método de Monte Carlo. No entanto, em problemas com equação de estado limite numérica com grande número de graus de liberdade, esse número reduzido de simulações pode ainda ser proibitivamente alto. Nestes casos, o uso de superfícies de resposta pode reduzir o número de avaliações da EEL.

O Método das Superfícies de Resposta (MSR) consiste um aproximar a EEL exata $g(x)$ por uma expressão polinômica aproximada $\tilde{g}(x)$. Essa expressão aproximada pode ser utilizada com os mais diversos fins, inclusive para a avaliação de probabilidades de falha. A aproximação polinômica pode ser utilizada na realização de simulações de Monte Carlo simples ou com amostragem por importância (MSRS e MSRI, respectivamente), com a vantagem de cada avaliação de $\tilde{g}(x)$ ser muito mais rápida do que avaliações de $g(x)$.

Para mais detalhes sobre os métodos de cálculo da probabilidade de falha, recomenda-se a consulta de Ang e Tang (1984), Benjamin e Cornell (1970), Ditlevsen e Madsen (1996), Rubinstein (1981), Bucher e Bourgund (1990). 


\section{Capítulo 4: OTIMIZAÇÃO MATEMÁTICA}

Neste capítulo apresenta-se, de maneira breve e simples, os conceitos fundamentais da otimização matemática necessários para o desenvolvimento deste trabalho. Para informações mais aprofundadas recomenda-se a consulta das referências indicadas.

\subsection{Introdução}

O projeto estrutural é uma atividade complexa que envolve a concepção da estrutura, seu arranjo estrutural e arquitetura, e o dimensionamento de seus elementos. Existe ainda a preocupação com os custos das obras, pois os projetos estruturais devem garantir a segurança satisfatória com os menores custos. Por conta disso, a otimização matemática constitui-se em uma ferramenta valiosa para a elaboração de projetos estruturais. Esse tratamento é possível, uma vez que o comportamento físico de uma estrutura pode ser descrito em termos de um conjunto de funções matemáticas. Assim, as técnicas de otimização podem ser empregadas para buscar valores extremos dessas funções. Vale ressaltar que à medida que se busca representar melhor a realidade, o problema de otimização estrutural torna-se mais complexo.

\subsection{Formulação do Problema de Otimização}

Ao se realizar um projeto, as quantidades numéricas variáveis são chamadas variáveis de projeto (ou parâmetros de construção). Deve-se notar que um "projeto" é simplesmente um conjunto de valores para as variáveis de projeto, mesmo que esses valores sejam inadequados. Se o projeto atende todos os requisitos dele exigidos, é chamado de projeto aceitável ou projeto factível. De todos os projetos factíveis, alguns são melhores que outros, possuindo alguma qualidade a mais. Se essa qualidade pode ser expressa como uma função computável das variáveis de projeto, podemos considerar a otimização como o processo de obtenção do "melhor" projeto. A função para qual o projeto é otimizado é 
chamada função objetivo. Portanto, a otimização consiste em encontrar valores para as variáveis de projeto que minimizem ou maximizem a função objetivo, de acordo com a necessidade do problema. Tal processo é realizado através da utilização de um algoritmo de otimização.

O problema de minimização pode ser escrito de maneira genérica como:

$$
\min f(x), \quad \text { sujeito à } \begin{cases}g_{i}(x) \geq 0 & i=1, \ldots n \\ h_{j}(x)=0 & j=1, \ldots m\end{cases}
$$

Onde $x$ é o vetor das variáveis de projeto, $f$ é a função objetivo, $g_{i}$ e $h_{j}$ são as restrições de desigualdade e de igualdade do problema, respectivamente. As funções $f, g_{i}$ e $h_{j}$ são funções escalares de valor real das variáveis $x$. O problema é resolvido pelas variáveis $x$ que satisfazem as restrições e minimizam a função $f$. Na otimização sem restrições, minimiza-se uma função objetivo que depende de variáveis reais, com nenhuma restrição nos valores dessas variáveis.

\subsection{Propriedades dos Pontos de Mínimo}

A noção usual de mínimo é a de um ponto onde a função tem o seu menor valor, i.e., $X_{M}$ tal que $f\left(X_{M}\right) \leq f(X)$ para qualquer $X$. No cálculo elementar, descobre-se que para uma função de $n$ variáveis $\left(x_{1}, x_{2}, \ldots, x_{n}\right)$ possuindo derivadas contínuas, o mínimo será um ponto onde

$$
\frac{\partial f}{\partial x_{i}}=0, \quad i=1,2, \ldots, n
$$

Um ponto que satisfaz a equação (4.2) seguramente será um mínimo relativo se a forma quadrática

$$
Q=\sum_{i=1}^{n} \sum_{j=1}^{n}\left(\frac{\partial^{2} f}{\partial x_{i} \partial x_{j}}\right)_{X_{0}} a_{i} a_{j}
$$


for positiva para todas as escolhas das constantes arbitrárias $a_{1}, a_{2}, \ldots, a_{n}$, exceto que $Q=0$ somente quando $a_{i}=0, i=1, \ldots, n$. As segundas derivadas são avaliadas em $X_{0}$, um ponto onde $\partial f / \partial x_{i}=0$. A declaração usual dessa propriedade é que a matriz

$$
\boldsymbol{H} \equiv\left(\begin{array}{cccc}
\frac{\partial^{2} f}{\partial x_{1}^{2}} & \frac{\partial^{2} f}{\partial x_{1} \partial x_{2}} & \cdots & \frac{\partial^{2} f}{\partial x_{1} \partial x_{n}} \\
\vdots & & \ddots & \vdots \\
\frac{\partial^{2} f}{\partial x_{n} \partial x_{1}} \frac{\partial^{2} f}{\partial x_{n} \partial x_{2}} & \cdots & \frac{\partial^{2} f}{\partial x_{n}^{2}}
\end{array}\right)
$$

deve ser positiva definida (uma matriz é positiva definida se todos os seus autovalores são positivos e positiva semi-definida se todos os seus autovalores são não-negativos). Essa matriz algumas vezes é chamada de matriz Hessiana de $f$.

\subsubsection{Ponto de Mínimo Global}

Geralmente busca-se um minimizador global de $f$, i.e., um ponto onde a função alcança seu menor valor em todo o domínio. Deste modo, pode-se dizer que o ponto $X_{M}$ é um mínimo global de $f$ se $f\left(X_{M}\right) \leq f(X)$ para qualquer $X$, onde $X$ varia para todo $\mathbb{R}^{n}$.

\subsubsection{Ponto de Mínimo Local}

Um mínimo local é um ponto que atinge o menor valor de $f$ na sua vizinhança. Formalmente diz-se que $X_{M}$ é um minimizador local se houver uma vizinhança $\mathcal{N}$ de $X_{M}$ tal que $f\left(X_{M}\right) \leq f(X)$ para todo $X \in \mathcal{N}$, onde a vizinhança $\mathcal{N}$ de $X_{M}$ é simplesmente um conjunto aberto que contém $X_{M}$.

Um ponto que satisfaz essa definição é algumas vezes chamado de mínimo local frágil. Essa terminologia distingue-o de um mínimo local forte, também chamado mínimo local estrito, que é um ponto $X_{M}$ em uma vizinhança $\mathcal{N}$ tal que $f\left(X_{M}\right)<f(X)$ para todo $X \in \mathcal{N} \operatorname{com} X \neq X_{M}$. 
A Figura 4.1 mostra uma função de uma variável que, na ausência de restrições, tem dois mínimos locais e um mínimo global.

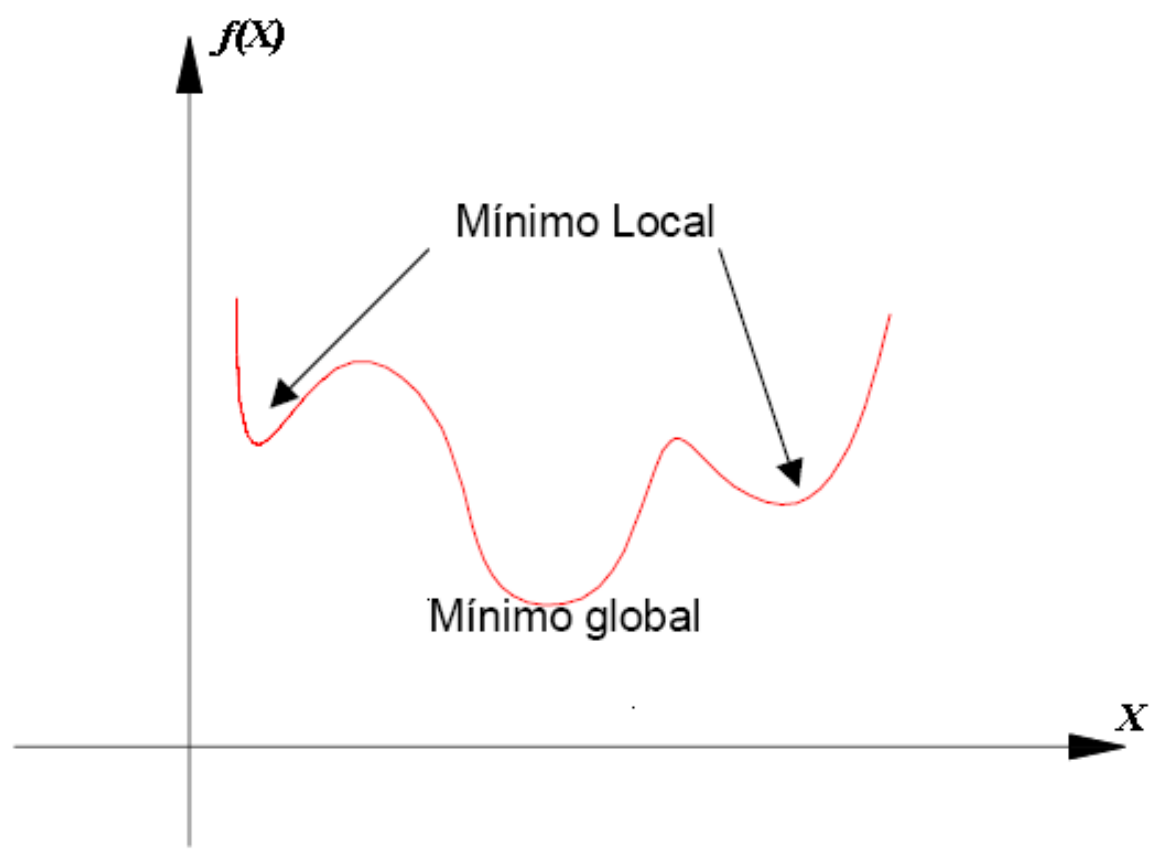

Figura 4.1: Exemplo de função de uma variável com um mínimo global e dois mínimos locais

Se $f$ for contínua e duas vezes diferenciável, pode-se ser capaz de dizer que $X_{M}$ é um mínimo local, e possivelmente um mínimo local estrito, pela análise do gradiente $\nabla f\left(X_{M}\right)$ e do Hessiano $\nabla^{2} f\left(X_{M}\right)$. As condições necessárias para a otimização são derivadas da suposição de que $X_{M}$ é um mínimo local da análise de $\nabla f\left(X_{M}\right)$ e $\nabla^{2} f\left(X_{M}\right)$.

\section{Condição Necessária de $1^{\mathrm{a}}$. Ordem:}

Se $X_{M}$ for um mínimo local de $f$ e $f$ for contínua e diferenciável em uma vizinhança aberta de $X_{M}$, então $\nabla f\left(X_{M}\right)=0$.

\section{Condição Necessária de $2^{\mathrm{a}}$. Ordem:}


Se $X_{M}$ for um mínimo local de $f$ e $\nabla^{2} f$ for contínua em uma vizinhança aberta de $X_{M}$, então $\nabla f\left(X_{M}\right)=0$ e $\nabla^{2} f\left(X_{M}\right)$ será positivo semi-definido (i.e., $\nabla^{2} f\left(X_{M}\right) \geq 0$ ).

\section{Condição Suficiente de $2^{\mathrm{a}}$. Ordem:}

Seja $\nabla^{2} f$ contínua em uma vizinhança aberta de $X_{M}, \nabla f\left(X_{M}\right)=0$ e $\nabla^{2} f\left(X_{M}\right)$ positivo definido. Neste caso, $X_{M}$ é um mínimo local estrito de $f$.

Nota-se que a condição suficiente de segunda ordem garante algo mais forte que as condições necessárias mostradas anteriormente.

Em muitos casos, essas propriedades de pontos de mínimo são úteis. Contudo, existem casos de problemas em que apenas a primeira noção de mínimo (i.e., $X_{M}$ tal que $f\left(X_{M}\right) \leq f(X)$ para qualquer $\left.X\right)$ é aplicável. Podem existir casos de funções que não possuem nem mesmo primeiras derivadas contínuas.

\subsection{Algoritmos Utilizados}

\subsubsection{Interpolação Quadrática}

A Interpolação Quadrática é um método comumente usado para encontrar o tamanho do passo $\alpha$ que minimiza $f$ em uma direção particular e, consequentemente, faz com que o processo de minimização tenha convergência mais rápida. Como os problemas formulados neste trabalho possuem apenas uma variável de projeto, existe apenas uma direção de busca e, portanto, a Interpolação Quadrática pode ser utilizada para encontrar o mínimo da função objetivo.

Procedendo de acordo com a seguinte prescrição,

$$
x_{q+1}=x_{q}+\alpha S_{q}
$$


onde $S_{q}$ é o vetor unitário que indica a direção de busca e $\alpha$ é o comprimento de passo positivo ou negativo escolhido tal que $f\left(x_{q+1}\right)<f\left(x_{q}\right)$. Se $\alpha$ for considerado uma variável, os pontos de $x$ para um intervalo de valores de $\alpha$ formam uma reta.

Substituindo (4.5) em $f(x)$, obtemos

$$
f(x)=f\left(x_{q}+\alpha S_{q}\right)=f(\alpha)
$$

e $f$ pode ser considerada uma função de $\alpha$ somente ( $x_{q}$ e $S_{q}$ são considerados fixos). Procura-se aqui o valor de $\alpha$ que minimiza $f(\alpha)$. Note que esse valor, denotado por $\alpha^{*}$, não produz o mínimo global de $f$ a menos que $x_{q+1}=x_{q}+\alpha S_{q}$ contenha o ponto de mínimo global.

Com esse conceito, o problema de minimizar $f(x)$ pode ser reduzido a uma sucessão de problemas de minimização unidimensional, independente da dimensão do vetor $x$. Usualmente, métodos numéricos são utilizados para encontrar $\alpha^{*}$.

Podemos aproximar a função $f(\alpha)$ por uma função $h(\alpha)$ cujo ponto de mínimo é facilmente determinado. A função de uma variável que possui um mínimo mais simples é a quadrática

$$
h(\alpha)=a+b \alpha+c \alpha^{2}
$$

cujo mínimo ocorre onde

$$
\frac{d h}{d \alpha}=b+2 c \alpha=0
$$

ou

$$
\alpha^{*}=-\frac{b}{2 c}
$$


As constantes $b$ e $c$ para a aproximação quadrática ( $a$ não é necessária) podem ser determinadas pela amostragem da função $f(\alpha)$ para três valores diferentes de $\alpha, \alpha_{1}$, $\alpha_{2}$ e $\alpha_{3}$, e pela resolução das equações

$$
\begin{aligned}
& f_{1}=a+b \alpha_{1}+c \alpha_{1}^{2}, \\
& f_{2}=a+b \alpha_{2}+c \alpha_{2}^{2}, \\
& f_{3}=a+b \alpha_{3}+c \alpha_{3}^{2},
\end{aligned}
$$

onde $f_{1}$ é o valor de $f\left(\alpha_{1}\right)$, etc. Se usarmos $0, t$ e $2 t$ para $\alpha_{1}, \alpha_{2}$ e $\alpha_{3}$, onde $t$ é uma tentativa de passo, as equações (4.10) são particularmente fáceis de resolver. Assim, obtemos:

$$
\begin{aligned}
a & =f_{1}, \\
b & =\frac{4 f_{2}-3 f_{1}-f_{3}}{2 t}, \\
c & =\frac{f_{3}+f_{1}-2 f_{2}}{2 t^{2}}, \\
\alpha^{*} & \simeq \frac{4 f_{2}-3 f_{1}-f_{3}}{4 f_{2}-2 f_{1}-2 f_{3}} t
\end{aligned}
$$

Para que $\alpha^{*}$ seja mínimo e não máximo de $h(\alpha)$, deve satisfazer a seguinte condição

$$
\left.\frac{d^{2} h}{d \alpha^{2}}\right|_{\alpha=\alpha^{*}}>0
$$

O caso em que $h$ é quadrática requer $c>0$, ou

$$
f_{3}+f_{1}>2 f_{2}
$$

Isto significa que o valor de $f_{2}$ deve estar abaixo da linha que conecta $f_{1}$ e $f_{3}$ (Figura 4.2). Um esquema para assegurar que a equação (4.14) é satisfeita e que o mínimo está no intervalo $0<\alpha<2 t$ é o seguinte: 
1) Escolher um valor inicial para $t$ baseado nas iterações prévias ou outras informações com respeito a um valor razoável de comprimento do passo. Idealmente $t$ seria da ordem de $\alpha^{*}$;

2) Computar $f(t)$;

3) Se $f(t)>f(0) \equiv f_{1}$, então estabelecer $f_{3}=f(t)$, dividir $t$ em dois, e repetir a etapa 2; caso contrário estabelecer $f_{2}=f(t)$, dobrar $t$, e repetir a etapa 2;

4) Quando for obtido um valor de $t$ tal que $f_{2}<f_{1}$ e $f_{3}>f_{2}$, computar $\alpha *$ de acordo com a equação (4.12). (As duas situações finais aceitáveis são ilustradas na Figura 4.3 a e $b$ ).

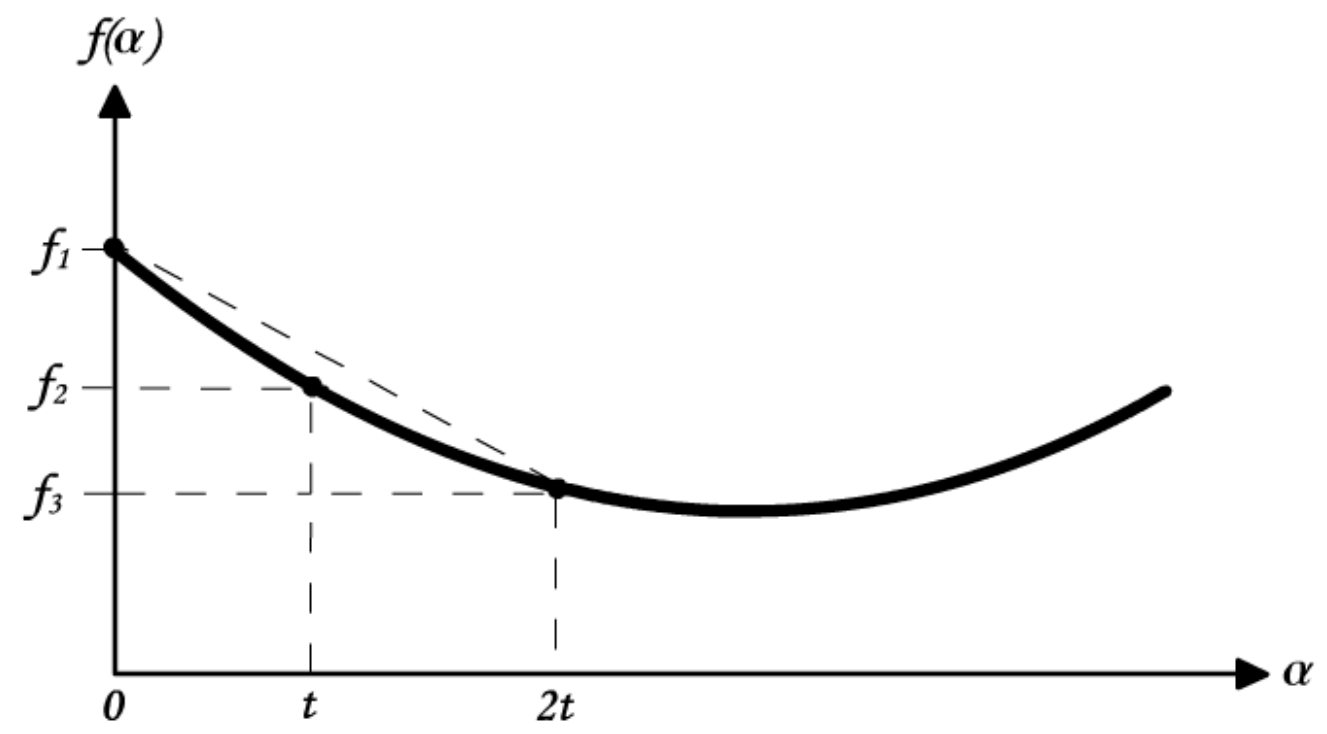

Figura 4.2: Método da Interpolação Quadrática 


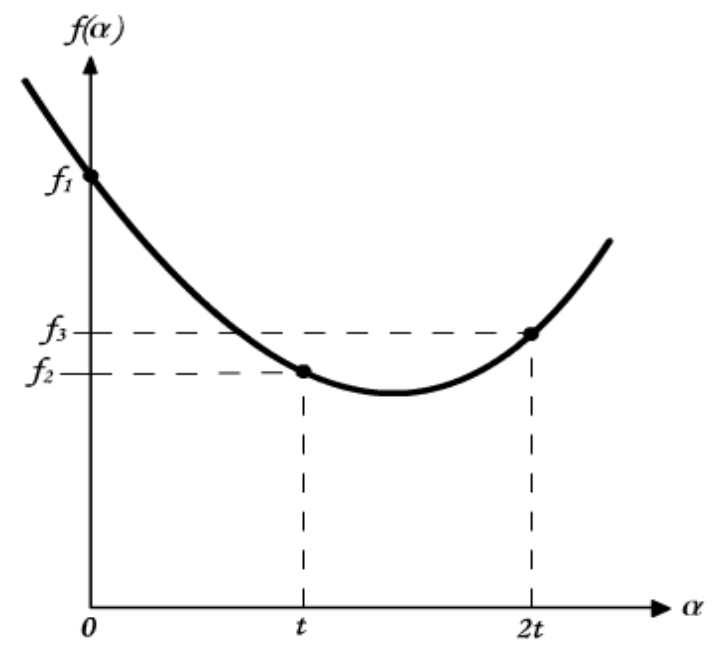

(a) $f_{3}>f_{2}$ $f_{3}<f_{1}$

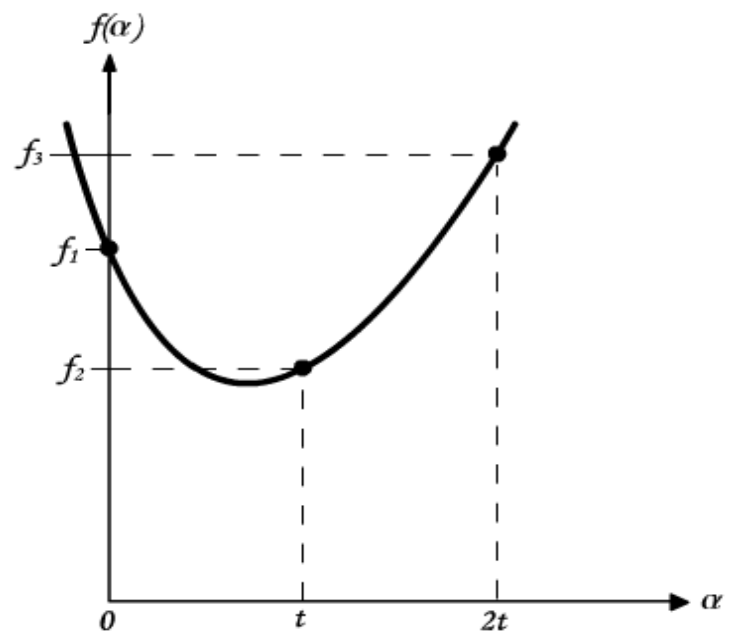

(b) $f_{3}>f_{1}$ $f_{2}<f_{1}$

Figura 4.3: Situações aceitáveis no método da Interpolação Quadrática

A lógica do algoritmo de interpolação quadrática descrito acima é mostrada no fluxograma da Figura 4.4. Se o $t$ inicial tiver o sinal errado (i.e., se $f$ aumenta na direção $x_{q}+t S_{q}, t>0$ ), o processo não terminará. Portanto, se o sinal correto de $t$ é dúvida, deve ser incorporado ao algoritmo um critério de parada, por exemplo através da introdução de um contador no bloco A da Figura 4.4.

\subsubsection{Regula Falsi}

O método Regula Falsi, ou da "Falsa Posição", ou ainda "Método da Secante", é um dos métodos mais simples utilizados para se encontrar zeros de funções não-lineares. Novamente, utiliza-se uma função $h(\alpha)$ para aproximar $f(x+\alpha \boldsymbol{S}) \equiv f(\alpha)$. No caso da otimização, buscamos encontrar a raiz $\alpha *$ que soluciona $\frac{d f}{d \alpha}=0$.

Suponha que se conhece a inclinação de $f$ na direção $\boldsymbol{S}$ em dois pontos $A$ e $B$, designadas por $f_{A}^{\prime}$ e $f_{B}^{\prime}$ (que são as derivadas da função $f$ nos pontos $A$ e $B$ ). Além disso, suponha que $f^{\prime}{ }_{A}<0$ e $f^{\prime}{ }_{B}>0$. Se assumirmos que $\frac{d f}{d \alpha}$ irá variar 
aproximadamente linearmente entre $A$ e $B$, então podemos fazer uma interpolação, utilizando a fórmula

$$
\begin{gathered}
\frac{d f(\alpha)}{d \alpha} \simeq a+b \alpha \\
f^{\prime}=a+b A \\
f^{\prime}{ }_{B}=a+b B
\end{gathered}
$$

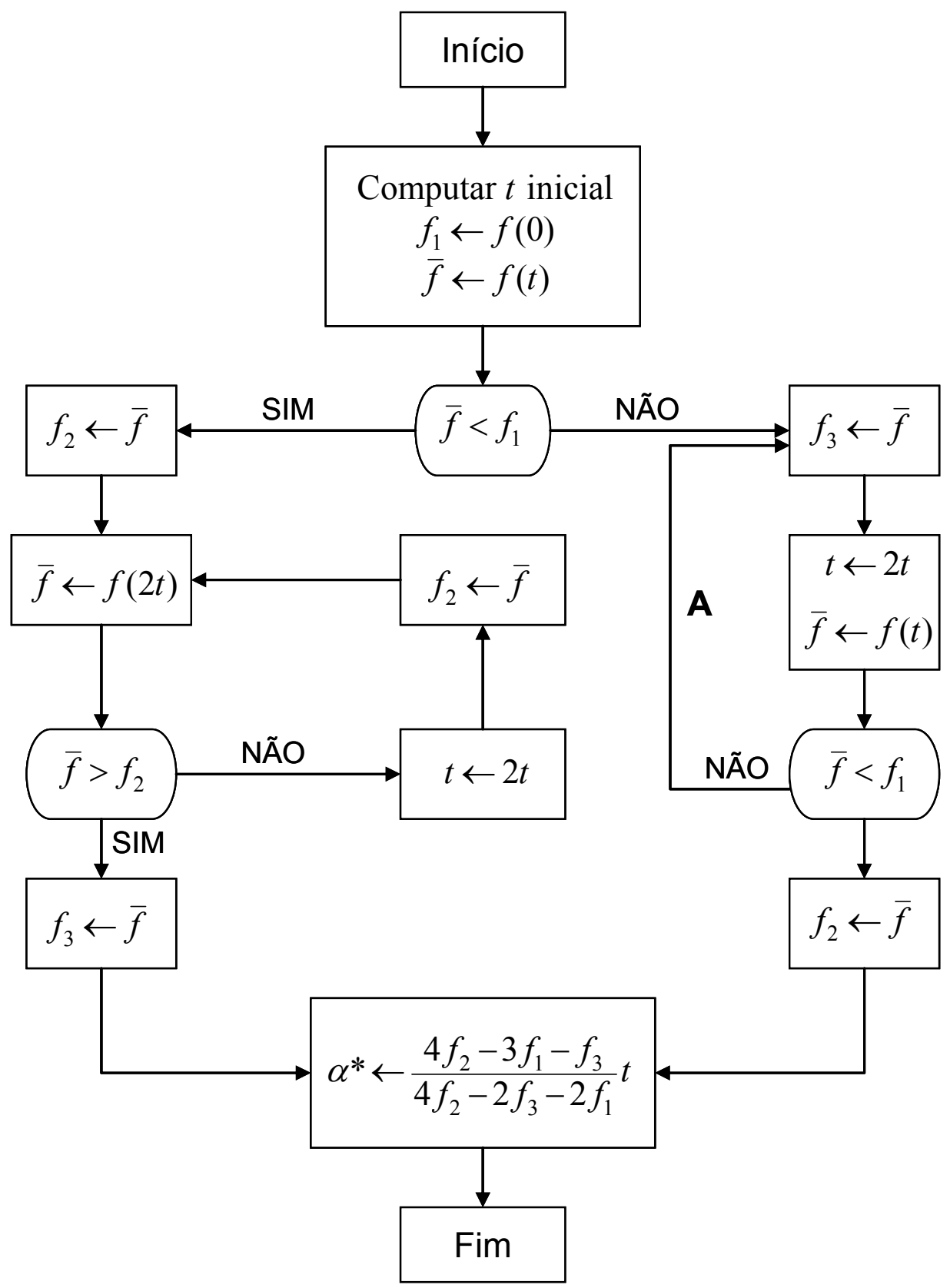

Figura 4.4: Fluxograma de uma iteração do Método da Interpolação Quadrática 
segue daí que

$$
\begin{gathered}
a=\frac{f^{\prime}{ }_{B} A-f_{A}^{\prime} B}{A-B} \\
b=\frac{f^{\prime}{ }_{A}-f_{B}^{\prime}}{A-B}
\end{gathered}
$$

Finalmente, de $\frac{d f\left(\alpha^{*}\right)}{d \alpha}=0$ obtém-se:

$$
\tilde{\alpha}^{*}=-\frac{a}{b}=\frac{f_{A}^{{ }_{A} B}-f^{{ }^{\prime}}{ }_{B} A}{f^{{ }^{\prime}}-f^{{ }^{\prime}}{ }_{B}}
$$

A interpretação geométrica desta formula é indicada na Figura 4.5. É significante o fato de que ao assumir $\frac{d f}{d \alpha}$ linear essa formulação implica que $f$ é aproximada por uma função quadrática. Isto significa que para uma função quadrática verdadeira, o resultado da primeira iteração irá teoricamente produzir o $\alpha^{*}$ exato. Quando o método é aplicado a funções quadráticas altamente excêntricas, essa formulação frequentemente produz resultados melhores que pelo método da Interpolação Cúbica (que não é discutido neste trabalho).

A equação (4.20) não depende de que $f^{\prime}{ }_{A}$ e $f^{\prime}{ }_{B}$ tenham sinais opostos, mas é recomendado que isso seja uma condição para iniciar o processo. O processo de iteração padrão pode ser:

1) Dados A, B, e os correspondentes $f^{\prime}{ }_{A}$ e $f^{\prime}{ }_{B}$ de sinais opostos, calcular $\tilde{a}^{*}$ como na equação (4.20).

2) Calcular $\frac{d f\left(\tilde{\alpha}^{*}\right)}{d \alpha}$ e comparar com o critério de convergência estipulado. Se o critério for satisfeito, terminar; caso contrário ir para a etapa 3. 
3) Se $\frac{d f\left(\tilde{\alpha}^{*}\right)}{d \alpha}$ tiver o mesmo sinal de ${f^{\prime}}_{A}$, substituir $A$ por $\tilde{a}^{*}$ e $f^{\prime}{ }_{A}$ por $\frac{d f\left(\tilde{\alpha}^{*}\right)}{d \alpha}$; caso contrário substituir $B$ por $\tilde{a}^{*}$ e $f^{\prime}{ }_{B}$ por $\frac{d f\left(\tilde{\alpha}^{*}\right)}{d \alpha}$, e repetir a etapa 1.

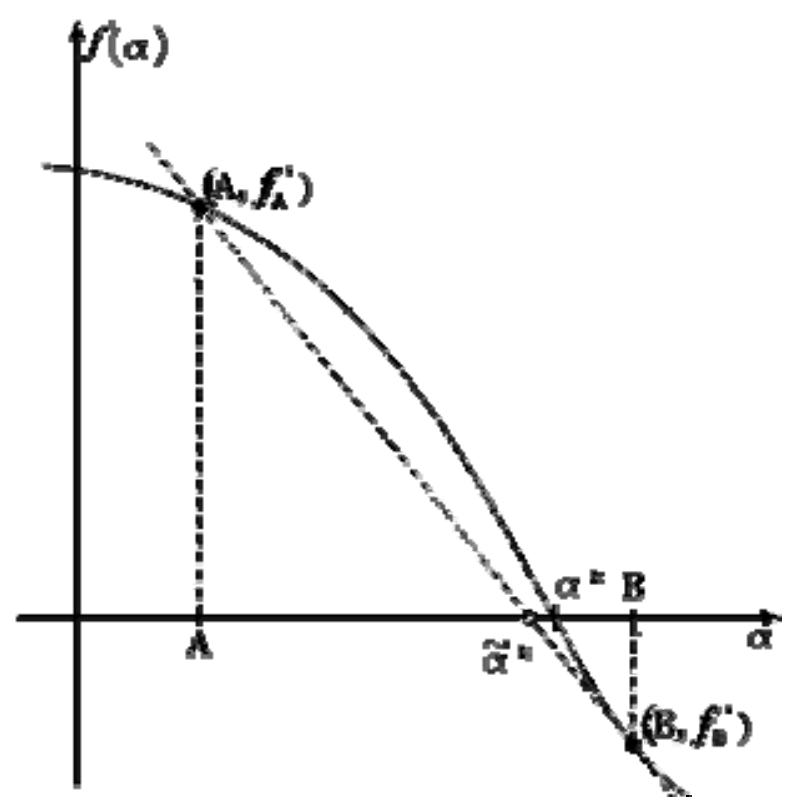

Figura 4.5: Interpretação geométrica do método regula falsi

Uma característica importante desse algoritmo é que o intervalo $B-A$ é sempre decrescente e a convergência é geralmente bem rápida. Ocasionalmente, contudo, a situação mostrada na Figura 4.6 irá surgir. Aqui, o ponto B irá se aproximar da raiz $\alpha^{*}$ apenas lentamente, mesmo depois de muitas iterações, e o ponto $A$ permanecerá inalterado. Uma técnica para evitar isso consiste simplesmente em alternar o método da bisecção com a iteração do regula falsi; isto é, computar $\tilde{a}^{*}$ de acordo com (4.20) e, se o resultado não produzir uma raiz suficientemente satisfatória, fazer a troca indicada na etapa 3. Então computar um novo $\tilde{a}^{*}$ dado por

$$
\tilde{a}^{*}=\frac{A+B}{2}
$$


que é simplesmente o ponto médio entre $A$ e $B$. Se isso não produzir a raiz, fazer a substituição indicada na etapa 3, repetir a equação (4.20), e assim por diante. Esse processo alivia o problema muito efetivamente sem causar complicações no algoritmo. $O$ fluxograma da Figura 4.7 resume o algoritmo do método regula falsi.

Para mais detalhes sobre a teoria de otimização matemática e os algoritmos utilizados recomenda-se a consulta de Fox (1971), Vanderplaats (1984) e Luenberger (1984).

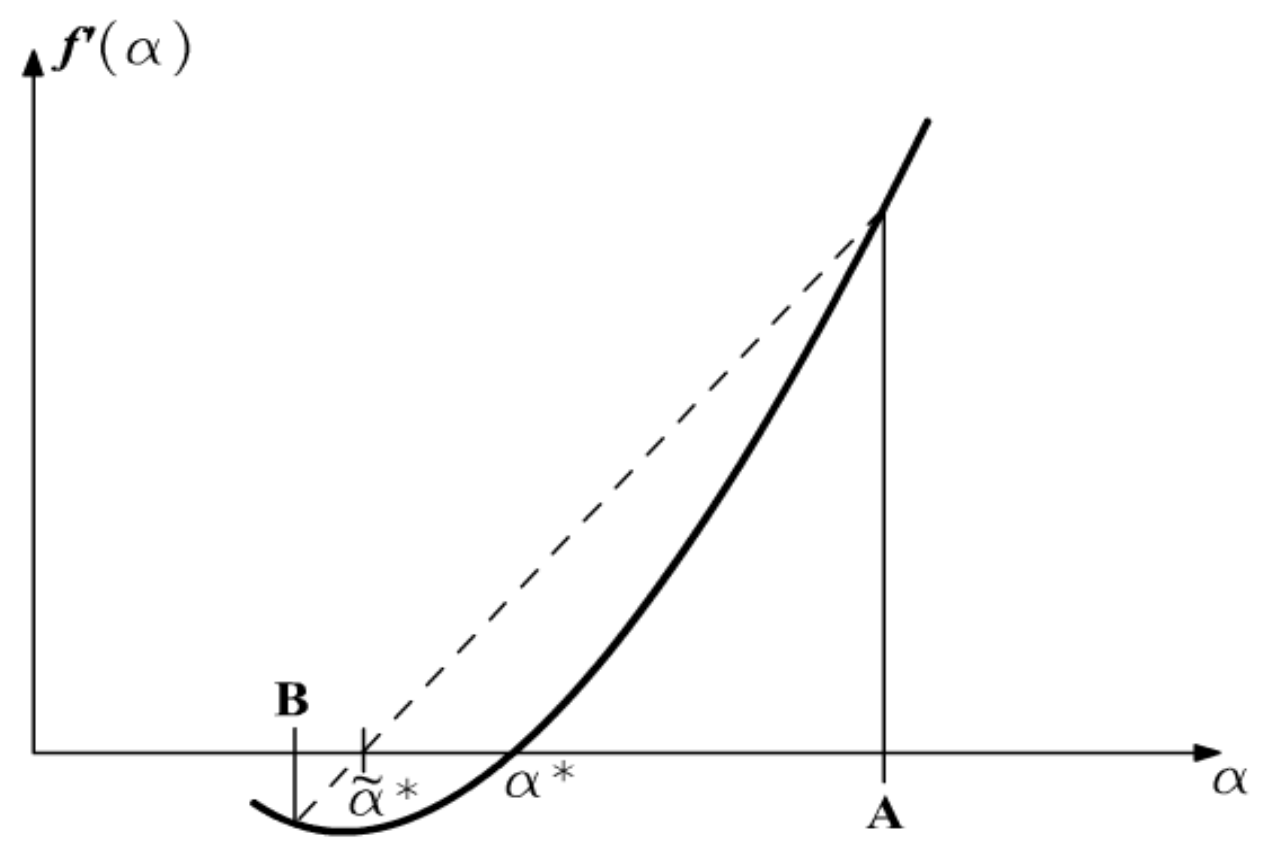

Figura 4.6: Caso particular em que o método regula falsi demora para convergir 


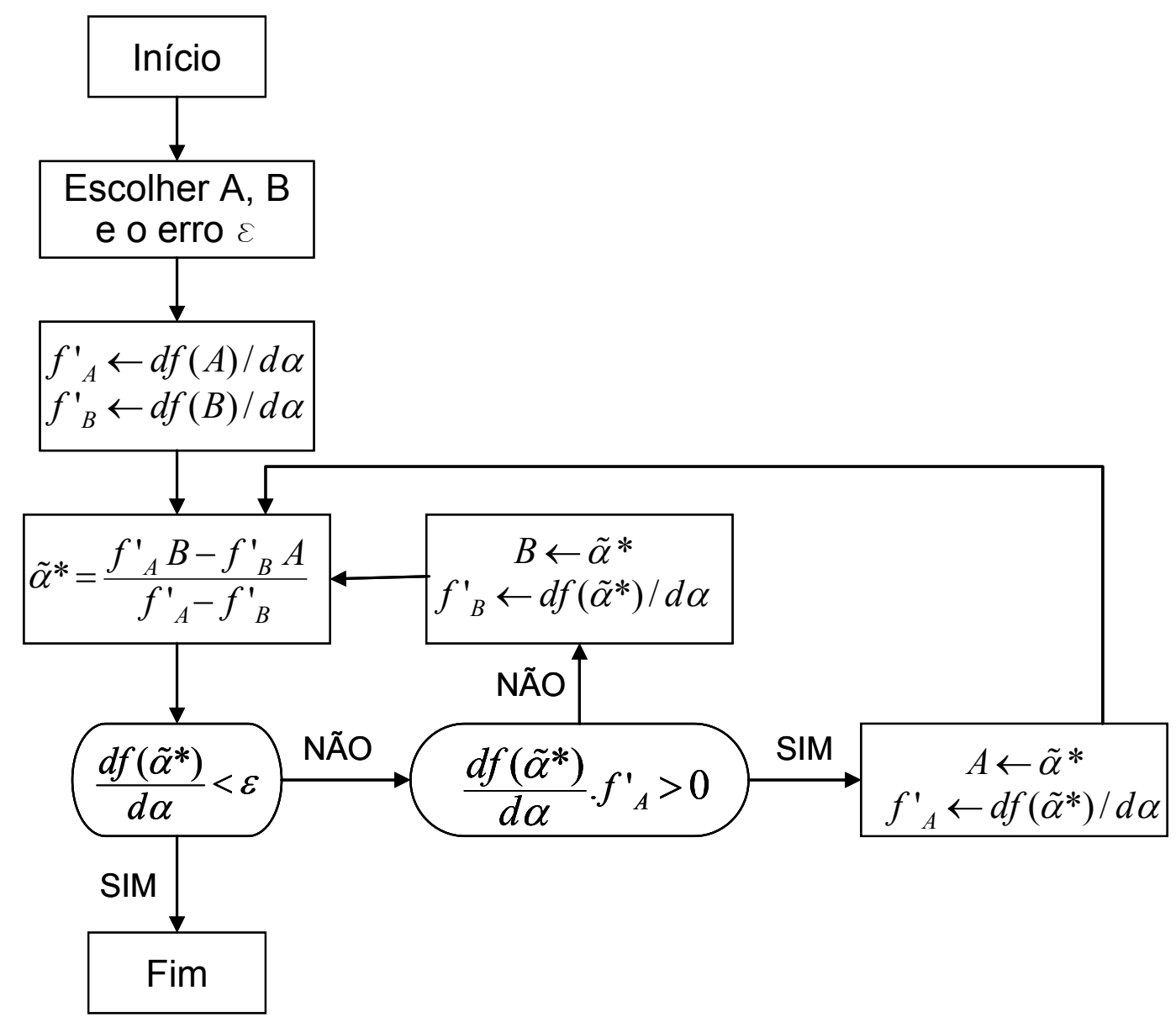

Figura 4.7: Fluxograma do método Regula Falsi 


\section{Capítulo 5: PROGRAMA DESENVOLVIDO}

Durante o presente trabalho de mestrado foi desenvolvido um programa computacional para a otimização de risco estrutural baseada em confiabilidade. Criado em linguagem Fortran e utilizando técnicas de orientação a objeto, ele funciona como um módulo do programa de confiabilidade StRAnD e opcionalmente acoplado ao Ansys.

Nesta seção será apresentada uma descrição do StRAnD e seu funcionamento, de como foi feito o acoplamento do StRAnD com o Ansys e, finalmente, de como foi desenvolvido o módulo de otimização, chamado RiskOPT, e suas funcionalidades.

\subsection{Structural Reliability Analysis and Design: o StRAnD}

Como o nome do programa diz, o StRAnD é um programa para projeto e análise estrutural de confiabilidade. Desenvolvido por Beck (2007) no Departamento de Estruturas da EESC/USP em linguagem Fortran, e utilizando as modernas técnicas da orientação a objeto, o programa permite aferir a confiabilidade de estruturas a partir da obtenção da probabilidade de falha das mesmas.

Através do arquivo de texto STRAND_INPUT.txt o usuário define o número de equações de estado limite da estrutura e as variáveis aleatórias envolvidas no problema, com suas distribuições estatísticas e coeficientes de correlação, se eles existirem. Até o presente momento o programa permite escolher entre 11 distribuições: uniforme, normal, log-normal, exponencial, Raleigh, logística, Gumbel para máximos ou mínimos, Frechet para máximos ou mínimos, e Weibull para máximos ou mínimos. Ao escolher a distribuição estatística o usuário pode optar por definir os parâmetros ou os valores médios da distrubuição. Ainda no arquivo de texto, o usuário define quais os métodos de avaliação de confiabilidade deseja utilizar. As possíveis escolhas são o FORM e o SORM, com opção de avaliação dos limites bi-modais, Simulação de Monte Carlo simples (SMCS) ou com 
amostragem por importância (SMCl), e o Método das Superfícies de Resposta utilizando Simulação de Monte Carlo simples (MSRS) ou com amostragem por importância (MSRI). É possível resolver o problema utilizando mais de um método ou até todos, porém quanto maio o número de métodos, maior o tempo de processamento.

Ao escolher o FORM é permitido ao usuário definir o critério de convergência, o número de iterações e a tolerância, além do ponto inicial de procura do ponto de projeto (que é o ponto médio por default). No caso das Simulações de Monte Carlo o usuário pode definir o número de amostras, o número de funções de amostragem, e a semente de geração dos números aleatórios.

Finalizada a edição do arquivo de entrada dos dados, as equações de estado limite devem ser escritas na sub-rotina LIMIT_STATE_FUNCTION.F90 que faz parte do código do programa e está acessível aos usuários para ser alterada como convenha. Como é possível ver na Figura 5.1 o usuário deve alterar a função "SELECT CASE" adicionando quantos CASES quanto houverem equações de estado limite. O último CASE refere-se à $\mathrm{P}_{f}$ do sistema, isto é, a intersecção de todos os estados limites da estrutura, utilizada na Simulação de Monte Carlo.

Após o processamento do StRAnD os resultados são fornecidos no arquivo de texto STRAND_OUTPUT.txt. O arquivo mostra as respostas obtidas com cada método resolvido, e ao final, uma tabela de resultados comparativos para facilitar a análise por parte do usuário. Tais resultados comparativos são o número realizado de avaliações das equações de estado limite, o índice de confiabilidade $\beta$, a probabilidade de falha, e os limites bimodais superior e inferior.

Exemplos dos arquivos de texto de entrada e saída de dados do StRAnD são mostrados no Apêndice A. 


\subsection{Acoplamento StRAnD/Ansys}

Em sua versão inicial, o StRAnD apenas aceitava equações de estado limite analíticas, ou seja, equações algebricamente fechadas. Uma parte deste projeto de

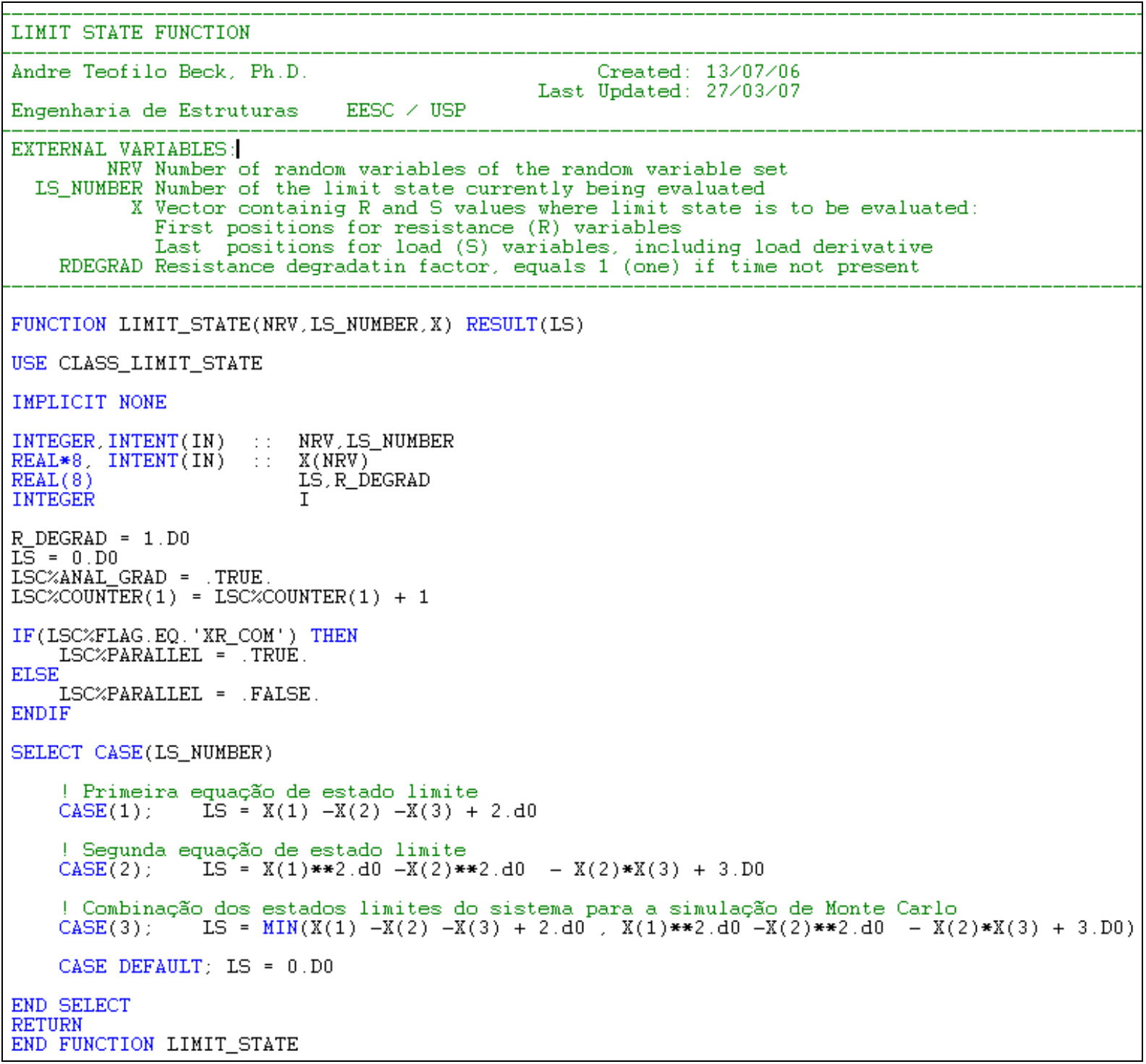

Figura 5.1: Parte da sub-rotina LIMIT_STATE_FUNCTION.F90

mestrado consistiu em desenvolver um acoplamento do StRAnD com o programa de elementos finitos Ansys, para permitir a análise de equações de estado limite não analíticas, nas quais existe uma sub-função que é avaliada de forma numérica. Nesse caso, a cada avaliação da equação de estado limite, uma análise do modelo mecânico deve ser feita, utilizando os valores atuais das variáveis aleatórias envolvidas no problema. 
Para que o Ansys possa ser executado pelo código Fortran é preciso que ele seja utilizado através do chamado modo "batch". Tal modo funciona através da execução de um arquivo de texto com extensão. $\log$. O arquivo $\log$ possui todas as linhas de comando que o Ansys deverá executar, escritas na seqüência de execução (veja Apêndice $A$ ), sendo a primeira linha o comando /BATCH. As próximas linhas de comando devem conter:

- definição dos parâmetros;

- definição dos tipos de elementos, constantes reais, e materiais, com suas propriedades;

- geração da geometria do modelo (nós, elementos, áreas, etc.);

- definição das condições de contorno (vinculações e carregamentos);

- comandos para solução do modelo;

- criação do arquivo de saída, de extensão .txt., que contém os dados necessários ao StRAnD.

Foram criadas então três sub-rotinas em Fortran, descritas a seguir:

$\checkmark$ CLASS_SR_FE_INTERFACE.F90: Módulo que contém a função responsável pela leitura dos resultados fornecidos pelo Ansys e contidos no arquivo Dados-file.txt.

$\checkmark$ UPDATE_FE_DATA_FILE.F90: Subrotina que atualiza o arquivo de entrada dados do Ansys (ansys_input.log) com os valores do próximo ponto a ser analisado (valores das variáveis aleatórias), obtidos pela análise de confiabilidade do StRAnD. Tal atualização é realizada a cada nova iteração do StRAnD.

$\checkmark$ FEMODEL.F90: Subrotina responsável por três tarefas: chamar a função UPDATE_FE_DATA_FILE.F90 que reescreve o arquivo de entrada do Ansys; chamar o executável do Ansys; e por fim, chamar o módulo de leitura dos resultados do modelo mecânico CLASS_SR_FE_INTERFACE.F90. A subrotina FEMODEL.F90 
é chamada pelo módulo LIMIT_STATE_FUNCTION.F90 do StRAnD a cada avaliação das equações de estado limite, quando as EEL são numéricas e exigem respostas do modelo mecânico.

\subsection{0 módulo de otimização RiskOPT}

Dois métodos de otimização foram programados: Interpolação Quadrática e Regula Falsi, ambos descritos no Capítulo 4. O RiskOPT é composto de 5 arquivos, criados em linguagem Fortran, e listados a seguir:

$\checkmark$ OPTIMIZATION_VARIABLES.F90: Neste módulo são feitas as definições das variáveis globais, à saber, os coeficientes de segurança parciais $\left(\gamma_{S}\right.$ e $\left.\phi_{R}\right)$ e o coeficiente de segurança adicional $\left(\lambda_{k}\right)$, que é a variável de projeto na função objetivo.

$\checkmark$ READ_DATA.F90: Módulo responsável pela leitura dos valores das probabilidades de falha de cada equação de estado limite no arquivo STRAND_OUTPUT.TXT.

$\checkmark$ COST_FUNCTIONS.F90: Módulo que avalia a função custo esperado total (função objetivo) e seu gradiente. É chamado pelos métodos de minimização, retornando o valor da função custo para um dado valor do $\lambda_{k}$. Este módulo deve ser alterado pelo usuário ao definir o problema, escrevendo as funções custo.

$\checkmark$ INT_QUAD.F90: Sub-rotina que contém o algoritmo de minimização que faz a busca do ponto de mínimo pelo método da Interpolação Quadrática. Escreve os resultados (número de iterações realizadas, coeficiente de segurança ótimo e custo mínimo) no arquivo de texto OPTIMIZATION_OUTPUT.TXT.

$\checkmark$ REGULA_FALSI.F90: Sub-rotina que contém o algoritmo de minimização que faz a busca do ponto de mínimo pelo método Regula Falsi. Escreve os resultados (número de iterações realizadas, coeficiente de segurança ótimo e custo mínimo) no arquivo de texto OPTIMIZATION_OUTPUT.TXT. 
Como mencionado acima, para utilizar o programa o usuário deve editar o arquivo COST_FUNCTIONS.F90, escrevendo nele as funções que compõem o custo esperado total (Figura 5.2). Estas funções devem ser escritas em função do coeficiente de segurança adicional. O coeficiente de segurança adicional $\left(\lambda_{k}\right)$ é uma variável global no código, chamada CS, e a variável de projeto no problema de otimização. Esses aspectos da formulação da função objetivo e da variável de projeto ficarão mais claros na discussão dos problemas resolvidos feita no capítulo a seguir.

Os custos esperados de falha são obtidos através do produto do custo da falha pela probabilidade de que ela aconteça. Tal probabilidade é obtida através da análise realizada pelo StRAnD, utilizando o método FORM. O programa realiza então a minimização da função custo esperado total, sendo o coeficiente de segurança adicional a variável de projeto, utilizando o método escolhido pelo usuário (Interpolação Quadrática ou Regula Falsi). 


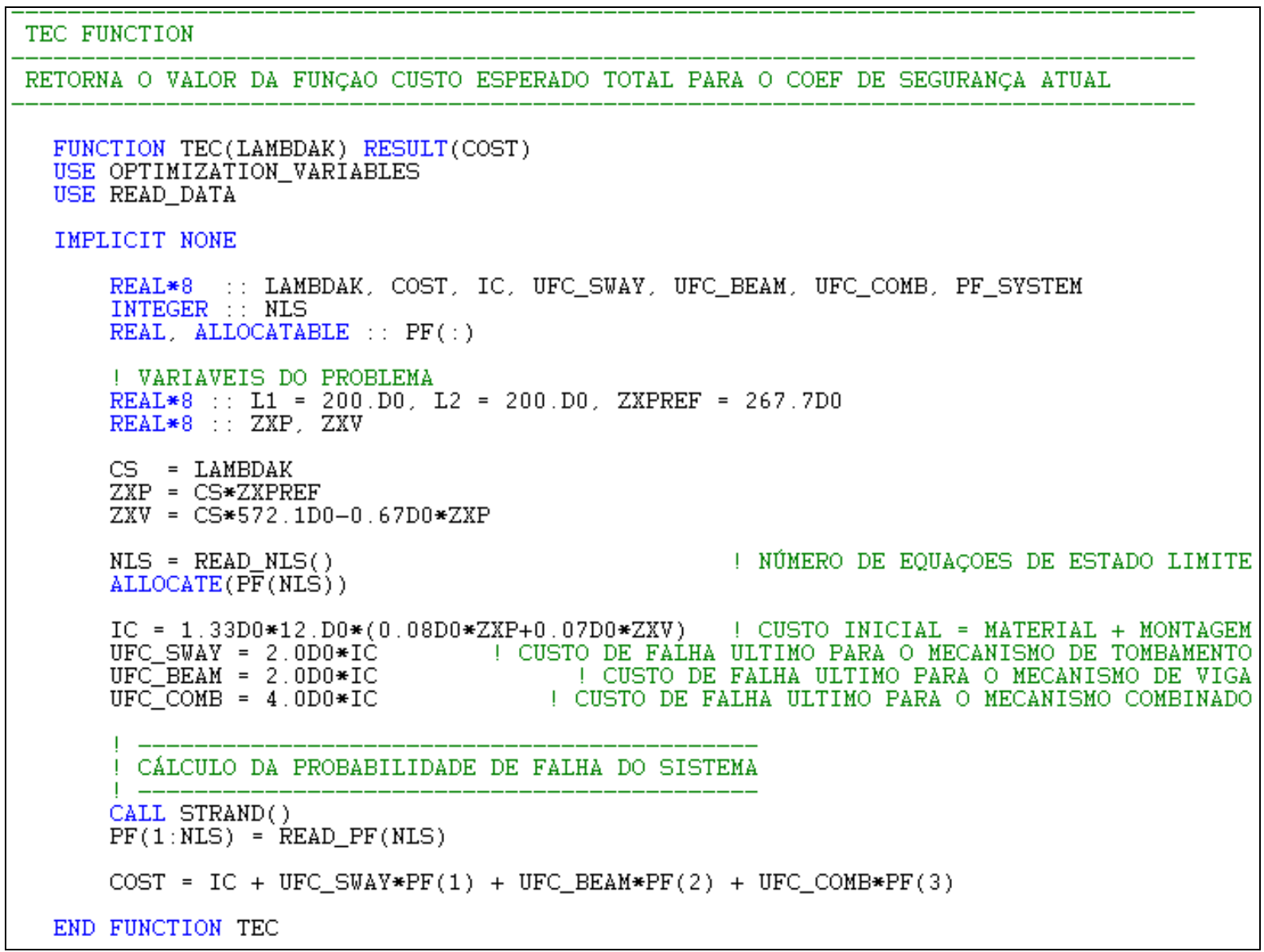

Figura 5.2: Trecho do módulo COST_FUNCTIONS.F90 mostrando a criação das funções custo inicial, custos de falha, e da função objetivo COST para um pórtico plano.

\subsection{Fluxograma}

Segue abaixo o fluxograma básico de funcionamento do RiskOPT. As etapas mostradas visam demonstrar a seqüência dos procedimentos realizados por ele, a interação com o StRAnD, e a comunicação deste último com o Ansys.

Para detalhes adicionais sobre o RiskOPT veja o Apêndice A. 


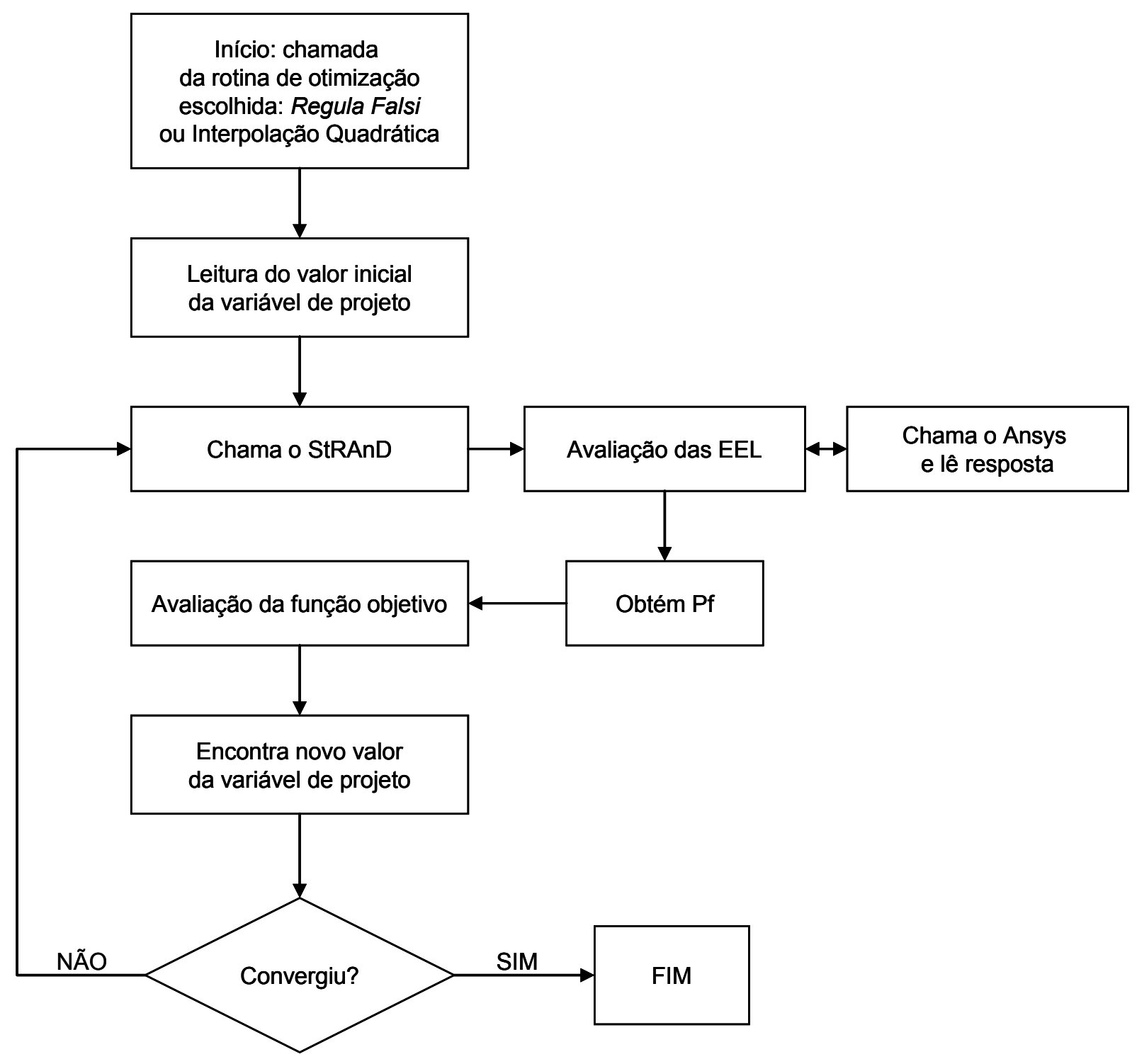

Figura 5.3: Fluxograma do RiskOPT 


\section{Capítulo 6: EXEMPLOS RESOLVIDOS}

Os primeiros exemplos resolvidos são exemplos simples e acadêmicos, que visam mostrar o comportamento geral das funções custo esperado total e o desenvolvimento de projetos utilizando o coeficiente de segurança característico como medida da margem de segurança. Por isso os valores obtidos nesses problemas não são necessariamente realistas. O último exemplo resolvido não se enquadra nessa descrição, pois trata de uma estrutura real. Para tal exemplo os resultados obtidos mostram de forma mais clara o que acontece na prática da engenharia.

\subsection{Barra tracionada}

O primeiro problema resolvido no RiskOPT é um dos problemas mais tradicionais da engenharia: o de uma barra tracionada. Considerou-se uma barra metálica circular de diâmetro $\mathbf{A}$ e tensão de escoamento $\sigma_{\mathbf{y}}$, tracionada em ambas as extremidades por uma força $\mathbf{F}$ (Figura 6.1). Essas 3 variáveis são as VA's do problema.

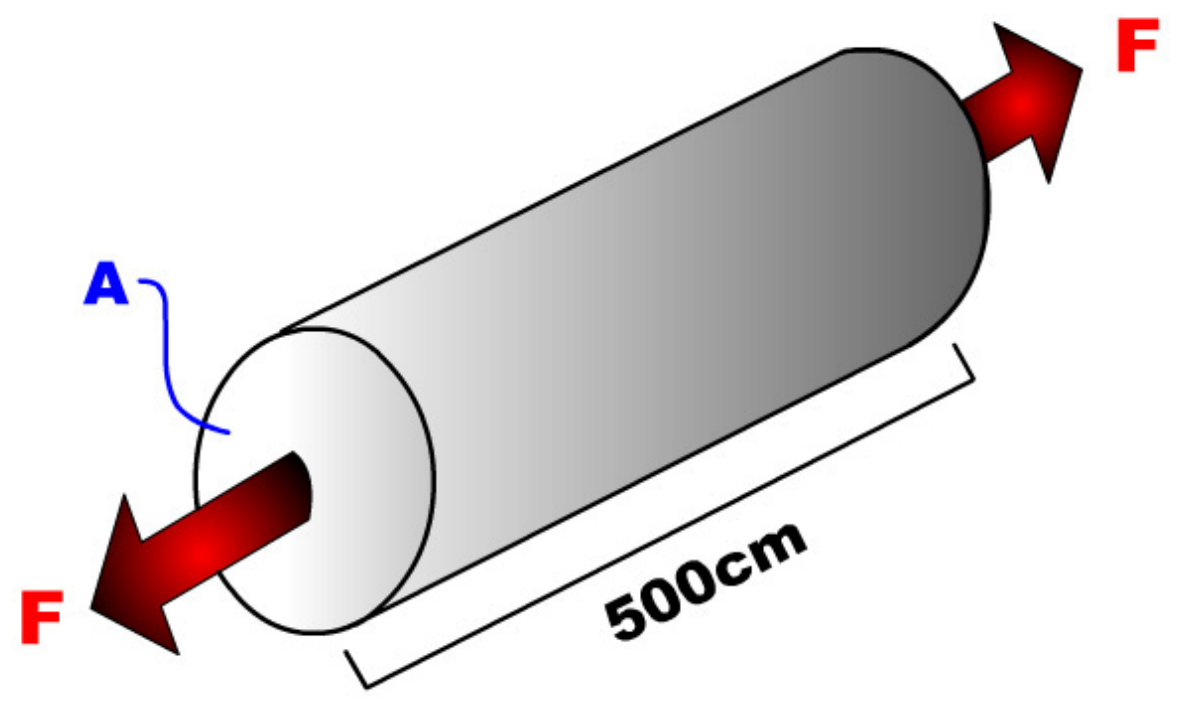

Figura 6.1: Barra tracionada 


\section{Dados do problema:}

3 VA's não correlacionadas.

Tabela 6.1: Variáveis aleatórias do problema da barra tracionada

\begin{tabular}{cccccc}
\hline VA & Designação & Distribuição & $\mu$ & $\sigma$ & Unidade \\
\hline $\mathrm{X}_{1}$ & Força $(\mathrm{F})$ & Normal & 55 & 11 & $\mathrm{kN}$ \\
$\mathrm{X}_{2}$ & Tensão de Escoamento $\left(\sigma_{\mathrm{y}}\right)$ & Log-normal & 12 & 0,6 & $\mathrm{kN} / \mathrm{cm}^{2}$ \\
$\mathrm{X}_{3}$ & Área de referência $\left(\mathrm{A}_{\mathrm{R}}\right)$ & Log-normal & 5,98 & 0,12 & $\mathrm{~cm}^{2}$ \\
\hline
\end{tabular}

\section{Coeficientes de segurança parciais:}

Como explicado no Capítulo 3, uma maneira de garantir a segurança é utilizar valores característicos, adotando-se coeficientes de segurança parciais, que provocam uma redução da resistência e um aumento da solicitação. Encontra-se os valores dos coeficientes de segurança parciais conhecendo a distribuição das variáveis aleatórias de resistência e de solicitação e fixando o nível de confiança desejado $\left(p_{k}\right)$.

Sendo a solicitação F uma VA com distribuição Normal, coeficiente de variação (c.o.v.) de $20 \%$, e fixando $p_{k}$ em $84,1 \%$, obtém-se a solicitação característica $\left(F_{k}\right)$ de 65,98 kN. O coeficiente de majoração da carga $\gamma_{k}$ é obtido através do quociente entre os valores característico e médio da solicitação:

$$
\gamma_{k}=\frac{s_{k}}{\mu_{S}}=\frac{F_{k}}{\mu_{F}}=\frac{65,98}{55}=1,1997 \cong 1,20
$$

A resistência é dada pela tensão de escoamento $\sigma_{y}$, que tem distribuição log-normal e c.o.v. de $5 \%$. Com esses dados obtém-se a resistência característica $\left(\sigma_{\mathrm{y}, \mathrm{k}}\right)$ de 11,04 $\mathrm{kN} / \mathrm{cm}^{2}$. Então, calcula-se o coeficiente de minoração da resistência $\phi_{k}$ :

$$
\phi_{k}=\frac{r_{k}}{\mu_{R}}=\frac{\sigma_{y, k}}{\mu_{\sigma_{y}}}=\frac{11,04}{12}=0,9199 \cong 0,92
$$




\section{Modos de falha:}

Foi considerado um modo de falha.

\section{Escoamento da barra:}

$$
g(x)=\sigma_{y} A-F
$$

\section{Projeto da barra:}

Projetando a resistência contra a solicitação e inserindo os coeficientes de segurança característicos:

$$
r_{k}=s_{k} \rightarrow \phi_{k} \mu_{A} \mu_{\sigma_{y}}=\gamma_{k} \mu_{F}
$$

Isolando a área:

$$
\mu_{A}=\frac{\gamma_{k} \mu_{F}}{\phi_{k} \mu_{\sigma_{y}}}
$$

Inserindo o coeficiente de segurança adicional $\lambda_{k}$ :

$$
\mu_{A}=\frac{\lambda_{k} \gamma_{k} \mu_{F}}{\phi_{k} \mu_{\sigma_{y}}}
$$

Ou seja,

$$
\lambda_{k}=\frac{\phi_{k} \mu_{A} \mu_{\sigma_{y}}}{\gamma_{k} \mu_{F}}=\frac{r_{k}}{s_{k}}
$$

Deste modo, quando $\lambda_{k}$ é maior que um, existe maior confiança de que a resistência será maior que a solicitação.

\section{Projeto de referência:}

Para $\lambda_{k}=1,0$ e utilizando os valores médios das variáveis aleatórias em (6.6), obtemos o valor médio da área da seção transversal da barra: 


$$
\mu_{A}=\frac{1,0.1,20.55}{0,92.12}=\frac{65,98}{11,04}=5,98 \mathrm{~cm}^{2}
$$

Adotando uma variabilidade de $2 \%$ para a área, o desvio padrão é de 0,1196 . Assim mostrou-se como foram encontrados os parâmetros da VA $\mathbf{X}_{3}$ que compõem a Tabela 6.1. $O$ valor médio encontrado é chamado de área de referência do projeto $\left(A_{R}\right)$. $A$ área da barra da seção transversal é dada então por:

$$
A=\lambda_{k} A_{R}
$$

Ou seja, o aumento do $\lambda_{k}$ significa aumento da área da seção transversal, que por sua vez aumenta a resistência da barra ao escoamento. Portando, substituindo (6.9) em (6.3) a equação de estado limite a ser usada no programa fica escrita da seguinte maneira:

$$
g(x)=\lambda_{k} A_{R} \sigma_{y}-F=\lambda_{k} X_{3} X_{2}-X_{1}
$$

\section{Função objetivo:}

O próximo passo na formulação do problema consiste na definição das parcelas que compõem a função custo esperado total $\operatorname{CET}\left(\lambda_{k}\right)$, que é a função objetivo do problema de otimização. Neste problema foram consideradas duas parcelas:

$\checkmark$ custo inicial: $\mathrm{Cl}\left(\lambda_{k}\right)$;

$\checkmark$ custo de falha última: $\operatorname{CFU}\left(\lambda_{k}\right)$.

O custo inicial está representado pelo custo do material. Considerando um custo de 2,00 R $\$ / \mathrm{kg}$ para o aço estrutural com densidade $(\rho)$ de $0,00785 \mathrm{~kg} / \mathrm{cm}^{3}$, obtém-se a massa da barra multiplicando a densidade pelo volume (V). O custo de falha última é definido como sendo 10 vezes maior que o custo inicial, representando uma conseqüência grave caso a barra venha a falhar (estrutura da classe 3). Assim tem-se o seguinte equacionamento:

$$
\text { massa }=\rho V=0,00785.500 \cdot A=3,925 \lambda_{k} A_{R}
$$




$$
\begin{gathered}
C I\left(\lambda_{\mathrm{k}}\right)=\text { custo }_{\text {aco }} . \text { massa }=7,85 \lambda_{k} A_{R} \\
\operatorname{CFU}\left(\lambda_{\mathrm{k}}\right)=10 C I=78,5 \lambda_{k} A_{R} \\
\operatorname{CET}\left(\lambda_{\mathrm{k}}\right)=C I\left(\lambda_{\mathrm{k}}\right)+\operatorname{CFU}\left(\lambda_{\mathrm{k}}\right) \cdot P_{f U}=7,85 \lambda_{k} A_{R}+78,5 \lambda_{k} A_{R} P_{f}[g(x)]
\end{gathered}
$$

\section{Resultado da otimização:}

A partir da formulação exposta, os resultados da Tabela 6.2 foram obtidos com o RiskOPT. Fez-se também a execução do StRAnD no ponto ótimo encontrado utilizando-se, além do FORM, a SMCI e o MSRI. Os valores do índice de confiabilidade $\beta$ encontrados com os dois últimos métodos são iguais entre si e muito próximos aos encontrados com o FORM, havendo diferença de apenas $0,2 \%$ tanto para a Interpolação Quadrática quanto para o Regula Falsi. Observa-se que o resultado da Interpolação Quadrática chegou mais perto do mínimo verdadeiro que o resultado do Regula Falsi.

Tabela 6.2: Resultados do RiskOPT para o problema da barra tracionada

\begin{tabular}{ccccc}
\hline Método & $\lambda_{\mathbf{k}}$ ótimo & CET mínimo & $\beta$ & $\mathbf{P}_{\mathbf{f}}$ \\
\hline Interpolação Quadrática & 1,1908 & 58,88 & 2,5537 & 0,005329 \\
Regula Falsi & 1,2039 & 58,93 & 2,6290 & 0,004282 \\
\hline
\end{tabular}

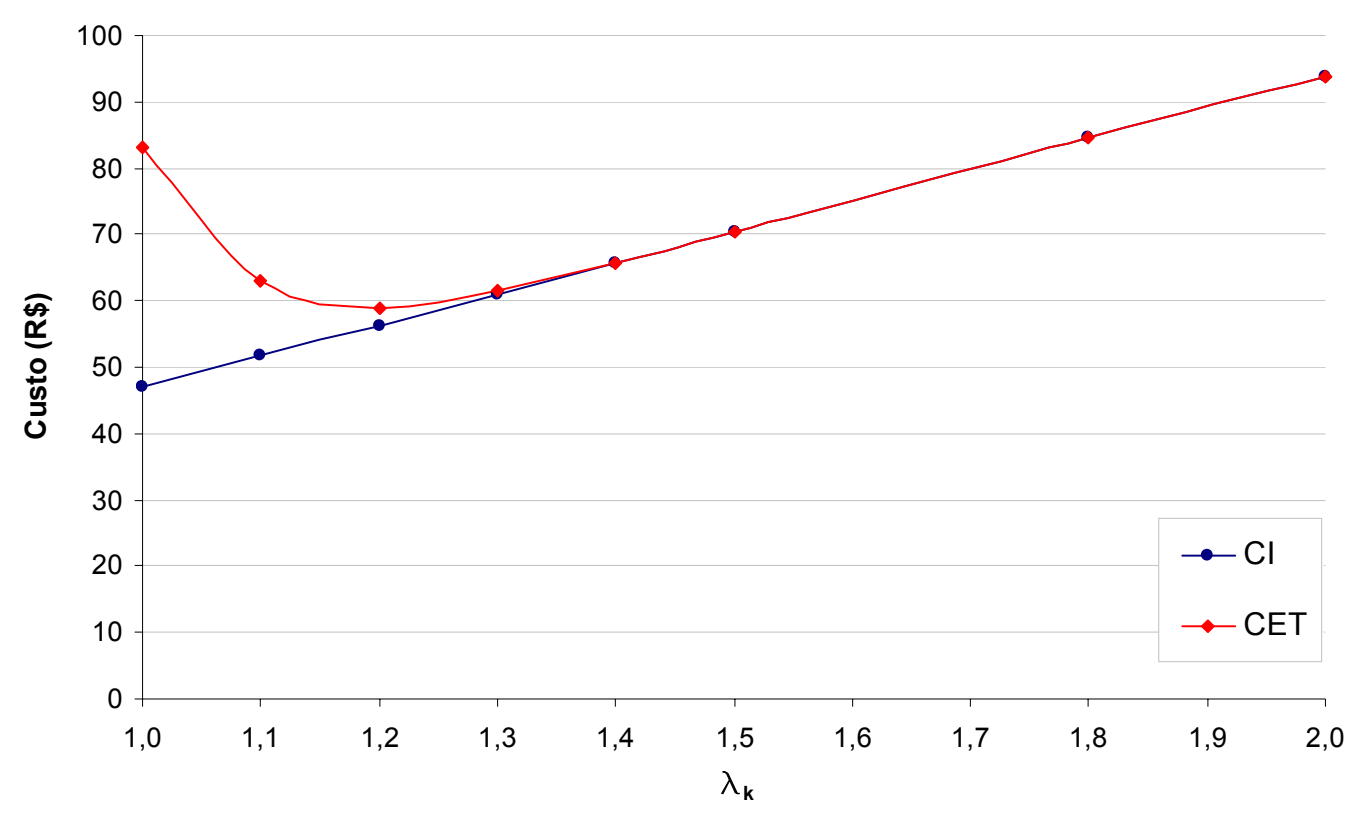

Figura 6.2: Gráfico custo $\mathrm{x} \lambda_{\mathrm{k}}$ para o problema da barra tracionada 


\subsection{Barra comprimida}

Este problema está baseado no exemplo resolvido por Enevoldsen e Sorensen (1994). Também é um problema simples, com 4 VA's, mas envolve mais de uma equação de estado limite. Trata-se de uma coluna tubular em aço formado a frio, simplesmente apoiada e submetida a uma carga vertical P (Figura 6.3).

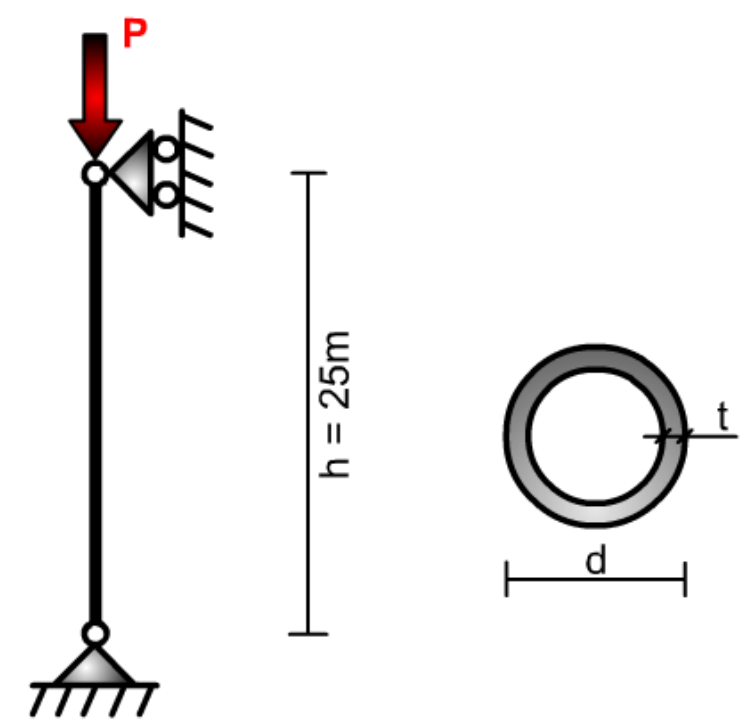

Figura 6.3: Coluna tubular metálica simplesmente apoiada carregada verticalmente

\section{Dados do problema:}

4 VA's não correlacionadas.

Tabela 6.3: Variáveis aleatórias do problema da barra comprimida

\begin{tabular}{cccccc}
\hline VA & Designação & Distribuição & $\mu$ & $\sigma$ & Unidade \\
\hline $\mathrm{X}_{1}$ & Tensão de escoamento $\left(\sigma_{\mathrm{y}}\right)$ & Log-normal & 65 & 3,25 & $\mathrm{kN} / \mathrm{cm}^{2}$ \\
$\mathrm{X}_{2}$ & Módulo de elasticidade $(\mathrm{E})$ & Log-normal & 21000 & 1050 & $\mathrm{kN} / \mathrm{cm}^{2}$ \\
$\mathrm{X}_{3}$ & Carga vertical $(\mathrm{P})$ & Normal & 10000 & 2000 & $\mathrm{kN}$ \\
$\mathrm{X}_{4}$ & Fator de abatimento $\left(\mathrm{k}_{\mathrm{d}}\right)$ & Normal & 0,54 & 0,0864 & - \\
\hline
\end{tabular}


Tabela 6.4: Variáveis determinísticas do problema da barra comprimida

\begin{tabular}{ccc}
\hline Designação & Valor & Unidade \\
\hline Espessura $(\mathrm{t})$ & $6,4 \cdot 10^{-3}$ & $\mathrm{~m}$ \\
Diâmetro externo(d) & 1,0 & $\mathrm{~m}$ \\
Altura $(\mathrm{h})$ & 25,0 & $\mathrm{~m}$ \\
Coeficiente de Poisson $(\nu)$ & 0,3 & - \\
\hline
\end{tabular}

\section{Modos de falha:}

Foram considerados dois modos de falha.

Escoamento do material:

$$
g_{1}(x)=\sigma_{y} A-P=\sigma_{y} \pi d t-P
$$

Flambagem local:

$$
g_{2}(x)=\sigma_{l b} A-P
$$

onde a tensão $\sigma_{l b}$, para a qual ocorre a flambagem local, é dada por:

$$
\sigma_{l b}=\left(1.5-\frac{1}{\sqrt{2}} \lambda_{b}\right) \sigma_{y}
$$

com

$$
\lambda_{b}=\sqrt{\frac{\sigma_{y}}{\theta_{b} \sigma_{e l}}}
$$

e,

$$
\sigma_{e l}=\frac{2 E t}{d \sqrt{3\left(1-v^{2}\right)}} \quad \text { e } \quad \theta_{b}=\frac{k_{d}}{\sqrt{1+0,005 d / t}}
$$

Sendo:

$$
\lambda_{b}=\text { taxa relativa de esbeltez }\left(\sqrt{1 / 2} \leq \lambda_{b} \leq \sqrt{2}\right)
$$


$\sigma_{e l}=$ tensão crítica teórica segundo a teoria da elasticidade;

$\theta_{b}=$ fator de correção que leva em conta imperfeições através do fator de abatimento $\mathrm{k}_{\mathrm{d}}$;

$E=$ módulo de elasticidade $;$
$v=$ coeficiente de Poisson.

\section{Projeto da barra:}

Projetando a resistência contra a solicitação utilizando os coeficientes de segurança parciais $\left(\lambda_{k}, \phi_{k}, \gamma_{k}\right)$, para a EEL de escoamento do material (6.15), temos:

$$
\lambda_{k}=\frac{r_{k}}{s_{k}}=\frac{\phi_{k} \sigma_{y} A}{\gamma_{k} P}
$$

Isolando a área, e para $\lambda_{k}$ unitário, obtém-se a área de referência $\left(A_{R}\right)$ do projeto:

$$
A_{R}=\frac{\gamma_{k}}{\phi_{k}} \frac{P}{\sigma_{y}} \quad \text { e } \quad A=\lambda_{k} A_{R}
$$

Para $\sigma_{y}$ com distribuição log-normal, c.o.v. de $5 \%$, e confiança de $95 \%$, obtém-se $\phi_{k}=0,92$. Para P com distribuição normal, c.o.v. de $20 \%$ e confiança de $84,1 \%$ obtém-se $\gamma_{k}=1,20$. Aplicando os valores médios em (6.21):

$$
A_{R}=\frac{1,20 \cdot 10000}{0,92 \cdot 65 \cdot 10^{4}}=0,02 m^{2}
$$

Existem várias combinações de $d$ e $t$ que totalizam essa área. Como o programa só aceita uma variável de otimização, optou-se por fixar $d$ em 1,0 m, o que resultou em $t$ de 0,0064 m. Assim foram obtidos os valores iniciais da geometria da seção transversal que estão na Tabela 6.4. Reescrevemos então as EEL's em função do $\lambda_{k}$ e da $A_{R}$ : 


$$
\begin{aligned}
& g_{1}(x)=\lambda_{k} A_{R} \sigma_{y}-P \\
& g_{2}(x)=\lambda_{k} A_{R} \sigma_{l b}-P
\end{aligned}
$$

\section{Função objetivo:}

A função $C E T\left(\lambda_{k}\right)$ é composta pelo custo inicial e pelos custos de falha. Considerou-se que as duas EEL's representam falha última para estrutura de classe 3, ou seja, conseqüências graves de falha. Como no problema 6.1, o custo inicial é composto pelo custo do material e o custo de falha última é uma proporção do custo inicial. Considerou-se custo de 2,00 R\$/kg de aço, sendo a densidade do aço igual $7850 \mathrm{~kg} / \mathrm{m}^{3}$. Assim:

$$
\begin{gathered}
C I\left(\lambda_{\mathrm{k}}\right)=\text { V. } \rho . \text { custo }=\lambda_{k} A_{R} 25.7850 .2=392500 \lambda_{k} A_{R} \\
\operatorname{CFU}\left(\lambda_{\mathrm{k}}\right)=10 C I\left(\lambda_{\mathrm{k}}\right) \\
\operatorname{CET}\left(\lambda_{\mathrm{k}}\right)=\operatorname{CI}\left(\lambda_{\mathrm{k}}\right)+\operatorname{CFU}\left(\lambda_{\mathrm{k}}\right) \cdot P_{f}\left[g_{1}(x)\right]+\operatorname{CFU}\left(\lambda_{\mathrm{k}}\right) \cdot P_{f}\left[g_{2}(x)\right]
\end{gathered}
$$

Resultado da otimização:

Tabela 6.5: Resultados do RiskOPT para o problema da barra comprimida

\begin{tabular}{ccccc}
\hline Método & $\lambda_{\mathbf{k}}$ ótimo & CET mínimo & $\beta$ & $\mathbf{P}_{\mathbf{f} \text { sistema }}$ \\
\hline Interpolação Quadrática & 1,5454 & 12995,97 & 2,4509 & 0,007124 \\
Regula Falsi & 1,5794 & 13040,33 & 2,5637 & 0,005177 \\
\hline
\end{tabular}

Com o $\lambda_{k}$ ótimo de 1,5454 a área ótima encontrada é de $0,031 \mathrm{~m}^{2}$. Como o diâmetro da barra está fixado em 1 metro, a espessura ótima é de aproximadamente 0,01 m. 


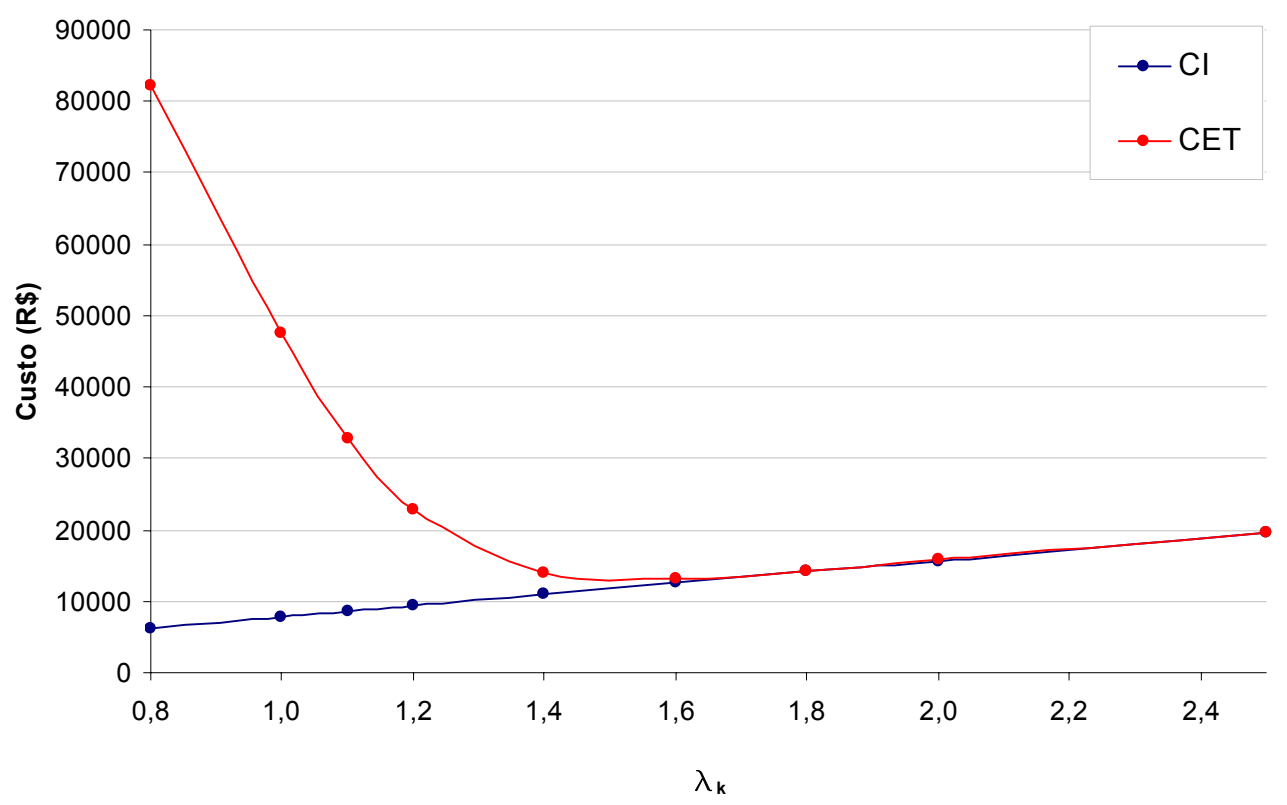

Figura 6.4: Gráfico custo $\mathrm{x} \lambda_{\mathrm{k}}$ para o problema da barra comprimida

\subsection{Viga em balanço}

O problema da viga em balanço (Figura 6.5) também é um problema simples do ponto de vista mecânico. Porém, do ponto de vista da análise de confiabilidade e da otimização, aumentou-se a complexidade ao se introduzir um número maior de VA's e EEL's.
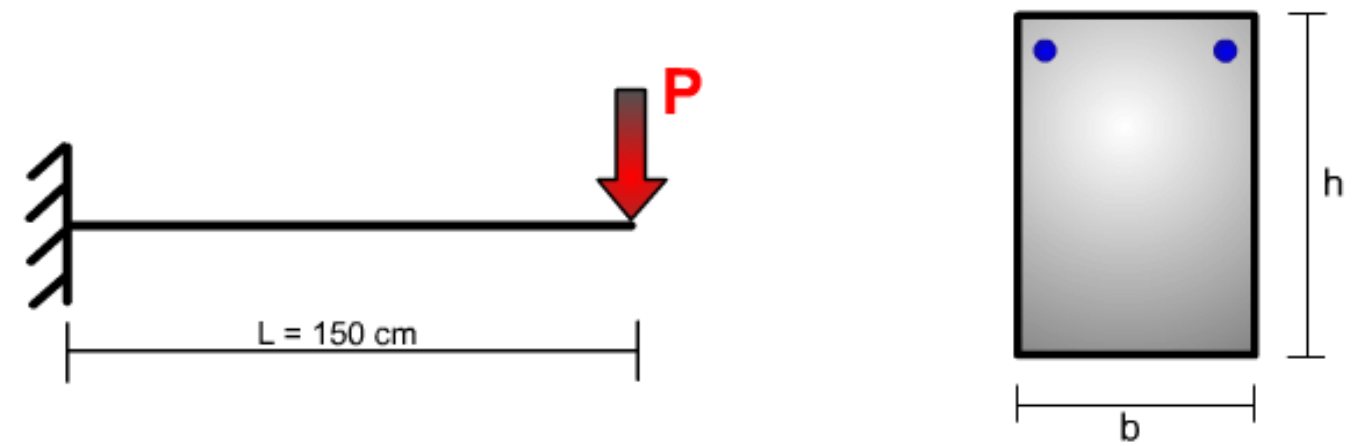

Figura 6.5: Geometria do problema da viga em balanço

Foi considerada uma viga feita com concreto C25 e armadura de aço CA-50, sendo a resistência característica à compressão $\left(f_{c k}\right)$ do concreto $C 20$ de $2,0 \mathrm{kN} / \mathrm{cm}^{2}$ e a resistência característica do aço CA-50 $\left(f_{\mathrm{sk}}\right)$ de $50 \mathrm{kN} / \mathrm{cm}^{2}$. Conforme mostrado por Melchers (1999), 
para distribuição normal e confiança de $95 \%$, as resistências médias para o concreto e para o aço podem ser dadas pelas seguintes relações:

$$
\begin{aligned}
& \mu_{f_{c}}=f_{c k}+1,645 . \sigma_{f_{c}} \\
& \mu_{f_{s}}=f_{s k}+1,645 . \sigma_{f s}
\end{aligned}
$$

Adotando c.o.v. de $5 \%$ para $\mathrm{f}_{\mathrm{c}}$ e $\mathrm{f}_{\mathrm{s}}$, após algumas iterações, obteve-se os valores médios mostrados na Tabela 6.6.

A armadura de compressão da viga consiste de duas barras de 16 mm de diâmetro, portanto a área de armadura $A_{s}$ é de $4 \mathrm{~cm}^{2}$.

\section{Dados do problema:}

7 VA's não correlacionadas.

Tabela 6.6: Variáveis aleatórias para o problema da viga em balanço

\begin{tabular}{lccccc}
\hline VA & Designação & Distribuição & $\mu$ & $\sigma$ & Unidade \\
\hline $\mathrm{X}_{1}$ & Carga vertical $(\mathrm{P})$ & Normal & 30,0 & 6,0 & $\mathrm{kN}$ \\
$\mathrm{X}_{2}$ & Resistência do concreto $\left(\mathrm{f}_{\mathrm{c}}\right)$ & Log-normal & 2,18 & 0,11 & $\mathrm{kN} / \mathrm{cm}^{2}$ \\
$\mathrm{X}_{3}$ & Resistência do aço $\left(\mathrm{f}_{\mathrm{s}}\right)$ & Log-normal & 54,5 & 2,72 & $\mathrm{kN} / \mathrm{cm}^{2}$ \\
$\mathrm{X}_{4}$ & Base da seção transversal $(\mathrm{b})$ & Log-normal & 12,0 & 0,12 & $\mathrm{~cm}$ \\
$\mathrm{X}_{5}$ & Altura da seção transversal $(\mathrm{h})$ & Log-normal & 25,0 & 0,25 & $\mathrm{~cm}$ \\
$\mathrm{X}_{6}$ & Módulo de elasticidade do concreto $(\mathrm{Ec})$ & Log-normal & 2380 & 119 & $\mathrm{kN} / \mathrm{cm}^{2}$ \\
$\mathrm{X}_{7}$ & Módulo de elasticidade do aço $(\mathrm{Es})$ & Log-normal & 21000 & 1050 & $\mathrm{kN} / \mathrm{cm}^{2}$ \\
\hline
\end{tabular}

\section{Modos de falha:}

Foram considerados 3 modos de falha, sendo um referente a estado limite último e dois a estados limites de serviço.

Formação de rótula plástica no engaste:

Trata-se de um estado limite último, ou seja, representa colapso da estrutura: 


$$
g_{1}(x)=M_{P}-M
$$

sendo $M_{P} \circ$ momento de plastificação e $M \circ$ momento atuante na viga. Para seções retangulares $M_{P}=1,5 M_{E}$, onde $M_{E}$ é o momento resistente da seção no regime elástico. Para a estrutura de concreto armado em análise foi considerado $M_{E}=0,81 A_{s} f_{s}(h-3)$. Deste modo:

$$
g_{1}(x)=4,86 f_{s}(h-3)-P L
$$

Flecha máxima:

É um estado limite de serviço. Não ocorre colapso da estrutura mas, ao ser atingido, pode causar desconforto aos usuários ou prejudicar o desempenho do sistema.

$$
\begin{aligned}
& g_{2}(x)=f_{A D M}-f \\
& g_{2}(x)=\frac{L}{250}-\frac{P L^{3}}{3 E I}
\end{aligned}
$$

onde $f_{A D M}$ é a flecha admissível e $f$ é a flecha atual na viga. A $f_{A D M}$ foi obtida da tabela 13.2 da NBR 6118 (2003) e considera a ocorrência de um deslocamento visível no elemento estrutural.

\section{Abertura de fissuras:}

Também se trata de um estado limite de serviço. Com base na NBR 6118 (2003), considerou-se uma abertura de fissura limite $\left(w_{\lim }\right)$ de $0,3 \mathrm{~mm}$, e a seguinte EEL:

$$
g_{3}(x)=w_{\lim }-\min \left(w_{k 1}, w_{k 2}\right)
$$

sendo,

$$
\begin{gathered}
w_{k 1}=\frac{\phi_{i}}{12,5 \eta_{1}} \frac{\sigma_{s i}}{E_{s i}} \frac{3 \sigma_{s i}}{f_{c t m}} \\
w_{k 2}=\frac{\phi_{i}}{12,5 \eta_{1}} \frac{\sigma_{s i}}{E_{s i}}\left(\frac{4}{\rho_{r i}}+45\right)
\end{gathered}
$$

onde:

$\phi i=$ diâmetro da barra que protege a região de envolvimento considerada; 
$\sigma_{s i}=$ tensão de tração no centro de gravidade da armadura considerada;

$E_{s i}=$ módulo de elasticidade do aço da barra considerada;

$\rho_{r i}=$ taxa de armadura passiva ou ativa aderente;

$f_{c t m}=$ resistência do concreto à tração média;

$\eta_{1}=$ coeficiente de conformação superficial da armadura considerada.

\section{Projeto da viga:}

Os coeficientes de segurança parciais foram inseridos na primeira EEL, sendo $\phi_{k}=0,92$ para $p_{k}=95 \%$ ( $f_{c m}$ tem distribuição log-normal, c.o.v. de $\left.5 \%\right)$, e $\gamma_{k}=1,20$ para $p_{k}=84,1 \%(P$ tem distribuição normal e c.o.v. de $20 \%$ ).

$$
\lambda_{k}=\frac{r_{k}}{s_{k}}=\frac{\phi_{k} 4,86 f_{s}(h-3)}{\gamma_{k} P L}
$$

Para $\lambda_{k}$ unitário, aplicamos os valores médios e obtemos assim o valor médio da variável aleatória $h$ mostrado na Tabela 6.6. Adotou-se para ela c.o.v. de 1\%.

$$
\begin{gathered}
\mu_{h}=\frac{\gamma_{k} \mu_{P} L}{\phi_{k} 7,29 f_{s}}+3=\frac{1,2.30 .150}{0,92.4,86.55}+3 \cong 25 \mathrm{~cm} \\
h=\lambda_{k} \mu_{h}
\end{gathered}
$$

Reescrevendo então as EEL's com a inserção dos coeficientes de segurança parciais e após algum desenvolvimento algébrico, temos:

$$
\begin{gathered}
g_{1}(x)=4,86 f_{s}\left(\lambda_{k} h-3\right)-150 P \\
g_{2}(x)=0,15 E_{c} b\left(\lambda_{k} h\right)^{3}-150^{3} P \\
g_{3}(x)=0,03 E_{s}\left(\lambda_{k} h-4\right)-\min \left[\frac{492,12 P^{2}}{\sqrt[3]{f_{c}^{2}}} ; 1,6732 P(10,73 b+45)\right]
\end{gathered}
$$


Note que apenas a dimensão altura da seção transversal está sendo otimizada através do coeficiente de segurança $\lambda_{k}$, enquanto a base da seção transversal permanece a mesma. Isso deve-se à limitação do programa desenvolvido que realiza otimização com apenas uma variável de projeto. Se forem implementados algoritmos com a capacidade de otimização de funções com mais de uma variável de projeto, o mesmo problema poderá ser resolvido, com, por exemplo, 3 variáveis de otimização: $\lambda_{k}, h$ e $b$.

\section{Função objetivo:}

Utilizando os dados mostrados na Tabela 6.7 estimou-se o custo de material da viga, que compõe a função CET. Esses dados foram obtidos com profissionais da construção civil e representam uma situação genérica. Não estão inclusos os custos de mão-de-obra.

Tabela 6.7: Custo dos materiais de construção

\begin{tabular}{cccc}
\hline ITEM & CUSTO & UNIDADE & CONSUMO POR m $^{3}$ DE CONCRETO \\
\hline Concreto Usinado & 180,00 & $\mathrm{R} \$ / \mathrm{m}^{3}$ & - \\
Aço CA-50 & 3,00 & $\mathrm{R} \$ / \mathrm{kg}$ & $80 \mathrm{~kg}$ \\
Forma & 5,00 & $\mathrm{R} \$ / \mathrm{m}^{2}$ & $10 \mathrm{~m}^{2}$ \\
\hline
\end{tabular}

Os custos de falha são escritos em proporção ao custo inicial. Adotou-se custo de falha última equivalente ao triplo do custo inicial, representando o custo de reposição da viga, limpeza do local, e eventuais prejuízos devidos ao período de não funcionamento da estrutura. Como mostrado no capítulo 3, segundo o Probabilistic Model Code (2001), um custo de falha última na ordem do triplo do custo de construção posiciona a estrutura na classe 2 de conseqüências de falha (conseqüências moderadas). O custo de falha de serviço foi arbitrado como sendo equivalente a $20 \%$ do custo inicial, pois representa apenas pequenas intervenções para corrigir as falhas. Temos, então, o seguinte equacionamento: 


$$
\begin{gathered}
V=L b h=1,50 b \lambda_{k} \mu_{h} \quad(\text { em metros }) \\
C I\left(\lambda_{k}\right)=180 V+3.80 \cdot V+5.10 \cdot V=705 b \lambda_{k} \mu_{h} \\
C F U\left(\lambda_{k}\right)=3 \cdot C I\left(\lambda_{k}\right) \\
C F S\left(\lambda_{k}\right)=0,2 \cdot C I\left(\lambda_{k}\right)
\end{gathered}
$$

A função a ser minimizada é:

$\operatorname{CET}\left(\lambda_{k}\right)=C I\left(\lambda_{k}\right)+C F U\left(\lambda_{k}\right) P_{f}\left[g_{1}(x)\right]+C F S\left(\lambda_{k}\right) P_{f}\left[g_{2}(x)\right]+C F S\left(\lambda_{k}\right) P_{f}\left[g_{3}(x)\right]$ (6.38)

\section{Resultado da otimização:}

Tabela 6.8: Resultado do RiskOPT para o problema da viga em balanço

\begin{tabular}{ccccc}
\hline Método & $\lambda_{\mathbf{k}}$ ótimo & CET mínimo & $\beta$ & $\mathbf{P}_{\mathbf{f} \text { sistema }}$ \\
\hline Interpolação Quadrática & 1,267 & 27,54 & 1,5962 & 0,05523 \\
Regula Falsi & 1,2643 & 27,54 & 1,5575 & 0,05968 \\
\hline
\end{tabular}

Arredondando $\lambda_{k}$ para 1,27 e substituindo este valor na equação (6.36), calculamos a altura ótima da viga, que é de $32 \mathrm{~cm}$.

Foi ainda feito um estudo da variação do coeficiente de segurança ótimo com a classe de conseqüência de falha, mostrado no gráfico da Figura 6.7. Pode-se afirmar que tal variação, para o problema apresentado, é aproximadamente linear. Nota-se que o $\lambda_{k}$ ótimo aumenta muito pouco, mesmo para uma grande variação da conseqüência de falha. 


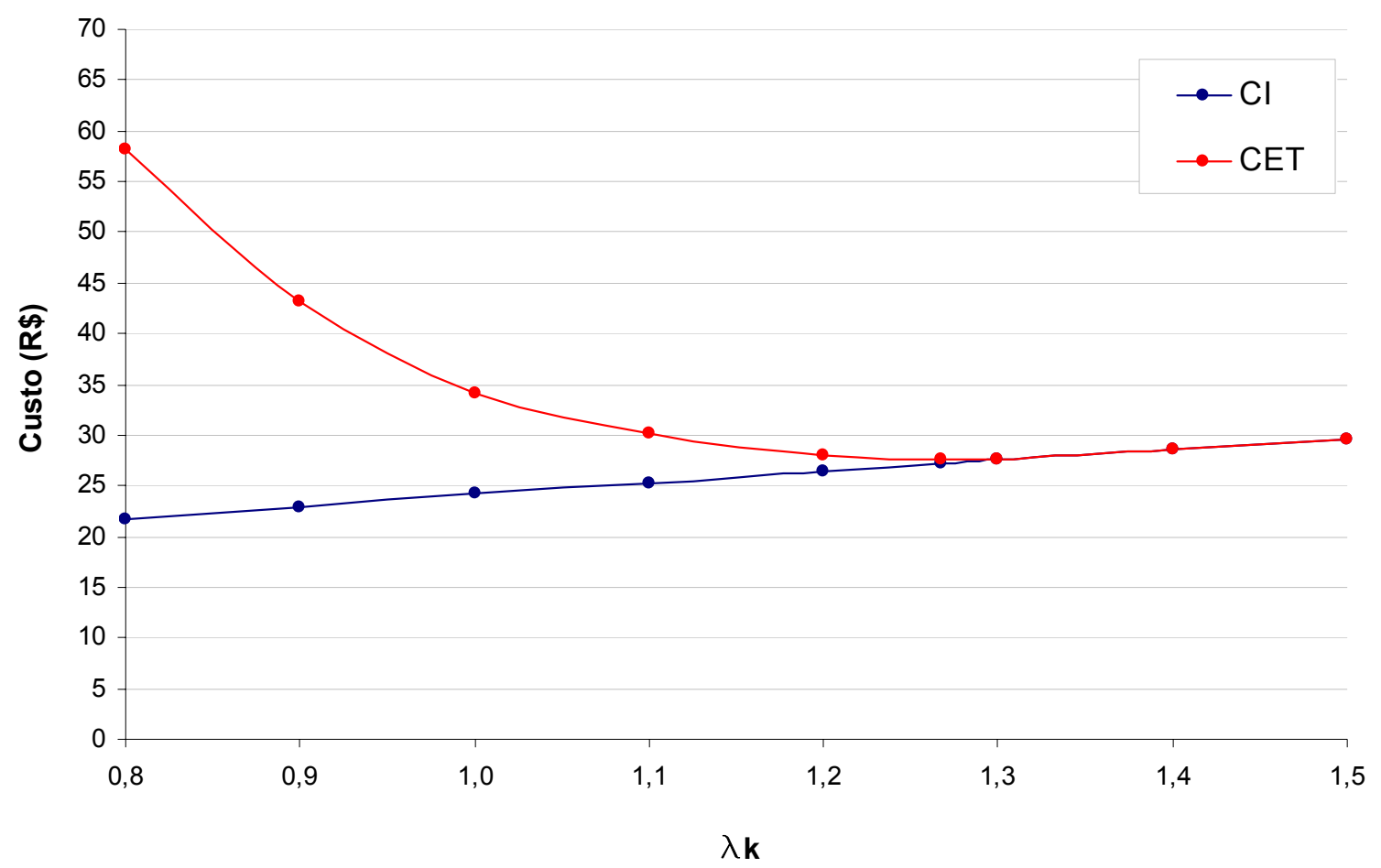

Figura 6.6: Gráfico custo $\mathrm{x} \lambda_{\mathrm{k}}$ para o problema da viga em balanço

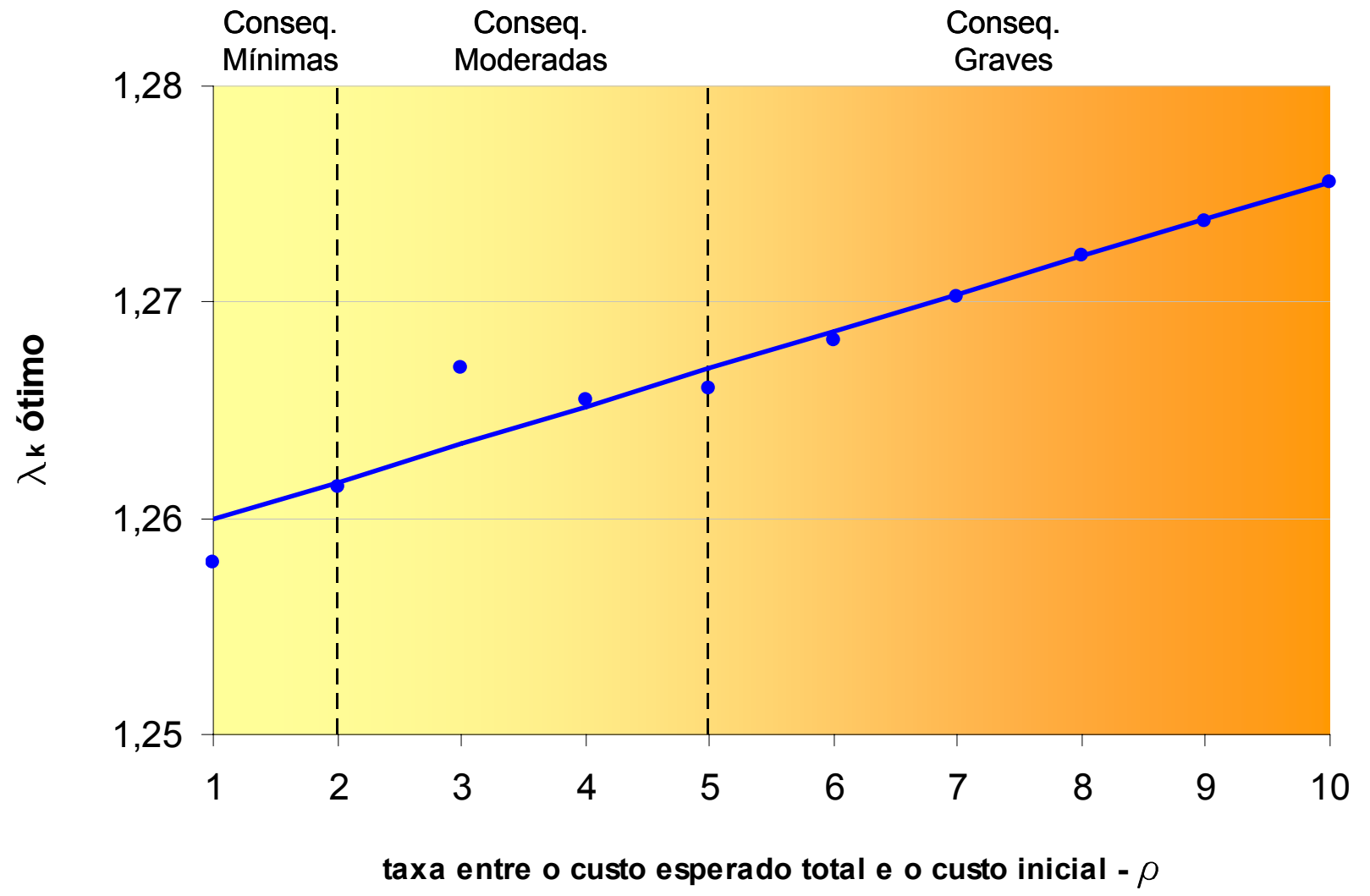

Figura 6.7: Variação do $\lambda_{k}$ ótimo com a classe de conseqüência de falha 


\subsection{Treliça Plana}

Este exemplo aborda os conceitos da probabilidade de falha de componentes, probabilidade de falha de sistemas em série, e inclui correlação entre as VA's. Trata-se de uma treliça plana de 6 barras, com 1 grau de redundância, carregada em um nó por duas cargas, uma vertical e uma horizontal, simultaneamente (Figura 6.8).

\section{Dados do problema:}

Inicialmente o problema teria 20 VA's: os 2 carregamentos, os 6 comprimentos das barras, os 6 módulos de elasticidade de cada barra, e as 6 tensões de escoamento de cada barra. No entanto, como as barras 1, 2, 3 e 6 atuam sob compressão as tensões de escoamento não são utilizadas nas EEL. Da mesma forma, os módulos de elasticidade das barras 4 e 5 não são utilizados nas EEL, pois essas atuam sob tração. Portanto, o problema fica reduzido para 14 VA's, havendo correlação entre algumas delas, como mostrado a seguir.

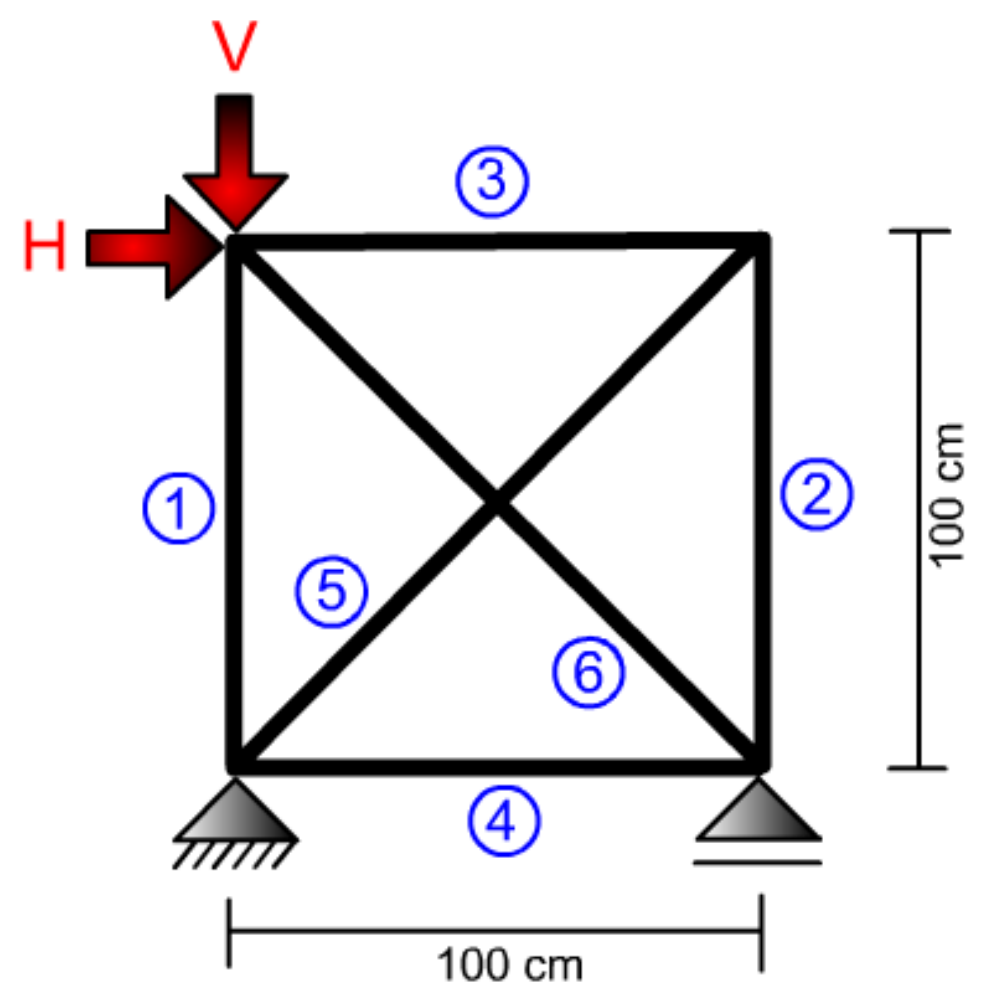

Figura 6.8: Treliça plana de 6 barras 
Tabela 6.9: Variáveis aleatórias para o problema da treliça plana

\begin{tabular}{lccccc}
\hline VA & Designação & Distribuição & $\mu$ & $\sigma$ & Unidade \\
\hline $\mathrm{X}_{1}$ & Módulo de Elasticidade da barra 1 $\left(\mathrm{E}_{1}\right)$ & Log-normal & 20500 & 1025 & $\mathrm{kN} / \mathrm{cm}^{2}$ \\
$\mathrm{X}_{2}$ & Módulo de Elasticidade da barra 2 $\left(\mathrm{E}_{2}\right)$ & Log-normal & 20500 & 1025 & $\mathrm{kN} / \mathrm{cm}^{2}$ \\
$\mathrm{X}_{3}$ & Módulo de Elasticidade da barra 3 $\left(\mathrm{E}_{3}\right)$ & Log-normal & 20500 & 1025 & $\mathrm{kN} / \mathrm{cm}^{2}$ \\
$\mathrm{X}_{4}$ & Tensão de escoamento da barra 4 $\left(\sigma_{\mathrm{y} 4}\right)$ & Log-normal & 25 & 1,25 & $\mathrm{kN} / \mathrm{cm}^{2}$ \\
$\mathrm{X}_{5}$ & Tensão de escoamento da barra 5 $\left(\sigma_{\mathrm{y5}}\right)$ & Log-normal & 25 & 1,25 & $\mathrm{kN} / \mathrm{cm}^{2}$ \\
$\mathrm{X}_{6}$ & Módulo de Elasticidade da barra 6 $\left(\mathrm{E}_{6}\right)$ & Log-normal & 20500 & 1025 & $\mathrm{kN} / \mathrm{cm}^{2}$ \\
$\mathrm{X}_{7}$ & Comprimento da barra 1 $\left(\mathrm{L}_{1}\right)$ & Log-normal & 100 & 1,00 & $\mathrm{~cm}$ \\
$\mathrm{X}_{8}$ & Comprimento da barra 2 $\left(\mathrm{L}_{2}\right)$ & Log-normal & 100 & 1,00 & $\mathrm{~cm}$ \\
$\mathrm{X}_{9}$ & Comprimento da barra 3 $\left(\mathrm{L}_{3}\right)$ & Log-normal & 100 & 1,00 & $\mathrm{~cm}$ \\
$\mathrm{X}_{10}$ & Comprimento da barra 4 $\left(\mathrm{L}_{4}\right)$ & Log-normal & 100 & 1,00 & $\mathrm{~cm}$ \\
$\mathrm{X}_{11}$ & Comprimento da barra 5 $\left(\mathrm{L}_{5}\right)$ & Log-normal & 141 & 1,41 & $\mathrm{~cm}$ \\
$\mathrm{X}_{12}$ & Comprimento da barra 6 $\left(\mathrm{L}_{6}\right)$ & Log-normal & 141 & 1,41 & $\mathrm{~cm}$ \\
$\mathrm{X}_{13}$ & Carga vertical $(\mathrm{V})$ & Normal & 10,0 & 2,0 & $\mathrm{kN}$ \\
$\mathrm{X}_{14}$ & Carga horizontal $(\mathrm{H})$ & Gumbell Max & 10,0 & 3,0 & $\mathrm{kN}$ \\
\hline
\end{tabular}

Matriz de correlação:

$$
\left[\begin{array}{cccccccccccccc}
1 & & & & & & & & & & & & \\
0,8 & 1 & & & & & & & & & & & \\
0,8 & 0,8 & 1 & & & & & & & & & & \\
0 & 0 & 0 & 1 & & & & & & & & & \\
0 & 0 & 0 & 0,8 & 1 & & & & & & & & \\
0,8 & 0,8 & 0,8 & 0 & 0 & 1 & & & & \text { sim. } & & & \\
0 & 0 & 0 & 0 & 0 & 0 & 1 & & & & & & \\
0 & 0 & 0 & 0 & 0 & 0 & 0,8 & 1 & & & & & \\
0 & 0 & 0 & 0 & 0 & 0 & 0,8 & 0,8 & 1 & & & & \\
0 & 0 & 0 & 0 & 0 & 0 & 0,8 & 0,8 & 0,8 & 1 & & & \\
0 & 0 & 0 & 0 & 0 & 0 & 0,8 & 0,8 & 0,8 & 0,8 & 1 & & \\
0 & 0 & 0 & 0 & 0 & 0 & 0,8 & 0,8 & 0,8 & 0,8 & 0,8 & 1 & & \\
0 & 0 & 0 & 0 & 0 & 0 & 0 & 0 & 0 & 0 & 0 & 0 & 1 & \\
0 & 0 & 0 & 0 & 0 & 0 & 0 & 0 & 0 & 0 & 0 & 0 & 0 & 1
\end{array}\right]
$$




\section{Modos de falha:}

Foram considerados ao todo 14 modos de falha. Os seis primeiros referem-se à falha individual das barras por flambagem ou escoamento, dependendo se o esforço é de compressão ou de tração, respectivamente. Os restantes modos de falha representam falhas condicionais, ou seja, falha de uma barra após o colapso da primeira e da conseqüente redistribuição de esforços na treliça, também por flambagem ou por escoamento.

\section{Falha por compressão:}

$$
g_{i}(x)=\frac{\pi^{2} E_{i} I_{i}}{L_{i}^{2}}+a_{i} V+b_{i} H
$$

onde:

$$
\begin{aligned}
& E_{i}=\text { módulo de elasticidade da barra } \mathrm{i} ; \\
& I_{i}=\text { momento de inércia da barra i; } \\
& L_{i}=\text { comprimento da barra } \mathrm{i} ; \\
& a_{i}=\text { fator de distribuição da carga vertical na barra i; } \\
& b_{i}=\text { fator de distribuição da carga horizontal na barra i. }
\end{aligned}
$$

Falha por tração:

$$
g_{i}(x)=\sigma_{y i} A_{i}-a_{i} V-b_{i} H
$$

onde:

$$
\begin{aligned}
& \sigma_{y i}=\text { tensão de escoamento da barra } \mathrm{i} ; \\
& A_{i}=\text { área da seção transversal da barra } \mathrm{i} ; \\
& a_{i}=\text { fator de distribuição da carga vertical na barra } \mathrm{i} ;
\end{aligned}
$$




$$
b_{i}=\text { fator de distribuição da carga horizontal na barra i. }
$$

Os fatores de distribuição de carga têm sinal negativo para compressão e positivo para tração.

\section{Projeto da treliça:}

As barras 1, 2, 3 e 6 atuam sobre compressão, enquanto as barras 4 e 5 atuam sobre tração. Portanto, dos seis primeiros modos de falha considerados, 4 são de compressão e 2 são de tração. Mostra-se a seguir como foram introduzidos os coeficientes de segurança parciais $\left(\phi_{k}=0,92\right.$ e $\left.\gamma_{k}=1,20\right)$ em cada uma dessas seis EEL e como foram encontradas as variáveis determinísticas do projeto de referência, mostradas na Tabela 6.10.

Sabendo que

$$
\lambda_{k}=\frac{r_{k}}{s_{k}}
$$

Para a barra 1, comprimida, temos:

$$
\lambda_{k}=\frac{\phi_{k} \pi^{2} E_{1} I_{1}}{\gamma_{k} L_{1}^{2}\left(a_{1} V+b_{1} H\right)}
$$

Isolando $I_{1}$ e utilizando $\lambda_{k}$ unitário, com os valores médios das VA's obtém-se o momento de inércia da barra 1 para o projeto de referência.

$$
\begin{gathered}
I_{1, \text { REF }}=\frac{\gamma_{k} L_{1}^{2}\left(a_{1} \mu_{V}+b_{1} \mu_{H}\right)}{\phi_{k} \pi^{2} \mu_{E_{1}}}=\frac{1,2 \cdot 100^{2} \cdot(-0,9 \cdot 10+0,5 \cdot 10)}{0,92 \cdot \pi^{2} \cdot 20500}=0,26 \mathrm{~cm}^{4} \\
I_{1}=\lambda_{k} I_{1, R E F}
\end{gathered}
$$

Analogamente,

$$
\begin{aligned}
& I_{2, R E F}=0,26 \mathrm{~cm}^{4} \\
& I_{3, \text { REF }}=0,26 \mathrm{~cm}^{4}
\end{aligned}
$$




$$
I_{6, R E F}=1,09 \mathrm{~cm}^{4}
$$

Para a barra 4, tracionada, temos:

$$
\lambda_{k}=\frac{\phi_{k} \sigma_{y 4} A_{4}}{\gamma_{k}\left(a_{4} V+b_{4} H\right)}
$$

Isolando $A_{4}$ e utilizando $\lambda_{k}$ unitário, com os valores médios das VA's obtém-se a área da seção transversal da barra 4, para o projeto de referência.

$$
\begin{gathered}
\mathrm{A}_{4, \mathrm{REF}}=\frac{\gamma_{\mathrm{k}}\left(\mathrm{a}_{4} \mu_{\mathrm{V}}+\mathrm{b}_{4} \mu_{\mathrm{H}}\right)}{\phi_{\mathrm{k}} \mu_{\sigma_{\mathrm{y} 4}}}=\frac{1,2 \cdot(0,10 \cdot 10+0,50 \cdot 10)}{0,92 \cdot 25}=0,32 \mathrm{~cm}^{2} \\
A_{4}=\lambda_{k} A_{4, \text { REF }}
\end{gathered}
$$

Analogamente,

$$
A_{5, R E F}=0,29 \mathrm{~cm}^{2}
$$

Para tornar o projeto mais realista, decidiu-se pela adoção de perfis comerciais. Utilizando perfis $U$ simples formados a frio, buscou-se na tabela A.2 do anexo A da NBR 6355 aqueles que atendem às medidas encontradas acima. Os perfis adotados estão mostrados na Tabela 6.10 abaixo.

Tabela 6.10: Perfis adotados para o projeto de referência da treliça plana

\begin{tabular}{cccc}
\hline Barra & Perfil U & $\mathbf{A}\left(\mathbf{c m}^{2}\right)$ & $\mathrm{I}_{\mathbf{y}}\left(\mathbf{c m}^{4}\right)$ \\
\hline 1 & $\mathrm{U} 50 \times 25 \times 1,20$ & 1,15 & 0,72 \\
2 & $\mathrm{U} 50 \times 25 \times 1,20$ & 1,15 & 0,72 \\
3 & $\mathrm{U} \mathrm{50 \times 25 \times 1,20}$ & 1,15 & 0,72 \\
4 & $\mathrm{U} \mathrm{50 \times 25 \times 1,20}$ & 1,15 & 0,72 \\
5 & $\mathrm{U} \mathrm{50 \times 25 \times 1,20}$ & 1,15 & 0,72 \\
6 & $\mathrm{U} \mathrm{50 \times 25 \times 2,00}$ & 1,87 & 1,13 \\
\hline
\end{tabular}




\section{Função objetivo:}

O custo inicial é composto por uma parcela referente ao custo do material, que depende da variável de projeto $\left(\lambda_{k}\right)$, e por uma parcela referente ao custo de montagem, que é fixa.

$$
C I\left(\lambda_{k}\right)=C_{M A T}+C_{M O N T}=13,91 \lambda_{k}+300
$$

Os custos de falha são proporcionais aos custos iniciais. Neste problema, a falha de serviço corresponde à probabilidade de qualquer uma das 6 barras falhar. A falha última corresponde à probabilidade de falhar a segunda barra, dado que já houve falha de uma primeira. O CFS é equivalente ao custo de reposição do elemento danificado. Adotou-se que este custo corresponde a $1 / 3$ do custo inicial. O CFU, considerando uma estrutura de classe 1, com conseqüências leves de falha, foi adotado como o dobro do custo inicial.

$$
\begin{aligned}
& \operatorname{CFS}\left(\lambda_{k}\right)=\operatorname{CI}\left(\lambda_{k}\right) / 3 \\
& \operatorname{CFU}\left(\lambda_{k}\right)=2 . \operatorname{CI}\left(\lambda_{k}\right)
\end{aligned}
$$

Para a treliça considerada existem várias seqüências possíveis que levam à falha, como pode ser visto na árvore de falhas mostrada na Figura 6.10. Para a função CET foram consideradas apenas as seqüências mais prováveis de falha, destacadas na figura (falha das barras 2, 3 ou 6 por primeiro). As seqüências de falha que se iniciam pelas barras 1, $4 \mathrm{e}$ 5 , têm probabilidade de falha da ordem de $10^{-7}$ ou menor e por isso foram negligenciadas.

Sendo $B_{i}$ o evento falha da barra $i$, temos:

$$
P_{f s}=P\left[B_{1} \cup B_{2} \cup B_{3} \cup B_{4} \cup B_{5} \cup B_{6}\right]
$$

Seqüência $1 \rightarrow P\left[S_{1}\right]=P\left[B_{2}\right] \cdot P\left[B_{1} / B_{2} \cup B_{3} / B_{2} \cup B_{4} / B_{2} \cup B_{5} / B_{2} \cup B_{6} / B_{2}\right]$

Seqüência $2 \rightarrow P\left[S_{2}\right]=P\left[B_{3}\right] \cdot P\left[B_{1} / B_{3} \cup B_{2} / B_{3} \cup B_{4} / B_{3} \cup B_{5} / B_{3} \cup B_{6} / B_{3}\right]$

Seqüência $3 \rightarrow P\left[S_{3}\right]=P\left[B_{6}\right] \cdot P\left[B_{1} / B_{6} \cup B_{2} / B_{6} \cup B_{3} / B_{6} \cup B_{4} / B_{6} \cup B_{5} / B_{6}\right]$ 
Então,

$$
\operatorname{CET}\left(\lambda_{k}\right)=C I\left(\lambda_{k}\right)+C F S\left(\lambda_{k}\right) \cdot P_{f s}+C F U\left(\lambda_{k}\right) \cdot\left(P\left[S_{1}\right]+P\left[S_{2}\right]+P\left[S_{3}\right]\right)
$$

\section{Resultado da otimização:}

Tabela 6.11: Resultado do RiskOPT para o problema da treliça plana

\begin{tabular}{ccc}
\hline Método & $\lambda_{\mathrm{k}}$ ótimo & CET mínimo \\
\hline Interpolação Quadrática & 1,6111 & 324,50 \\
Regula Falsi & 1,5999 & 324,50 \\
\hline
\end{tabular}

A probabilidade de colapso da treliça, para o $\lambda_{k}$ ótimo de 1,60 é de aproximadamente $5.10^{-6}$. Utilizando esse $\lambda_{k}$ encontrado, obtêm-se as medidas mínimas dos perfis:

$$
\begin{gathered}
I_{1}=I_{2}=I_{3}=1,6.0,72=1,15 \mathrm{~cm}^{4} \\
I_{6}=1,6.1,13=1,81 \mathrm{~cm}^{4} \\
A_{4}=1,6.1,15=1,84 \mathrm{~cm}^{2}
\end{gathered}
$$

Adotou-se então os perfis U comerciais mais próximos, como mostrado na Tabela 6.12.

Tabela 6.12: Perfis comerciais adotados para o projeto otimizado

\begin{tabular}{cccc}
\hline Barra & Perfil U & $\mathbf{A}\left(\mathbf{c m}^{2}\right)$ & $\mathrm{I}_{\mathbf{y}}\left(\mathbf{c m}^{4}\right)$ \\
\hline 1 & $\mathrm{U} 50 \times 25 \times 2,00$ & 1,87 & 1,13 \\
2 & $\mathrm{U} 50 \times 25 \times 2,00$ & 1,87 & 1,13 \\
3 & $\mathrm{U} 50 \times 25 \times 2,00$ & 1,87 & 1,13 \\
4 & $\mathrm{U} 50 \times 25 \times 2,00$ & 1,87 & 1,13 \\
5 & $\mathrm{U} \mathrm{50 \times 25 \times 2,00}$ & 1,87 & 1,13 \\
6 & $\mathrm{U} 75 \times 40 \times 1,20$ & 1,81 & 2,97 \\
\hline
\end{tabular}




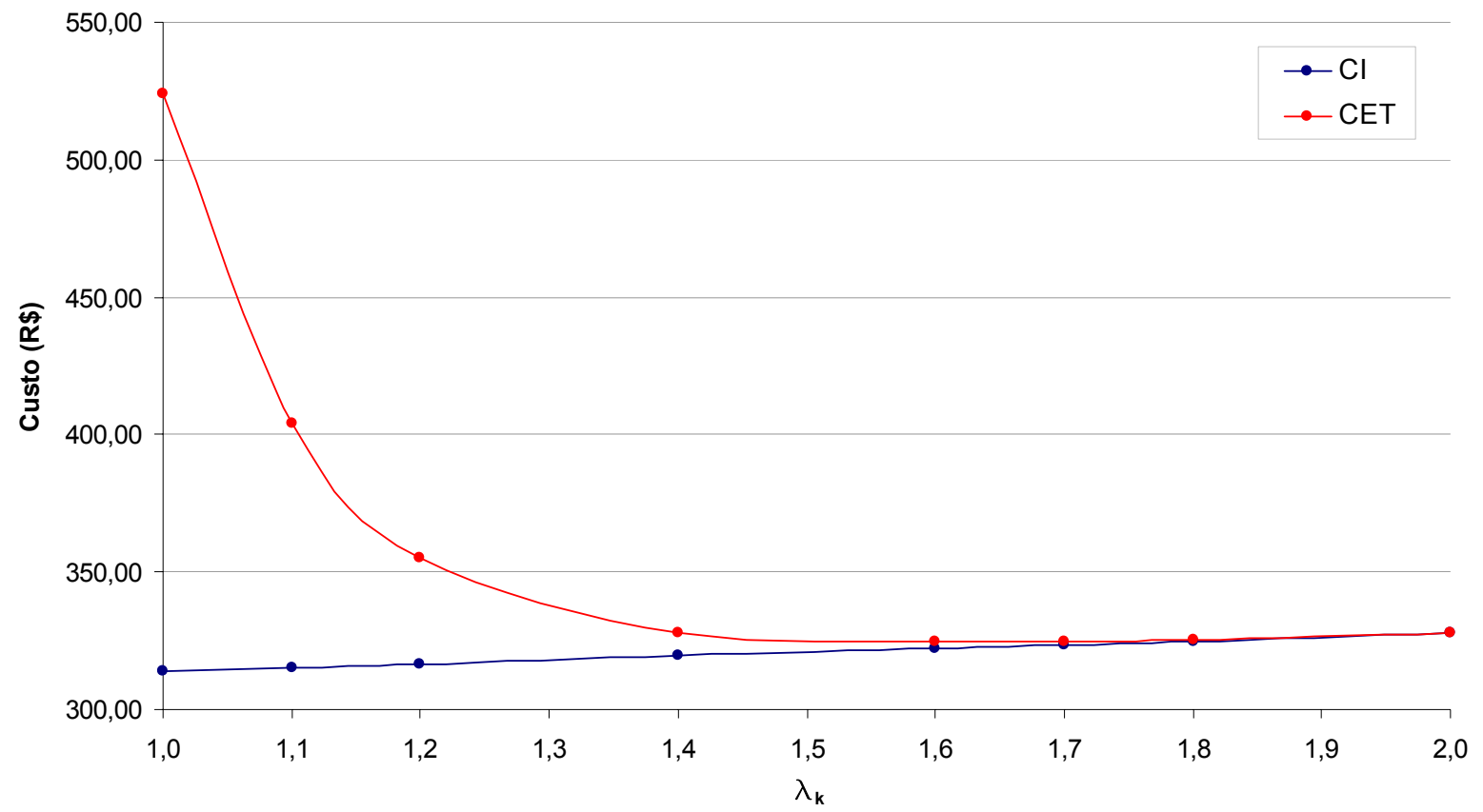

Figura 6.9: Gráfico custo $x \lambda_{\mathrm{k}}$ para o problema da treliça plana 


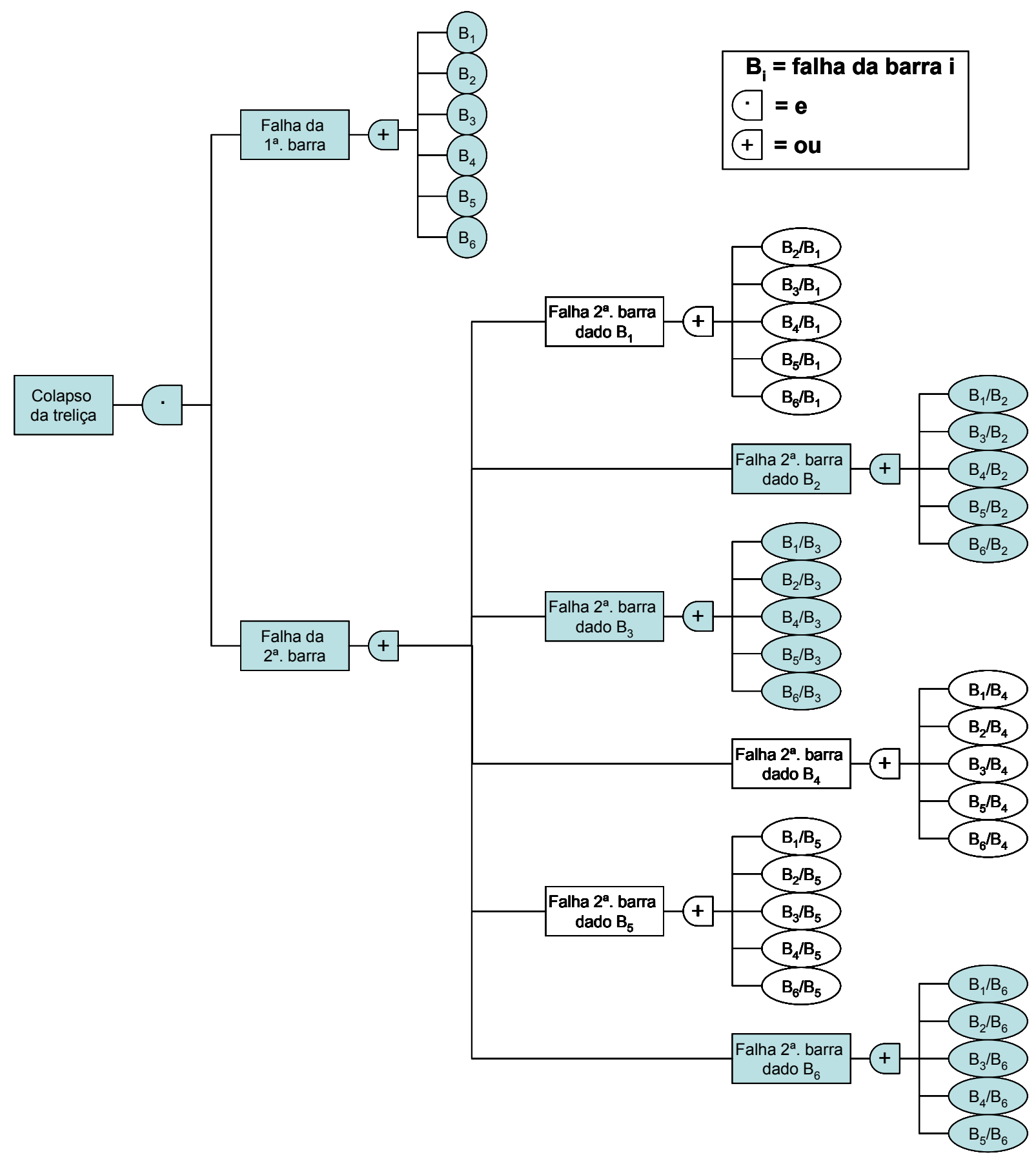

Figura 6.10: Árvore de falhas da treliça plana de 6 barras 


\subsection{Pórtico Plano}

Inspirado no problema resolvido por Melchers (1999), este exemplo trata de um pórtico plano simples, submetido a uma carga vertical no meio do vão e a uma carga horizontal (Figura 6.11). O exemplo foi resolvido considerando a fabricação do pórtico em aço, com a utilização de perfis $I$ laminados.

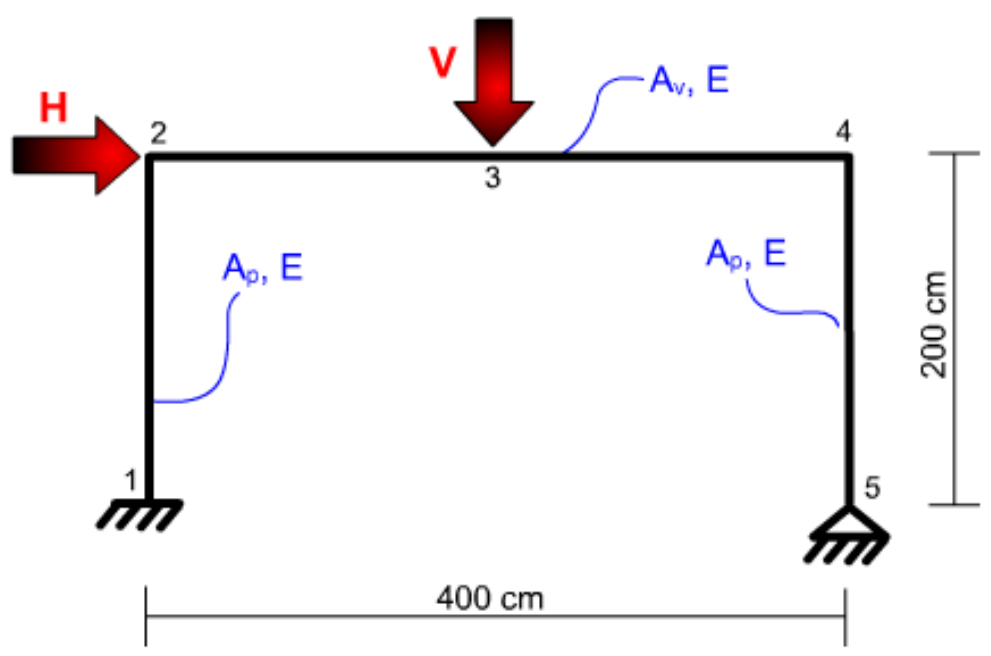

Figura 6.11: Geometria do pórtico plano

\section{Dados do problema:}

Três VA's não correlacionadas.

Tabela 6.13: Variáveis aleatórias para o problema do pórtico plano

\begin{tabular}{lccccc}
\hline VA & Designação & Distribuição & $\mu$ & $\sigma$ & Unidade \\
\hline $\mathrm{X}_{1}$ & Carga vertical $(\mathrm{V})$ & Normal & 100,0 & 20,0 & $\mathrm{kN}$ \\
$\mathrm{X}_{2}$ & Carga horizontal $(\mathrm{H})$ & Normal & 70,0 & 35,0 & $\mathrm{kN}$ \\
$\mathrm{X}_{3}$ & Tensão de escoamento do aço $\left(\sigma_{\mathrm{y}}\right)$ & Log-normal & 25,0 & 1,25 & $\mathrm{kN} / \mathrm{cm}^{2}$ \\
\hline
\end{tabular}

\section{Modos de falha:}

Foram considerados 3 modos de falha, referentes ao colapso através da formação de rótulas plásticas, sendo, portanto, todos estados limites últimos (Figura 6.12). 

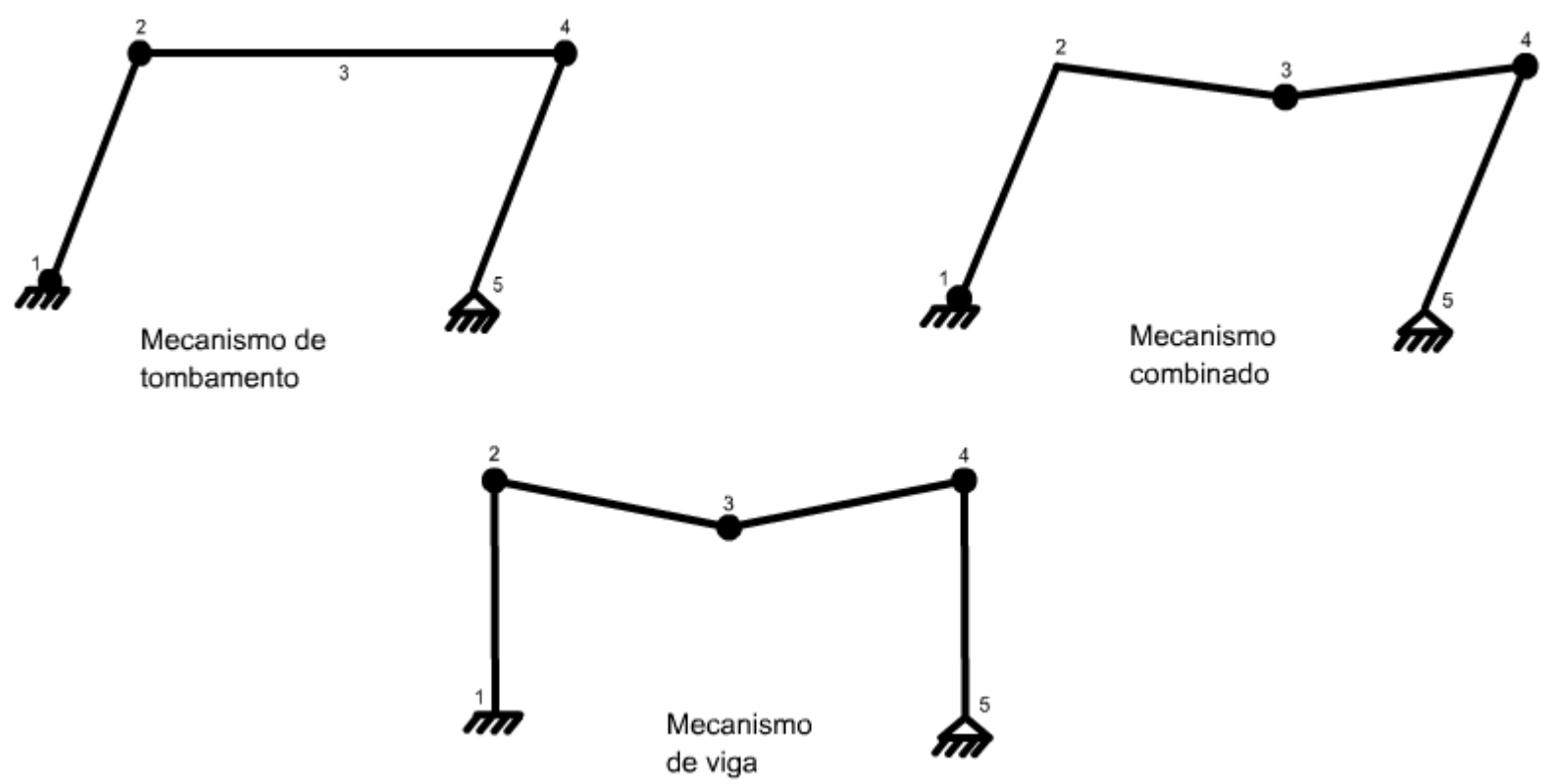

Figura 6.12: Modos de falha do pórtico

Sendo $M_{i}$ o momento de plastificação no nó $i$, temos:

Mecanismo de Tombamento:

$$
g_{1}(x)=M_{1}+M_{2}+M_{4}-200 \cdot H=0
$$

Mecanismo de Viga:

$$
g_{2}(x)=M_{2}+2 M_{3}+M_{4}-200 . V=0
$$

Mecanismo Combinado:

$$
g_{3}(x)=M_{1}+2 M_{3}+2 M_{4}-200 \cdot H-200 \cdot V=0
$$

\section{Projeto do pórtico:}

Primeiramente foram obtidos os coeficientes de segurança parciais. A VA de resistência $\left(\sigma_{\mathrm{y}}\right)$ tem distribuição log-normal, c.o.v. de $5 \%$, e para $p_{\mathrm{k}}$ de $95 \%$, obtém-se $\phi_{k}=0,92$. Já as solicitações têm c.o.v diferentes, e por isso, teremos um fator de majoração para cada carga, sendo $\gamma_{k H}$ para a carga horizontal e $\gamma_{k V}$ para a carga vertical. Como $\mathrm{H}$ é normal com 
c.o.v. de $50 \%$, para $p_{\mathrm{k}}$ de $84,1 \%$ obtém-se $\gamma_{k H}=1,5$. Já para $\bigvee$ normal com c.o.v. de $20 \%$ e $\mathrm{p}_{\mathrm{k}}$ de $84,1 \%$, obtém-se $\gamma_{k V}=1,2$.

Como mostrado na Figura 6.11 o pórtico pode possuir dimensões diferentes para os pilares e para viga. O projeto de referência foi feito em relação ao módulo plástico da seção transversal $\left(Z_{\mathrm{x}}\right)$, considerando perfis $I$ laminados comerciais.

Considerando pilares de dimensões constantes e iguais, na equação (6.58) os valores de $M_{1}, M_{2}$ e $M_{4}$ são os mesmos. Sabendo que para perfis $I$ o momento de plastificação é dado por $1,14 . Z_{x} \cdot \sigma_{y}$ (Neal, 1977), e inserindo os coeficientes de segurança parciais, obtém-se os módulos plásticos de referências $\left(Z_{X P, \text { ref }}\right.$ e $\left.Z_{X V \text {,ref }}\right)$ para os pilares e para a viga.

Da equação (6.58) obtemos $Z_{x P, \text { ref: }}$

$$
\begin{gathered}
\phi_{k} 3 \sigma_{y} 1,14 Z_{X P}-\gamma_{k H} 200 . H=0 \\
\lambda_{k}=\frac{r_{k}}{s_{k}}=\frac{\phi_{k} 3 \sigma_{y} 1,14 Z_{X P}}{200 \gamma_{k H} H}
\end{gathered}
$$

Para $\lambda_{k}$ unitário, no ponto médio, isolamos $Z_{X P}$ :

$$
\begin{aligned}
Z_{X P, r e f}=\frac{\gamma_{k H} 200 \cdot H}{3,42 \phi_{k} \sigma_{y}} & =\frac{1,5 \cdot 200 \cdot 70}{3,42 \cdot 0,92 \cdot 25} \cong 267 \mathrm{~cm}^{3} \\
Z_{X P} & =\lambda_{k} Z_{X P, r e f}
\end{aligned}
$$

Na tabela de perfis I laminados comerciais (GERDAU AÇOMINAS, 2007) adota-se o perfil com $Z_{x}$ mais próximo do valor encontrado, no caso o perfil $W 250$ x 22,3 que possui $Z_{x}=267,7 \mathrm{~cm}^{3}$.

Tendo obtido $Z_{X P}$, podemos obter $Z_{X V}$ utilizando a equação (6.60). Nesta equação temos duas rótulas plásticas em pilares $\left(M_{1}\right.$ e $\left.M_{4}\right)$ e três rótulas plásticas na viga $\left(2 M_{3}\right.$ e $\left.M_{4}\right)$. 


$$
\begin{gathered}
2 \phi_{k} \sigma_{y} 1,14 Z_{X P}+3 \phi_{k} \sigma_{y} 1,14 Z_{X V}-\left(\gamma_{k H} 200 H+\gamma_{k V} 200 V\right)=0 \\
\lambda_{k}=\frac{2 \phi_{k} \sigma_{y a} 1,14 Z_{X P}+3 \phi_{k} \sigma_{y} 1,14 Z_{X V}}{\left(\gamma_{k H} 200 H+\gamma_{k V} 200 V\right)}
\end{gathered}
$$

Isolando $Z_{x v}$ :

$$
\begin{gathered}
Z_{X V}=\frac{\lambda_{k}\left(\gamma_{k H} 200 H+\gamma_{k V} 200 \mathrm{~V}\right)-2 \phi_{k} \sigma_{y} 1,14 Z_{X P}}{3,42 \phi_{k} \sigma_{y}} \\
Z_{X V}=572,1 \lambda_{k}-0,67 Z_{X P} \\
Z_{X V, r e f}=572,1-0,67.267,7 \cong 392,7 \mathrm{~cm}^{3}
\end{gathered}
$$

O perfil adotado é o $W 310 \times 28,3$ que possui $Z_{x}=412 \mathrm{~cm}^{3}$.

Verifica-se, a seguir, se o valor encontrado para o $Z_{X v}$ de referência da viga obedece à equação (6.59). Em tal equação quatro rótulas plásticas são formadas na viga $\left(M_{1}, 2 M_{3}\right.$ e $\left.\mathrm{M}_{4}\right)$.

$$
\begin{gathered}
4 \phi_{k} \sigma_{y} 1,14 Z_{X V}-\gamma_{k V} .200 . V \geq 0 \\
4.0,92.25 .412-1,2.200 .100 \geq 0 \\
19210,56 \geq 0 \rightarrow O K
\end{gathered}
$$

Note que também nesse problema o fato do RiskOPT permitir apenas uma variável de projeto limita a otimização, e o valor de $Z_{X V}$ é dependente de $Z_{X P}$.

\section{Função objetivo:}

A função CET é composta pela soma do custo inicial e dos custos esperados dos 3 modos de falha. Os custos de falha últimos são proporcionais ao custo inicial da seguinte maneira, caracterizando uma estrutura da classe 3 de conseqüências de falha:

$$
\begin{gathered}
C F_{\text {tombamento }}=4 . \mathrm{Cl} \\
C F_{\text {viga }}=\mathrm{Cl} \\
C F_{\text {combinado }}=5 . \mathrm{Cl}
\end{gathered}
$$


O custo inicial é composto pelo custo dos materiais (CM) somado ao custo da mãode-obra (CMO). Considerou-se que o $\mathrm{CMO}$ representa $25 \%$ do custo inicial total. Considerando o custo do aço estrutural de $\mathrm{R} \$ 3,00 / \mathrm{kg}$ escreve-se o $\mathrm{CM}$ em função do módulo plástico $Z_{x}$.

$$
C M=3\left(0,32 Z_{X P}+0,28 Z_{X V}\right)=3 \lambda_{k}\left(0,1324 Z_{X P, r e f}+160,2\right)
$$

Definido o custo de material temos o seguinte equacionamento:

$$
\begin{gathered}
C M O=\frac{25}{75} C M=0,33 C M \\
C I=C M+C M O \\
C E T=C I+C F_{\text {tombamento }} P_{f}\left[g_{1}(x)\right]+C F_{\text {viga }} P_{f}\left[g_{2}(x)\right]+C F_{\text {combinado }} P_{f}\left[g_{3}(x)\right]
\end{gathered}
$$

\section{Resultado da otimização:}

Tabela 6.14: Resultados do RiskOPT para o problema do pórtico plano

\begin{tabular}{ccccc}
\hline Método & $\lambda_{\mathrm{k}}$ ótimo & CET mínimo & $\beta$ & $\mathbf{P}_{\mathbf{f} \text { sistema }}$ \\
\hline Interpolação Quadrática & 1,9400 & 1710,68 & & \\
Regula Falsi & 1,9225 & 1710,93 & & \\
\hline
\end{tabular}

Foi encontrado $\lambda_{k}$ ótimo igual a 1,94 com o método da interpolação quadrática. Utilizando esse valor nas equações (6.62) e (6.63), encontra-se o módulo plástico dos elementos do pórtico e na tabela de perfis adota-se o perfil comercial mais adequado para cada elemento.

Tabela 6.15: Dimensões do pórtico otimizado

\begin{tabular}{ccc}
\hline Elemento do pórtico & $\mathbf{Z}_{\mathbf{x}}$ & Perfil adotado \\
\hline Pilar & 519,4 & W $250 \times 38,5$ \\
Viga & 761,9 & W $310 \times 52$ \\
\hline
\end{tabular}




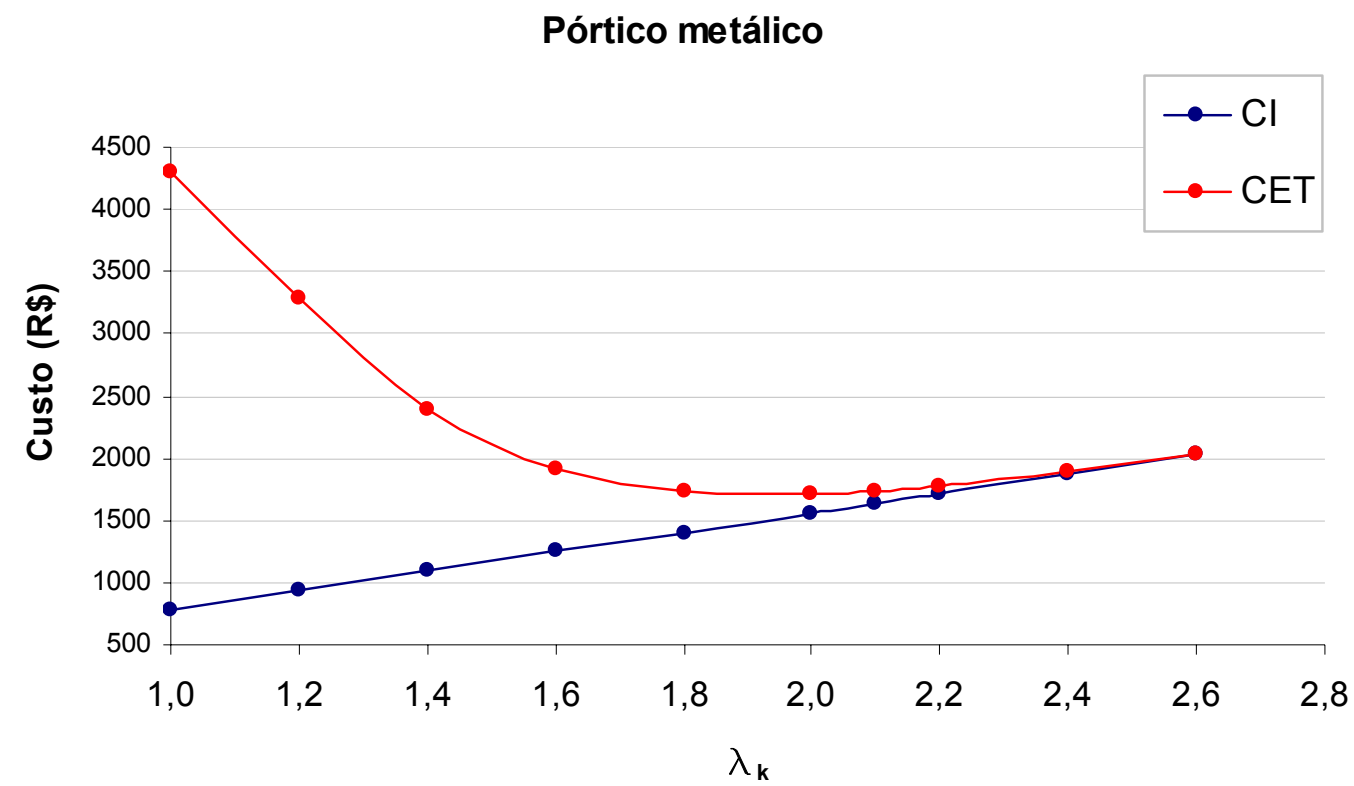

Figura 6.13: Gráfico custo $x \lambda_{k}$ para o pórtico

Foi também realizado um estudo da variação do coeficiente de segurança com as classes de conseqüência de falha. Podemos observar no gráfico da Figura 6.14 como o $\lambda_{k}$ aumenta com a gravidade da conseqüência de falha.

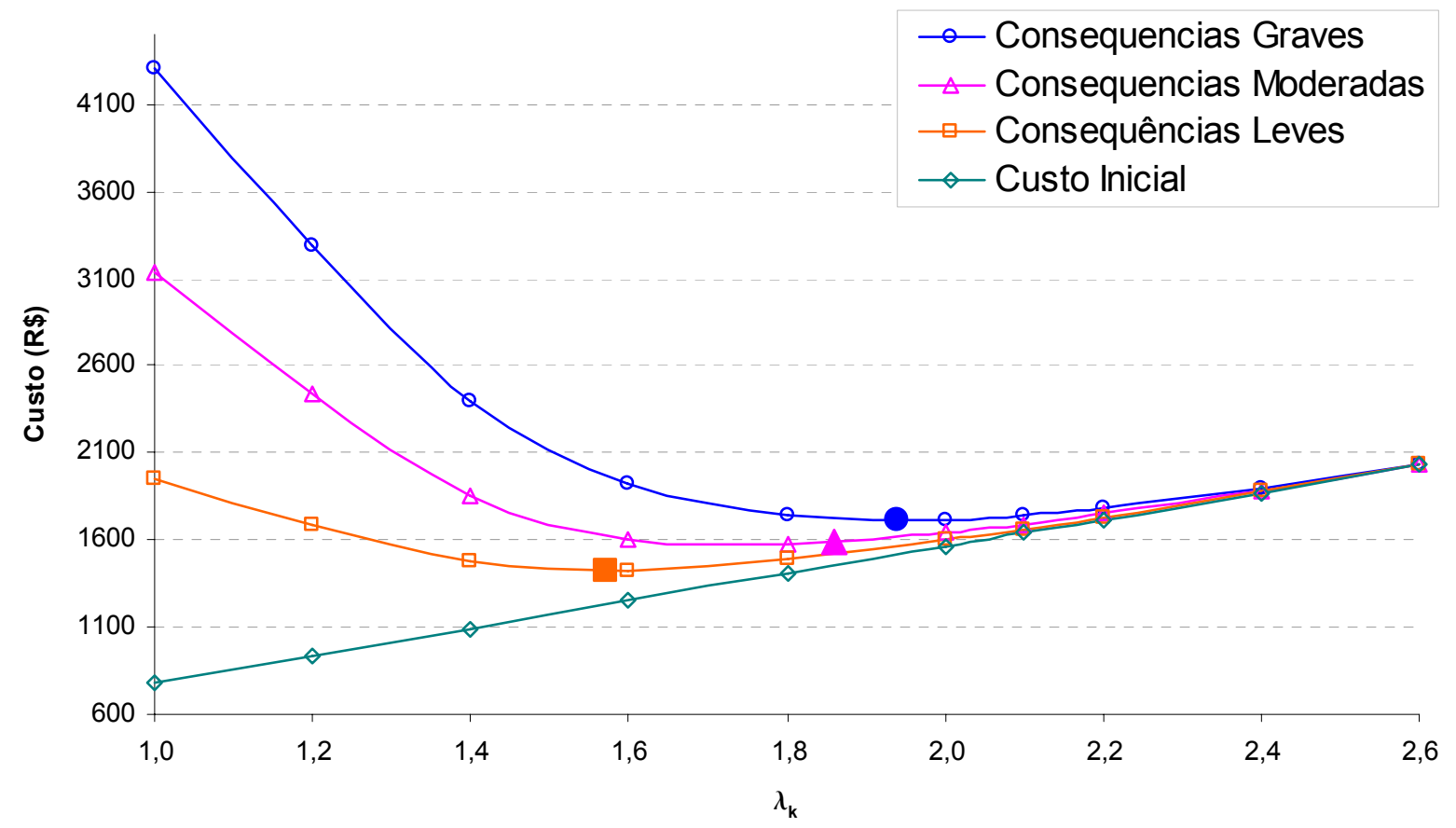

Figura 6.14: Variação do ponto ótimo com a conseqüência de falha 


\subsection{Torre Tridimensional}

O último problema resolvido é também o mais completo e o que mais se aproxima da realidade da engenharia. Nele está presente a interação StRAnD/Ansys, pois a EEL é numérica. Trata-se da análise de uma torre metálica tridimensional que suporta antenas de telefonia (Figura 6.15). A torre analisada é do modelo TAB 050 1500L, modelo este bastante comum e utilizado por várias empresas de telefonia. O modelo e os carregamentos foram fornecidos por uma empresa fabricante de torres.
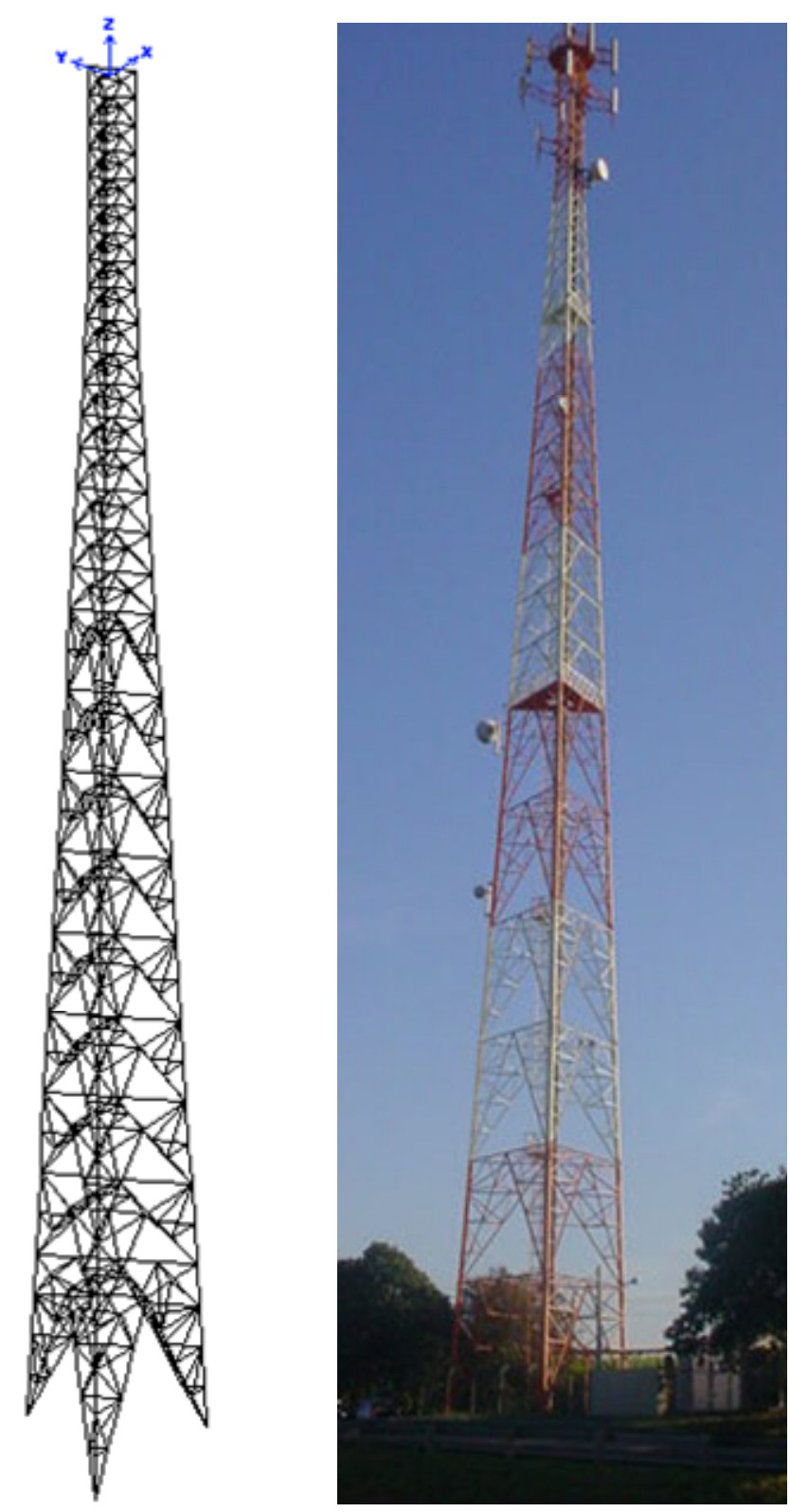

Figura 6.15: Modelo da torre feito no Ansys e torre verdadeira 
Além das cargas verticais de antenas e peso próprio, a principal solicitação na torre é exercida pelo vento. A NBR 6123 (1988) estabelece que para torres reticuladas de seção triangular deve-se considerar 3 casos de direção de incidência do vento, sendo sua velocidade básica a que apresenta um período de recorrência médio de 50 anos. O presente exemplo foi resolvido utilizando-se apenas uma das direções de incidência do vento, mas os resultados obtidos podem ser estendidos para as outras duas situações. O esquema de carregamento é definido conforme as componentes $n$ e $t$ da NBR 6123 e a carga é aplicada em cada nó, proporcionalmente. Foram feitas análises do custo ótimo para a torre submetida ao vento de norma (vento de 50 anos) e a ventos de tornado.

\section{Tornados:}

"O tornado é uma coluna ondulante de nuvens, com diâmetro de menos de $2 \mathrm{~km}$, que se desloca a uma velocidade de $30 \mathrm{~km} / \mathrm{h}$ a $60 \mathrm{~km} / \mathrm{h}$. Ele ocorre com a chegada de frentes frias, em regiões onde o ar está mais quente e instável. Os tornados são os mais destruidores de todas as perturbações atmosféricas, mas a área afetada por eles é limitada. O tornado percorre um caminho muito irregular. Quando o funil toca o solo, ele pode mover-se em linha reta ou descrever um trajeto sinuoso." (DEFESA CIVIL RS, 2005). Tornados classificados, pela quantia de estrago que causam, através da escala Fujita, que vai de F0 até F6 (FUJITA, 1971).

Tabela 6.16: Escala Fujita de classificação de tornados

\begin{tabular}{ccc}
\hline Classificação & Velocidade do vento $(\mathbf{k m} / \mathbf{h})$ & Danos provocados \\
\hline F0 & $65-117$ & Leves \\
F1 & $117-180$ & Moderados \\
F2 & $182-252$ & Fortes \\
F3 & $253-333$ & Severos \\
F4 & $334-419$ & Devastadores \\
F5 & $420-511$ & Incríveis \\
F6 & Acima de 511 & Inconcebíveis \\
\hline
\end{tabular}

Tornados de fato ocorrem no Brasil. Danos causados por tornados isolados são relatados todo ano, especialmente na parte sul e sudeste do país (ANTONIO, ANTONIO, 
FIGUEIREDO, 2005; AGÊNCIA ESTADO, 2005; MARCELINO, 2004; NECHET, 2002; SILVA DIAS, 1991). Verifica-se que a ocorrência de tornados no Brasil não é tão rara quanto se pensava anteriormente. Vesilind (2004), em uma discussão sobre ocorrência de tornados no mundo, mostra as regiões da América do Sul mais favoráveis à formação de tornados (Figura 6.16). Percebe-se na figura que o sul do Brasil possui regiões com alto risco de ocorrência de tornados. Outro tipo de evento localizado que atinge o sul do Brasil são as tormentas elétricas frontais formadas em sistemas de baixa pressão. Assim como os tornados, tais tormentas elétricas provocam carregamentos localizados extremos nas estruturas, diferentes das tempestades abrangentes que são consideradas em normas, e são responsáveis pela ruína de muitas torres no sul do Brasil. Esse tipo de tormenta não é considerado neste trabalho.

Como os dados estatísticos sobre tornados no Brasil ainda são muito escassos, foram utilizadas informações sobre tornados dos Estados Unidos. De acordo com a graduação de cores da Figura 6.17, a região mais suscetível à formação de tornados no Brasil é equivalente à região sudoeste do estado de Oklahoma, no mapa dos EUA. A partir dos trabalhos de Goliger e Milford (1998), Meyer, Brooks e Kay (2002), e Daneshvaran e Morden (2007), foi composta a Tabela 6.17.

Devido à falta de dados sobre a distribuição de velocidades de vento em tornados, adotou-se a distribuição de Gumbel para máximos, também conhecida como distribuição de extremos do tipo I (MELCHERS, 1999). Segundo Holmes (2001), a distribuição do tipo I pode ser considerada um caso conservador da distribuição do tipo III (Weibull) e possui apenas dois parâmetros. Por essa razão a tipo I (Gumbel) é facilmente adaptada aos dados reais, e é comumente usada como modelo de extremos para velocidades de vento, pressões e resposta estrutural.

O c.o.v. adotado foi de $12 \%$, que é o valor fornecido por Melchers (1999) para as máximas anuais de vento nos EUA. A média foi estabelecida como a metade do intervalo de velocidades de vento de cada categoria de tornado. 
Tabela 6.17: Dados adotados para tornados na região Sul do Brasil

\begin{tabular}{cccc}
\hline Tornado & $\mu_{\mathbf{v} \mathbf{0}}(\mathbf{m} / \mathbf{s})$ & $\sigma \mathrm{v}_{\mathbf{0}}(\mathbf{m} / \mathbf{s})$ & Taxa de ocorrência anual $(\nu)$ \\
\hline $\mathrm{F}_{1}$ & 42 & 5,04 & $1,3 \cdot 10^{-3}$ \\
$\mathrm{~F}_{2}$ & 60 & 7,20 & $1,167 \cdot 10^{-3}$ \\
$\mathrm{~F}_{3}$ & 81 & 9,72 & $3,5 \cdot 10^{-4}$ \\
$\mathrm{~F}_{4}$ & 105 & 12,60 & $3,3 \cdot 10^{-5}$ \\
$\mathrm{~F}_{5}$ & 130 & 15,60 & $3,3 \cdot 10^{-6}$ \\
\hline
\end{tabular}

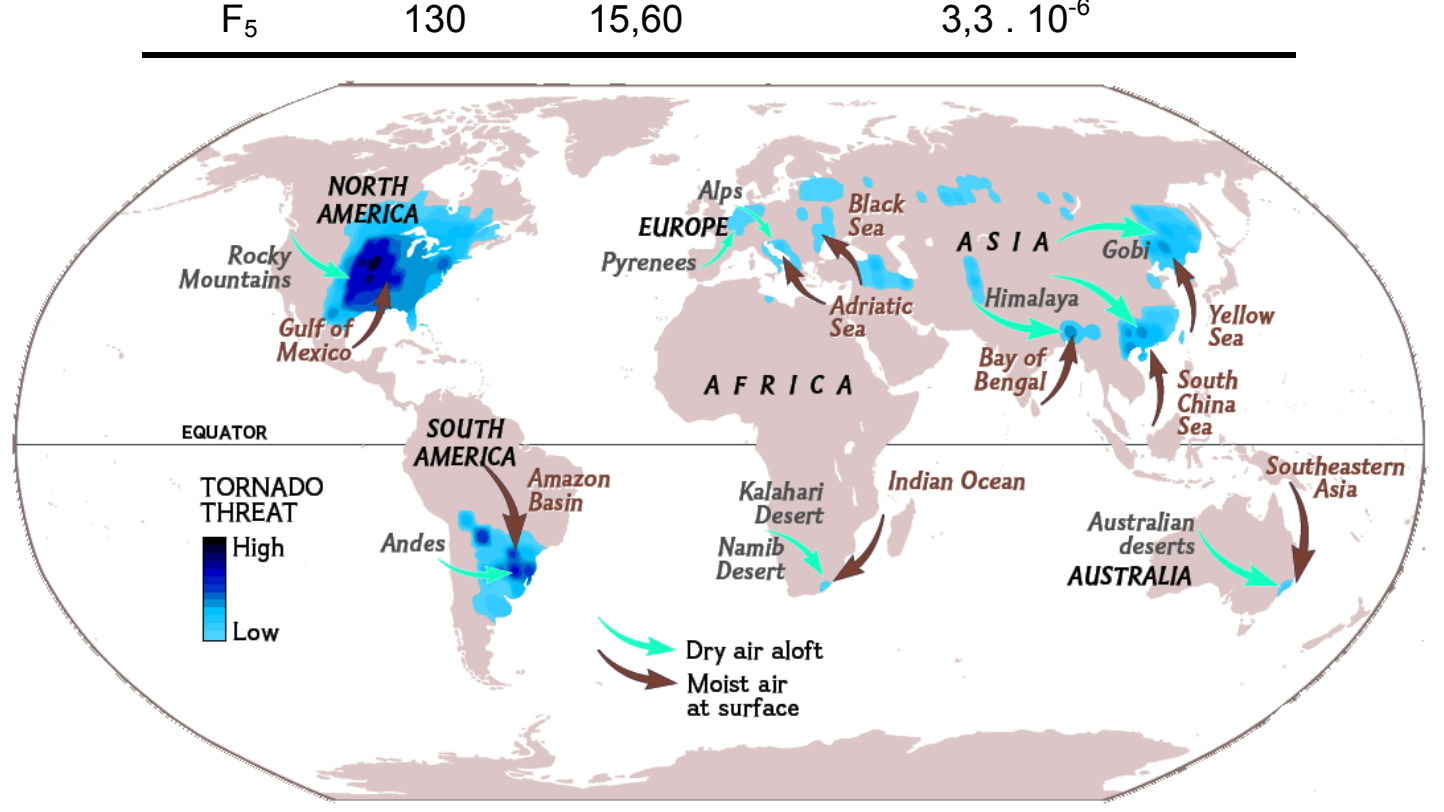

Figura 6.16: Regiões favoráveis à formação de tornado no mundo

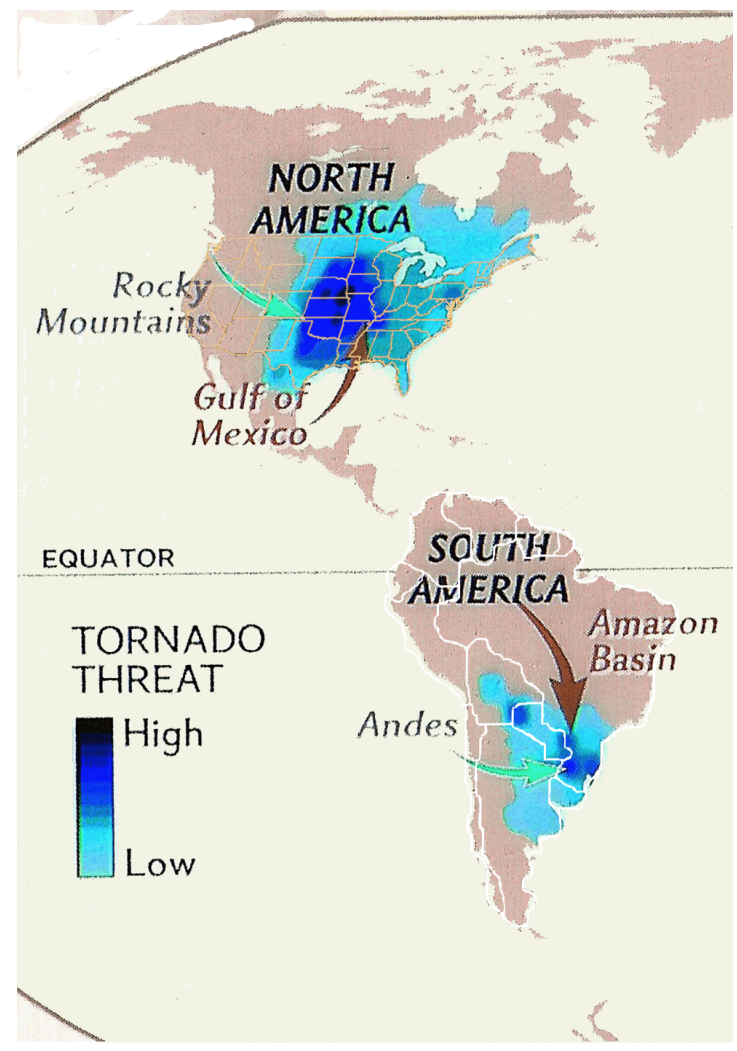

Figura 6.17: Detalhe das regiões das Américas favoráveis à formação de tornado 


\section{Dados do problema:}

Foram consideradas três VA's não correlacionadas, sendo que a terceira VA, a velocidade básica do vento, tem seus parâmetros alterados para cada caso analisado (tempestade de 50 anos e 5 tipos de tornado).

Pra a VA velocidade básica do vento, foi adotada distribuição de extremos do tipo I (Gumbel para máximos) e c.o.v. de 12\% (MELCHERS, 1999).

Tabela 6.18: Dados para o problema da torre

\begin{tabular}{|c|c|c|c|c|c|c|}
\hline VA & Designação & Distribuição & & $\mu$ & $\sigma$ & Unidade \\
\hline $\mathrm{X}_{1}$ & Módulo de elasticidade (E) & Log-Normal & & 21000 & 1050 & $\mathrm{kN} / \mathrm{cm}^{2}$ \\
\hline $\mathrm{X}_{2}$ & Tensão de escoamento $\left(\sigma_{\mathrm{y}}\right)$ & Log-Normal & & 25 & 1,25 & $\mathrm{kN} / \mathrm{cm}^{2}$ \\
\hline \multirow{6}{*}{$\mathrm{X}_{3}$} & \multirow{6}{*}{ sica do vento } & \multirow{6}{*}{$\begin{array}{c}\text { Gumbel para } \\
\text { máximos }\end{array}$} & $\mathrm{V}_{50}$ & 30 & 3,60 & $\mathrm{~m} / \mathrm{s}$ \\
\hline & & & $\mathrm{V}_{\mathrm{F} 1}$ & 42 & 5,04 & $\mathrm{~m} / \mathrm{s}$ \\
\hline & & & $V_{F 2}$ & 60 & 7,20 & $\mathrm{~m} / \mathrm{s}$ \\
\hline & & & $\mathrm{V}_{\mathrm{F} 3}$ & 81 & 9,72 & $\mathrm{~m} / \mathrm{s}$ \\
\hline & & & $\mathrm{V}_{\mathrm{F} 4}$ & 105 & 12,60 & $\mathrm{~m} / \mathrm{s}$ \\
\hline & & & $\mathrm{V}_{\mathrm{F} 5}$ & 130 & 15,60 & $\mathrm{~m} / \mathrm{s}$ \\
\hline
\end{tabular}

\section{Projeto de Referência:}

A empresa fabricante carrega a estrutura utilizando a NBR 6123 e a dimensiona pela norma americana AISC-ASD (tensões admissíveis). Tal dimensionamento realizado pela empresa, foi considerado como projeto de referência, ou seja, aquele que tem $\lambda_{k}$ unitário. $O \lambda_{k}$ foi aplicado às áreas das seções transversais de todas as barras, aumentando a robustez da torre como um todo. Neste problema em particular $\lambda_{k}$ não é um fator que afasta os valores característicos de resistência e solicitação, mas sim um fator que afasta os valores originais de projeto.

Dada qualquer barra $i$ :

$$
A_{i}=\lambda_{k} \cdot A_{i \text { projeto de norma }}
$$




\section{Modos de falha:}

Foi considerada uma EEL, que representa estado limite último:

$$
g(x)=u_{y_{C R}}-u_{y_{1}}=0
$$

onde $u_{y_{C R}}$ é o deslocamento crítico no topo, que caracteriza o colapso da torre, e $u_{y_{1}}$ é o deslocamento horizontal do nó 1 na direção do eixo Y.

Foi realizado um estudo da sensibilidade do deslocamento horizontal crítico com o $\lambda_{k}$. Como pode ser visto na Figura 6.19 a carga crítica de vento varia com o $\lambda_{k}$ mas $0 u_{y_{C R}}$ permanece em torno de $60 \mathrm{~cm}$, não sofrendo variação significativa, validando, portanto, a utilização da EEL (6.69). A Figura 6.20 reflete uma dessas análises, considerando não linearidade física e geométrica, e realizada incrementando-se a carga $V_{0}$ de vento de um valor nulo até $50 \mathrm{~m} / \mathrm{s}$. Nela pode-se notar o deslocamento crítico no topo da torre de $60 \mathrm{~cm}$.

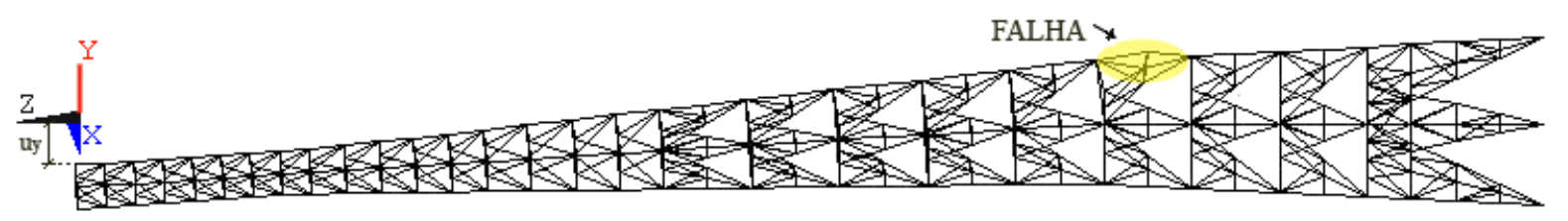

Figura 6.18: Colapso da torre
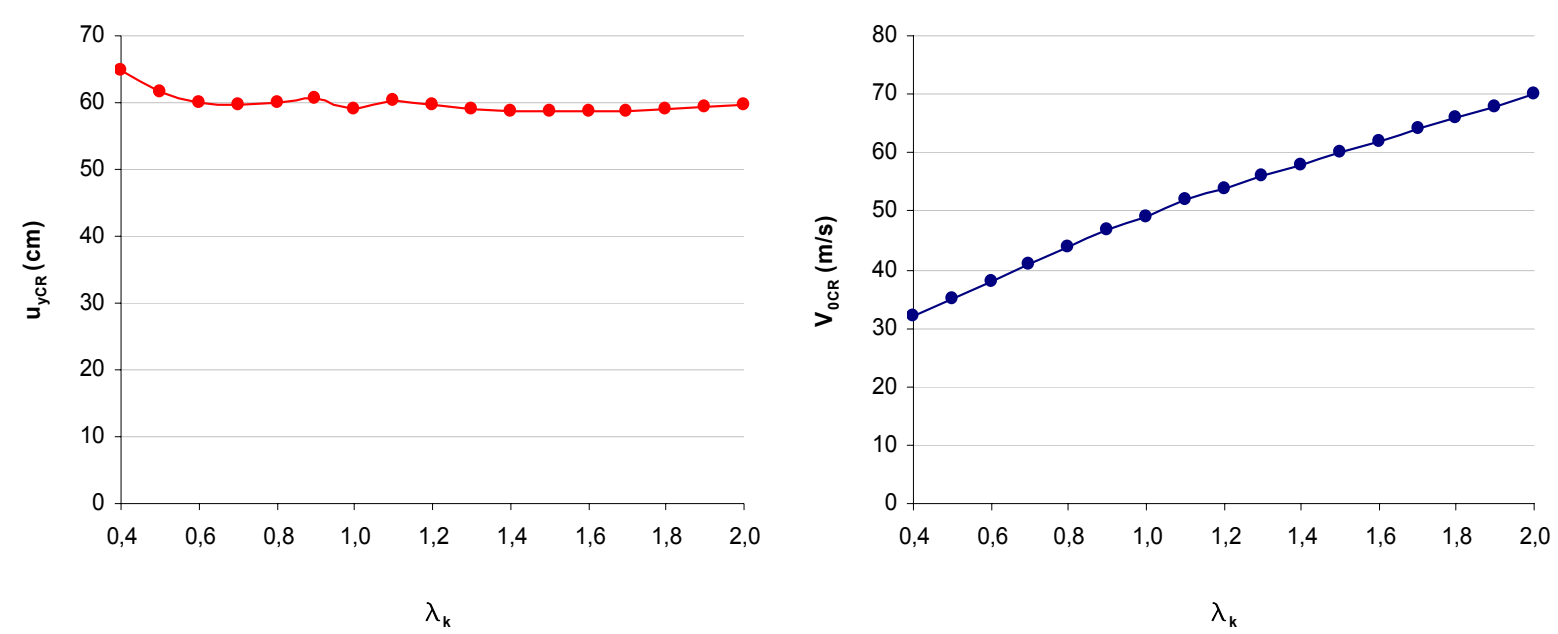

Figura 6.19: Estudo da variação do deslocamento e da carga críticos com o $\lambda_{k}$ 


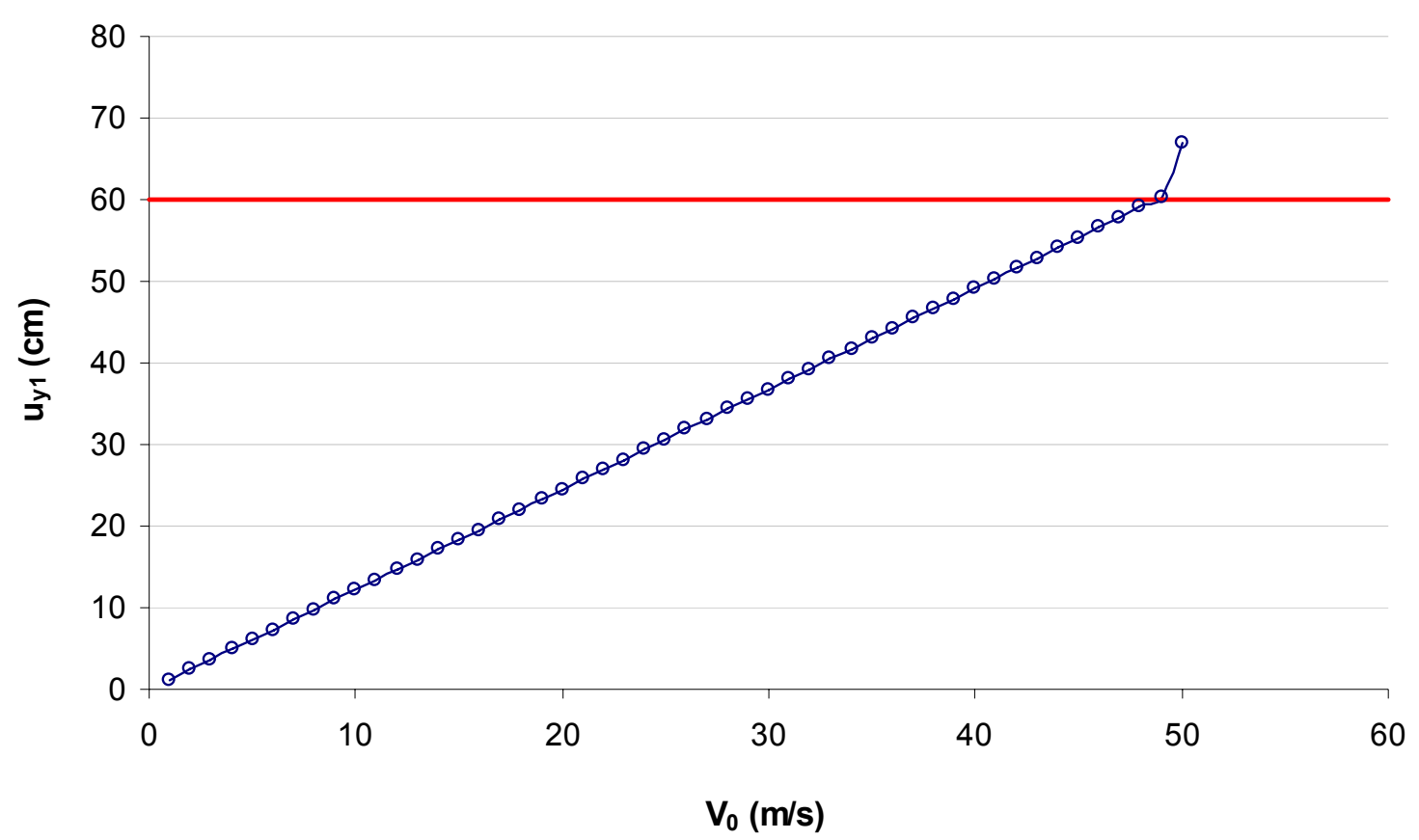

Figura 6.20: Curva carga X deslocamento da torre

Esta torre possui ainda modos de falha de serviço, que não causam ruína, mas prejudicam seu correto funcionamento. Por exemplo, deslocamentos excessivos podem prejudicar a transmissão/recepção de sinal. Neste exemplo, falhas de serviço não são consideradas.

\section{Função objetivo:}

O custo inicial foi composto pela soma do custo de material $(95 \%)$ e do custo de mão de obra $(5 \%)$, sendo o custo de material composto por uma parcela fixa mais uma parcela que varia com o $\lambda_{k}$. A torre originalmente projetada possui um custo inicial de aproximadamente $\mathrm{R} \$ 40.000,00$.

Os custos de falha foram definidos como valores fixos, proporcionais à gravidade da falha, e englobam despesas referentes à remoção da estrutura danificada e sua reposição, prejuízos devidos ao período de não funcionamento da estrutura, pagamento de eventuais multas e/ou indenizações. Foram consideradas quatro possibilidades: conseqüências leves, 
moderadas, graves e extremas (devido à ocorrência de uma fatalidade dado o colapso da torre).

$$
\begin{gathered}
C M=14400+\lambda_{k} 22400 \\
C M O=(5 / 95) \cdot C M \\
C I=C M+C M O
\end{gathered}
$$

$$
\text { Consequências Graves } \rightarrow C F_{3}=350.000,00
$$

Consequências Graves +1 fatalidade $\rightarrow C F_{4}=500.000,00$

O problema foi resolvido considerando duas situações: estrutura submetida apenas ao vento de 50 anos da norma e estrutura submetida também a vento de tornados. Por isso, temos duas funções objetivo, mostradas a seguir.

\section{$\underline{\text { Vento de } 50 \text { anos: }}$}

Sendo $\mathrm{V}_{50}$ o vento de 50 anos, e denotando por $\mathrm{E}_{0}$ o evento falha da torre devido ao $\mathrm{V}_{50}$, temos:

$$
C E T=C I+C F_{i} \cdot P\left[E_{0} / V_{50}\right]
$$

onde $i$ representa uma das quatro possibilidades de conseqüência de falha.

\section{Tornados:}

A probabilidade de ocorrência de tornados foi descrita por um processo de Poisson (HOSSAIN et al., 1999), sendo a estrutura projetada para uma vida útil de 50 anos. Conhecendo a taxa de ocorrência do tornado $\nu$ (Tabela 6.17) e o tempo de recorrência $t$, temos: 
$P[\mathrm{x}$ ocorrências em $\mathrm{t}]=\frac{(v t)^{x}}{x !} e^{-v t}$

$P[1$ ocorrência em 50 anos $]=50 v \cdot e^{-50 v}$

$P[$ pelo menos 1 ocorrência em 50 anos $]=1-P[0$ ocorrências em 50 anos $]=1-e^{-50 v}$

Por exemplo, a probabilidade de ocorrência de tornados de intensidade $F_{1}$ num período de 50 anos, na região de instalação da torre é:

$P\left[\right.$ exatamente 1 tornado $\mathrm{F}_{1}$ em 50 anos $]=50.1,3 \cdot 10^{-3} e^{-50.1,3 \cdot 10^{-3}}=0,0609$

$P\left[\right.$ pelo menos 1 tornado $\mathrm{F}_{1}$ em 50 anos $]=1-e^{-50.1,3 \cdot 10^{-3}}=0,0629$

A probabilidade de falha total da torre é composta pelas parcelas de probabilidade de falha da torre dada a ocorrência de um tornado multiplicada pela probabilidade de ocorrência de tal tornado.

Sendo $F_{i}$ a ocorrência de um ou mais tornados de intensidade $i$ e $E_{i}$ o evento falha da torre devido ao $\mathrm{F}_{\mathrm{i}}$, com $i$ podendo assumir os valores inteiros de 1 a 5 , temos:

$$
\begin{gathered}
P_{\text {fTOTAL }}=P\left[E_{0} / V_{50}\right]+P\left[E_{1} / F_{1}\right] P\left[F_{1}\right]+P\left[E_{2} / F_{2}\right] P\left[F_{2}\right]+ \\
+P\left[E_{3} / F_{3}\right] P\left[F_{3}\right]+P\left[E_{4} / F_{4}\right] P\left[F_{4}\right]+P\left[E_{5} / F_{5}\right] P\left[F_{5}\right]
\end{gathered}
$$

Temos, então, a função objetivo:

$$
C E T=C I+C F_{i} \cdot P_{\text {fTOTAL }}
$$

\section{Resultados:}

As probabilidades de falha obtidas para a torre em função do $\lambda_{k}$, para o vento de 50 anos, para cada intensidade de tornado e a probabilidade total (eq. 6.75) são apresentados na Tabela 6.19. Nesta tabela pode ser observado como, à medida que a torre é reforçada (aumento de $\lambda_{k}$ ), as probabilidades de falha dado tornados de menor intensidade vão diminuindo. A mesma tabela mostra que o reforço da torre não chega a afetar as 
probabilidades de falha para os tornados de maior intensidade, i.e., a ocorrência de um destes tornados $\left(F_{4}\right.$ ou $\left.F_{5}\right)$ certamente provoca o colapso da torre. Estes números ilustram a dificuldade de se projetar estruturas sujeitas a cargas como as de tornados:

"Qual vento de projeto deveria ser utilizado no projeto desta torre?"

Em verdade, não há resposta para esta pergunta. A torre é projetada para o vento de 50 anos, e a maneira de determinar se este projeto é adequado, em função da possibilidade de ocorrência de tornados, é através de uma análise de risco conforme aqui apresentado.

A Tabela 6.20 apresenta os valores de $\lambda_{k}$ e $\beta$ ótimos obtidos na análise de risco para a torre.

Tabela 6.19: Custos para o problema da torre submetida ao vento de norma e a tornados

\begin{tabular}{cccccccc|}
$\lambda_{k}$ & $P\left[E / V_{50}\right] P\left[E / F_{1}\right]$ & $P\left[E / F_{2}\right]$ & $P\left[E / F_{3}\right] P\left[E / F_{4}\right] P\left[E / F_{5}\right]$ & $P_{\text {fTOTAL }}$ \\
\hline 0,5 & 0,1089 & 0,9693 & 1 & 1 & 1 & 1 & 0,2457 \\
0,6 & 0,0339 & 0,7823 & 1 & 1 & 1 & 1 & 0,1590 \\
0,7 & 0,0113 & 0,5021 & 1 & 1 & 1 & 1 & 0,1188 \\
0,8 & 0,0041 & 0,2893 & 0,9998 & 1 & 1 & 1 & 0,0981 \\
0,9 & 0,0016 & 0,1576 & 0,9953 & 1 & 1 & 1 & 0,0871 \\
1,0 & 0,0006 & 0,0862 & 0,9697 & 1 & 1 & 1 & 0,0802 \\
1,1 & 0,0003 & 0,0474 & 0,9002 & 1 & 1 & 1 & 0,0734 \\
1,2 & 0,0001 & 0,0265 & 0,7884 & 1 & 1 & 1 & 0,0656 \\
1,3 & 0,0001 & 0,0160 & 0,6525 & 1 & 1 & 1 & 0,0572 \\
1,4 & 0,0000 & 0,0094 & 0,5121 & 0,9999 & 1 & 1 & 0,0488 \\
1,5 & 0,0000 & 0,0052 & 0,3973 & 0,9993 & 1 & 1 & 0,0420 \\
1,6 & 0,0000 & 0,0031 & 0,3001 & 0,9966 & 1 & 1 & 0,0363 \\
1,7 & 0,0000 & 0,0019 & 0,2236 & 0,9888 & 1 & 1 & 0,0318 \\
1,8 & 0,0000 & 0,0012 & 0,1657 & 0,9715 & 1 & 1 & 0,0281 \\
1,9 & 0,0000 & 0,0007 & 0,1233 & 0,9411 & 1 & 1 & 0,0252 \\
2,0 & 0,0000 & 0,0005 & 0,0916 & 0,8946 & 1 & 1 & 0,0226 \\
\hline
\end{tabular}

Tabela 6.20: $\lambda_{k}$ e $\beta$ ótimos obtidos para a torre

\begin{tabular}{ccccc}
\hline \multirow{2}{*}{$\begin{array}{c}\text { Consequência } \\
\text { de Falha }\end{array}$} & \multicolumn{2}{c}{$\mathbf{V}_{\mathbf{5 0}}$} & \multicolumn{2}{c}{ Tornados } \\
\cline { 2 - 5 } & $\lambda_{\mathbf{k} \text { ótimo }}$ & $\beta$ & $\lambda_{\mathbf{k} \text { ótimo }}$ & $\beta$ \\
\hline Leve & 0,60 & 1,2816 & 0,70 & 0,9986 \\
Moderada & 0,68 & 2,0537 & 0,80 & 1,2925 \\
Grave & 0,75 & 2,4232 & 1,40 & 1,6566 \\
Grave + 1 fatalidade & 0,80 & 2,6474 & 1,60 & 1,7953 \\
\hline
\end{tabular}


Os resultados apresentados na Tabela 6.20 podem ser comparados com índices de confiabilidade alvo utilizados na calibração da norma americana ANSI A58. Esta norma foi calibrada utilizando $\beta_{\mathrm{ALVO}}=\mathbf{2 , 5 0}$ para estruturas submetidas simultaneamente a cargas de peso próprio, acidental e vento, e $\beta_{\mathrm{ALVO}}=1,75$ para estruturas submetidas a tornados ou terremotos. Percebe-se que os resultados obtidos na análise para os casos de conseqüências "grave" e "grave +1 fatalidade" são muito próximos desses valores alvo, o que confirma a validade dos resultados.

Pode-se notar ainda, pelos índices de confiabilidade obtidos (Tabela 6.20) que ao se projetar uma estrutura submetida a diferentes ações (e.g., vento de 50 anos e vento de tornados) não é necessário que a estrutura tenha os mesmos níveis de segurança para as diferentes ações. Para situações de projeto diferentes é aceitável obter-se níveis de confiabilidade distintos, apropriados à cada situação, maximizando benefícios e minimizando o custo esperado total, mantendo os níveis de segurança desejados.

Observa-se também que quanto mais grave a conseqüência de falha, mais reforçada deve ser a estrutura (maior $\circ \lambda_{k}$ ), para se ter o custo esperado total otimizado (Figura $6.22 \mathrm{e}$ Figura 6.23). Além de variar com a conseqüência da falha, o $\lambda_{k}$ também varia com a vida útil para a qual a estrutura é projetada. No gráfico da Figura 6.21 mostra-se a sensibilidade do $\lambda_{k}$ com a vida útil e com a conseqüência de falha, para o caso da torre submetida a ventos de tornado. Quanto mais grave é a conseqüência de falha, mais acentuado é o aumento no $\lambda_{k}$. Também se percebe a obtenção de vários $\lambda_{k}$ ótimos abaixo de 1,0 . Isso se deve ao fato do projeto de referência utilizado nessa análise já ser um projeto de norma, com vários coeficientes de segurança nele imbutidos. 


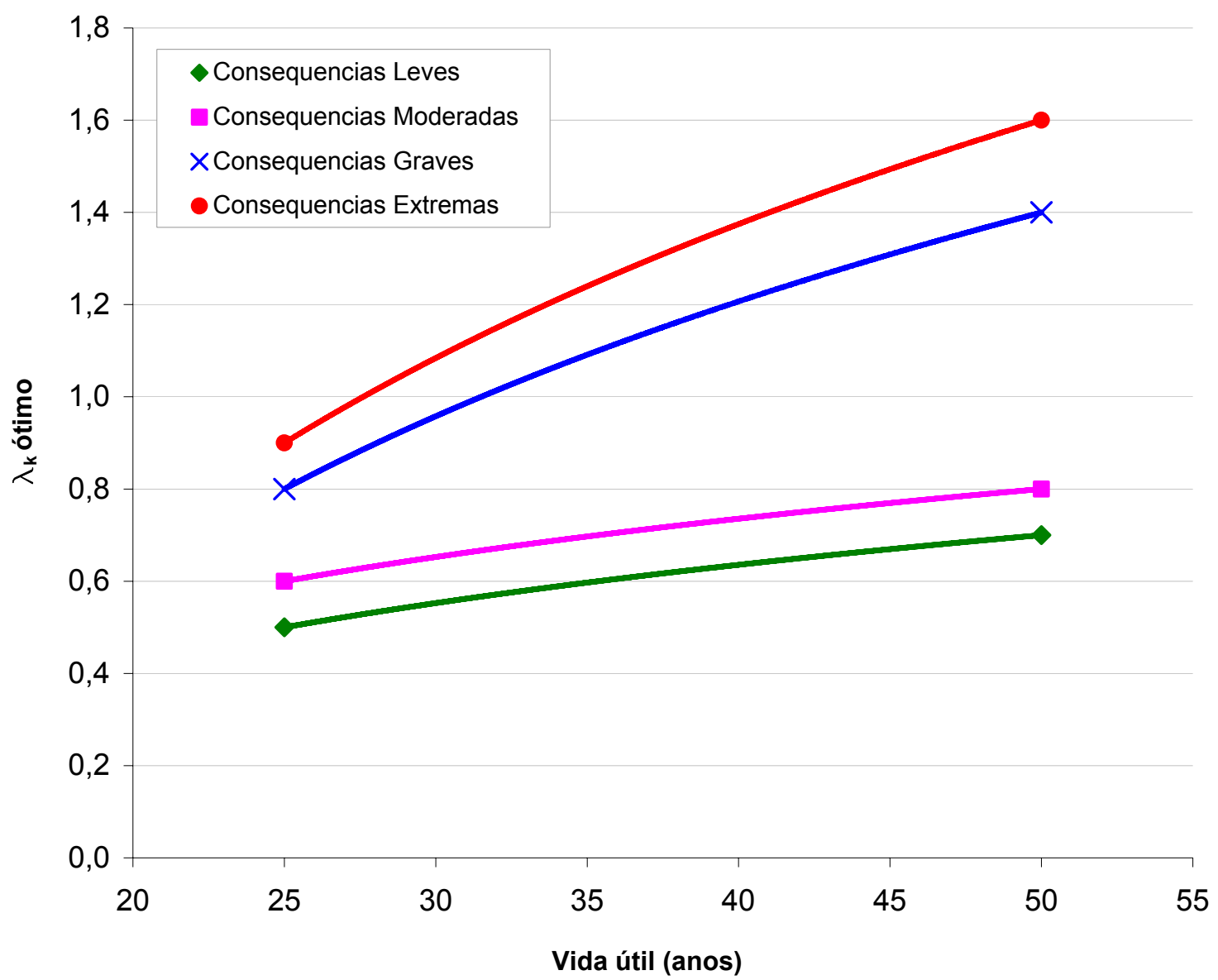

Figura 6.21: Sensibilidade do $\lambda_{k}$ com a vida útil e a conseqüência de falha para o caso da torre submetida a ventos de tornado 


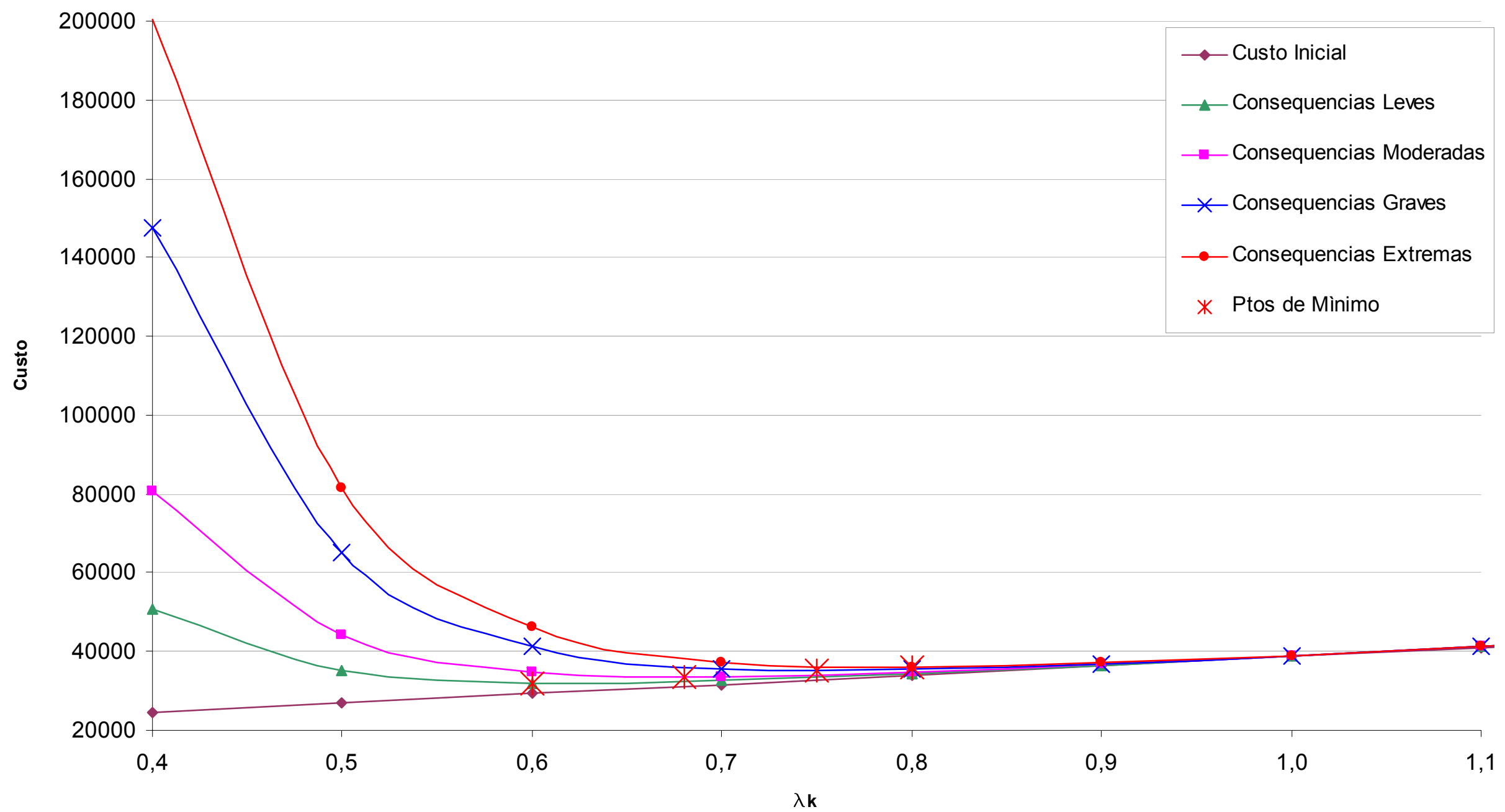

Figura 6.22: Gráfico custo $\mathrm{x} \lambda_{\mathrm{k}}$ para a estrutura submetida ao vento de 50 anos 


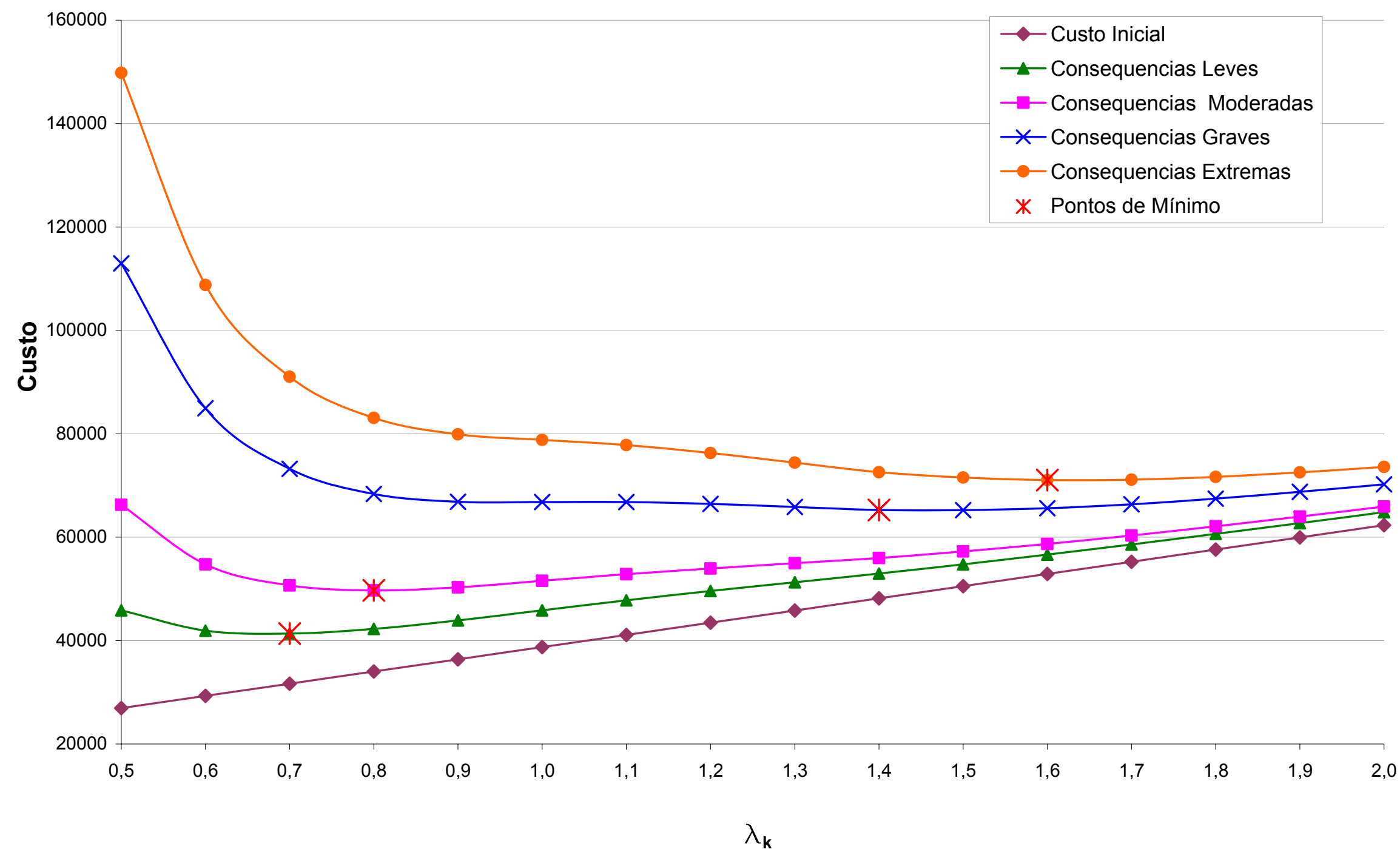

Figura 6.23: Gráfico custo $\mathrm{x} \lambda_{\mathrm{k}}$ para estrutura submetida ao vento de tornado 


\section{Capítulo 7: CONCLUSÕES}

O trabalho de investigação realizado permite a elaboração de algumas conclusões. A primeira delas é a de que o desempenho econômico de um sistema estrutural depende diretamente das conseqüências e custos de falhas. Quanto maiores as conseqüências (custos) de falhas estruturais, maior deve ser coeficiente de segurança adotado. A minimização do custo esperado total da vida útil da estrutura (incluindo lucro, custos de manutenção, depreciação, etc.) é uma abordagem viável para se estabelecer níveis de desempenho e de confiabilidade ótimos.

Pode-se notar nos gráficos do custo esperado total obtidos para os exemplos resolvidos que, antes do ponto ótimo a curva é acentuada e após o ponto ótimo ela sobe suavemente. As curvas de custo esperado total apresentadas têm aproximadamente a mesma configuração, pois, para todos os exemplos analisados, o custo estrutural inicial contribui apenas com uma pequena parcela do custo esperado total. Essa é uma característica de estruturas como edifícios comerciais e residenciais. A partir dessa forma da curva, conclui-se que se o projetista atuar conservadoramente e adotar um coeficiente de segurança maior que o ótimo, não haverá grande diferença no custo esperado total, e, logo, não haverá grande perda econômica. Essa situação está de acordo com a prática observada para estruturas não otimizadas. No entanto, qualquer erro no projeto que provoque um índice de confiabilidade para a estrutura menor que aquele do ponto ótimo pode vir a causar graves prejuízos dada a falha da estrutura. Supõe-se que nas estruturas para as quais o custo estrutural inicial tem grande contribuição (e.g., barragens), a curva de custos teria uma configuração diferente, sendo o aumento no custo esperado total após o ponto ótimo bem mais acentuado e, nesse caso, uma análise da otimização de risco é altamente recomendável. 
As normas técnicas de projeto, ao avaliarem as estruturas de maneira generalizada, muitas vezes são conservadoras quanto a estruturas com conseqüências leves e moderadas de falha, mas podem vir a fornecer coeficientes de segurança insuficientes para estruturas com graves conseqüências de falha. Isto ficou claro no exemplo da torre. Este fato mostra a importância de uma análise econômica de risco para determinar os índices de confiabilidade ótimos. Este tipo de análise pode ser utilizado para definir índices de confiabilidade alvo a ser utilizados na calibração dos coeficientes de segurança parciais das normas técnicas, desde que as mesmas contemplem provisões distintas para diferentes conseqüências de falha.

Ao se projetar uma estrutura submetida a diferentes ações (e.g., vento de 50 anos e vento de tornados) não é necessário que a estrutura tenha os mesmos níveis de segurança para as diferentes ações. Casualidades que possuem grande incerteza e grandes conseqüências de falha tendem a dominar o projeto. Para situações de projeto diferentes é aceitável obter-se níveis de confiabilidade distintos, apropriados à cada situação, maximizando benefícios e minimizando o custo esperado total, mantendo os níveis de segurança desejados.

Percebe-se também que as curvas ótimas de uma estrutura podem ser diferentes para as diversas partes interessadas. No exemplo 6.6, da torre de telefonia, para a empresa fabricante da torre as conseqüências de falha são mais leves, pois ela só tem que arcar com os custos de reposição da estrutura caso essa venha a falhar antes do período de garantia. Já a empresa de telefonia que compra a torre pode ter grandes despesas caso a torre atinja o colapso, como pagamento de multas contratuais devido à interrupção na transmissão de sinal, custos com eventuais processos e indenizações, custo de retirada dos entulhos, entre outros. Neste caso, o coeficiente de segurança ótimo para a empresa fabricante da torre é diferente do da empresa de telefonia que opera a torre. Entendemos que esta situação decorre de uma falta de percepção do risco pelas partes envolvidas, o que leva a contratos inadequados. Neste exemplo, o coeficiente de segurança a ser utilizado no projeto da torre 
deveria ser especificado pela operadora de telefonia, com base na análise de risco, de maneira a minimizar os custos esperados totais.

Também se constatou que conforme aumenta a vida útil (ciclo de vida) da estrutura, aumenta o coeficiente de segurança ótimo, o que é bastante lógico. No entanto, um aspecto importante a se observar, é que esse aumento no coeficiente de segurança é suave quando as conseqüências de falha são leves, mas é muito acentuado quando as conseqüências são graves ou extremas. Uma estrutura com vida útil de 50 anos e conseqüências leves de falha pode vir a ter um nível de confiabilidade ótimo menor do que uma estrutura com vida útil de 20 anos mas cujas conseqüências de falha são catastróficas. Pode-se perceber com isso que diferentes situações exigem projetos individualizados.

As probabilidades de falha calculadas neste trabalho são probabilidades nominais. Como os valores de $\beta$ e $\lambda_{k}$ ótimos encontrados dependem diretamente destas probabilidades, resulta que os projetos ótimos aqui encontrados também não são absolutos. Estas probabilidades de falha, e portanto os projetos ótimos aqui encontrados, dependem de inúmeros fatores não considerados no escopo deste trabalho, como por exemplo as incertezas de modelo. Incertezas de modelo reconhecidamente afetam as probabilidades de falha nominais calculadas (KAMINSKI JR., 2007), e devem ser consideradas em trabalhos futuros.

\subsection{Sugestões para trabalhos futuros}

Este é um primeiro trabalho sobre a otimização de risco baseada em confiabilidade desenvolvido no Departamento de Estruturas da EESC/USP e existem vários itens que não puderam ser abordados. Sugere-se, neste tópico, alguns estudos que podem ser fundamentais para a consolidação desta nova linha de pesquisa.

Como visto em alguns dos exemplos resolvidos no Capítulo 6, o programa desenvolvido proporciona a otimização com relação a apenas uma variável de projeto, o que muitas vezes 
limita a resolução dos problemas. Em trabalhos futuros poderá ser realizada a expansão do programa, tornando-o apto a realizar a otimização de uma função objetivo com mais de uma variável de projeto. Sendo assim, podem ser realizados:

$\checkmark$ Inclusão, no programa RiskOPT, de outros algoritmos de otimização, principalmente com a capacidade de otimizar funções com mais de uma variável de projeto (e.g., método de Newton, dos Gradientes e/ou dos Gradientes Conjugados);

$\checkmark$ Estudo do comportamento do coeficiente de segurança ótimo para estruturas que possuem grande custo estrutural inicial como barragens, por exemplo;

$\checkmark$ Estudos direcionados para avaliação dos índices de confiabilidade alvo utilizados na calibração dos coeficientes de segurança parciais nas normas técnicas.

$\checkmark$ Análise de sensibilidade dos $\beta$ e $\lambda_{k}$ ótimos encontrados em função das probabilidades de falha nominais calculadas. 


\section{REFERÊNCIAS}

AGÊNCIA ESTADO (2005). Tornado de Indaiatuba foi dos mais fortes no país. Último Segundo, 28.mai. Disponível em: http://ultimosegundo.ig.com.br/materias/brasil/19900011990500/1990239/1990239_1.xml

AKIN, E. (2003). Object-Oriented Programming via Fortran 90/95. New York: Cambridge University Press.

ANG, A. H. S.; MA, H. F. (1981). On the reliability of structural systems. In: International Conference on Structural Safety and Reliability (ICOSSAR), $3^{\text {rd }}$., 1981, Trondheim, Norway. Proceedings... Amsterdam: Elsevier Science, p. 295-314.

ANG, A. H-S; TANG, W. H. (1984). Probability Concepts in Engineering Planning and Design. Vol. 2 - Decision, Risk, and Reliability. New York: John Wiley \& Sons.

ANG, A. H-S; TANG, W. H. (2007). Probability Concepts in Engineering: Emphasis on Applications to Civil and Environmental Engineering. $2^{\text {nd }}$ Edition. John Wiley \& Sons.

ANTONIO, M. A.; ANTONIO, C. A. A.; FIGUEIREDO, J. C. (2005). Tornados do Outono de 2004 no Interior Paulista. In: Simpósio Brasileiro de Sensoriamento Remoto, 12., 2005, Goiânia. Anais... São José dos Campos: INPE, p. 2819-2826. Disponível em: http://marte.dpi.inpe.br/col/lid.inpe.br/sbsr/2004/11.19.13.31.09/doc/2819.pdf. Acesso em: 17.out.2007

AOKI, N. (2006). Segurança e confiabilidade de fundações profundas. Engenharia Estudo e Pesquisa, Editora Interciência, v.8, n.2, p.98 -106, jul/05-dez/06.

ASSAN, A. E. (2003). Método dos Elementos Finitos: Primeiros Passos, 2a . Ed. Campinas, SP: Editora da Unicamp;

ASSOCIAÇÃO BRASILEIRA DE NORMAS TÉCNICAS (1988). NBR 6123: Forças devidas ao vento em edificações. Rio de Janeiro.

ASSOCIAÇÃO BRASILEIRA DE NORMAS TÉCNICAS (2004). NBR 6118: Projeto de estruturas de concreto: procedimento. Rio de Janeiro.

ASSOCIAÇÃO BRASILEIRA DE NORMAS TÉCNICAS (2004). NBR 6355: Perfis estruturais de aço formados a frio. Rio de Janeiro.

AZEVEDO, C. P. B; DINIZ, S. M. C. (2007). Avaliação da confiabilidade de fundações de torres estaiadas em linhas de transmissão. In: CMNE 2007 - Congress on Numerical Methods in Engineering / XXVIII CILAMCE - Iberian Latin American Congress on Computational Methods in Engineering. Proceedings... Porto.

BECK, A. T. (1999). Um método para análise de confiabilidade para elementos finitos. 194f. Dissertação (Mestrado) - Universidade Federal de Santa Catarina, Florianópolis, 1999.

BECK, A. T. (2006). Curso de Confiabilidade Estrutural: Notas de Aula. São Carlos: EESC-USP. 
BECK, A. T. (2007). StRAnD: Manual do Usuário. São Carlos: EESC-USP

BECK, A. T.; VERZENHASSI, C. C. (2008). Risk optimization of a steel frame communications tower subject to tornado winds. Submetido para publicação em Latin American Journal of Solids and Structures.

BECK, A. T.; VERZENHASSI, C. C. (2008). Reliability based risk optimization. In: INTERNATIONAL CONFERENCE ON ENGINEERING OPTIMIZATION, 2008, Rio de Janeiro. Proceedings...

BECK, A. T.; VERZENHASSI, C. C. (2008). Reliability based risk optimization. In: INTERNATIONAL ASRANet COLLOQUIUM, $4^{\text {th }}$, 2008, Athens. Proceedings...

BEJAMIN, J. R. (1968). Probabilistic structural analysis and design. Journal of the Structural Division, ASCE, v.94, n.ST7, p.1665-1679.

BENJAMIN, J. R.; CORNELL, C. A. (1970). Probability, Statistics and Decision for Civil Engineers. New York: McGraw-Hill.

BUCHER, C. G.; BOURGUND, U. (1990). A fast and efficient response surface approach for structural reliability problems. Structural Safety, v.7, n.1, p.57-66. Jan.

DANESHVARAN, S.; MORDEN, R. E. (2007). Tornado risk analysis in the United States. The Journal of Risk Finance, v.8, n.2, p.97-111. Disponível em: <http://www.emeraldinsight.com>. Acesso em: 20.jul.2007.

DEFESA CIVIL RS (2005), Especial - Tornados são comuns no Brasil. Defesa Civil do Rio Grande do Sul, 26/mai. Disponível em: <http://www.defesacivil.rs.gov.br/meteorologia>. Acesso em: 16.out.2007.

DITLEVSEN, O; MADSEN, H. O. (1996). Structural Reliability Methods. Chichester: John Wiley and Sons.

ELLINGWOOD, B.; GALAMBOS, T. V. (1982). Probability-based criteria for structural design, Structural Safety, v.1, n.1, p. 15-26. Disponível em: <http://nvl.nist.gov/pub/nistpubs/sp958lide/283-288.pdf> Acesso em: 20.out.2007.

ENEVOLDSEN, I.; SORENSEN, J. D. (1993). Reliability-based optimization of series systems of parallel systems. Journal of Structural Engineering, v.119, n.4, p.1069-1084, Abr. Disponivel em: <http://scitation.aip.org/getpdf/servlet/GetPDFServlet?filetype=pdf\&id=JSENDH00011900000 $4001069000001 \&$ idtype=cvips\&prog=normal>. Acesso em: 6.fev.2007.

ENEVOLDSEN, I.; SORENSEN, J. D. (1994). Reliability-based optimization in structural engineering. Structural Safety, v.15, n.3, p.169-196, Set. Disponível em: <http://www.sciencedirect.com>. Acesso em: 6.fev.2007.

FOX, R. L. (1971). Optimization Methods for Engineering Design. Reading, Mass: Addison-Wesley.

FRANGOPOL, D. M. (1985). Structural optimization using reliability concepts. Journal of Structural Engineering, ASCE, v.111, n.11, p.2288-2301, Nov.

FUJITA, T.T. (1971). Proposed characterization of tornadoes and hurricanes by area and intensity. Satellite Mesometeorology Research Program Research Paper Number 91, Department of Geophysical Sciences, University of Chicago. 42pp. 
GERDAU AÇOMINAS (2007). Tabela de bitolas I e H. Disponível em: <http://www.gerdau.com.br/GerdauAcominas/br/produtos/tabeladebitolaspf.asp>. Acesso em: 10.jun.2007.

GOLIGER, A. M.; MILFORD, R. V. (1998). A review of worldwide occurrence of tornadoes. Journal of Wind Engineering and Industrial Aerodynamics, v.74-76, p.111-121, Abr. Disponível em:<http://www.sciencedirect.com>. Acesso em: 20.out.2007.

HASOFER, A. M.; LIND, N. C. (1974). Exact and Invariant Second Moment Code Format. Journal of Engineering Mechanics, v.100, n.1, p.111-121.

HOLMES, J. D. (2001). Wind Loading of Structures. London: Spon Press.

HOSSAIN Q.; MENSING, R.; SAVY, J.; KIMBALL, J. (1999). A probabilistic tornado wind hazard model for the continental United States. In: Joint Meeting of the U.S.-Japan Cooperative Program in Natural Resources Panel on Wind and Seismic Effects, 1999, Tsukuba. Proceedings... p.86-92. Disponível em: <http://sciencelinks.jp>. Acesso em: 20.jul. 2007

JCSS - Joint Committee on Structural Safety (2001). Probabilistic Model Code. Disponível em: http://www.jcss.ethz.ch/. Acesso em: 05.out.2006).

KAMINSKI JR., JOÃO (2007). Incertezas de modelo na análise de torres metálicas treliçadas de linhas de transmissão. 279f. Tese (Doutorado) - Escola de Engenharia da Universidade Federal do Rio Grande do Sul, Porto Alegre, RS, 2007.

KIM, S. H.; WEN, Y. K. (1990). Optimization of structures under stochastic loads. Structural Safety, v.7, p.177-190. Disponível em: <http://www.sciencedirect.com>. Acesso em: 13.dez.2006.

KRISHNAMOORTHY, K. (2006). Handbook of statistical distributions with applications. Boca Raton: Chapman \& Hall/CRC.

LIN, K-Y.; FRANGOPOL, D. M. (1996). Reliability-based optimum design of reinforced concrete girders. Structural Safety, v.18, n.2/3, p.239-258, Set. Disponível em: $<$ http://www.sciencedirect.com>. Acesso em: 5.fev.2007.

LIU, P-L.; KIUREGHIAN, A. D. (1991). Optimization algorithms for structural reliability. Structural Safety, v.9, n.3, p.161-177, Fev. Disponível em: <http://www.sciencedirect.com>. Acesso em: 6.fev.2007.

LIU, Y. W.; MOSES, F. (1992). Truss optimization including reserve and residual reliability constraints. Computers \& Structures, v.42, n.3, p.355-363, Fev. Disponível em: < http://www.sciencedirect.com >. Acesso em: 6.fev.2007.

LUENBERGER, D. (1984). Linear and Nonlinear Programming. $2^{\text {nd }}$. Ed., Reading: Addison-Wesley.

MARCELINO, I. P. V. O. (2004). Análise de episódios de tornado em Santa Catarina: caracterização sinótica e mineração de dados. 224f. Dissertação (Mestrado) - Instituto Nacional de Pesquisas Espaciais, São José dos Campos, 2004.

MAU, S.; SEXSMITH, R. G. (1972). Minimum expected cost optimization. Journal of the Structural Division, ASCE, v.98, n.ST9, p.2043-2058.

McCRACKEN, D. D. (1967). FORTRAN with Engineering Applications. New York: Wiley. 
MELCHERS, R. E. (1999). Structural Reliability Analysis and Prediction. 2nd. Ed., Wiley.

MEYER, C. L.; BROOKS, H. E.; KAY, M. P. (2002). A hazard model for tornado occurrence in the United States. In: 13th Symposium on Global Change and Climate Variations, 2002, Orlando. Proceedings... Boston: American Meteorological Society. Disponível em: <http://www.nssl.noaa.gov/users/brooks/public_html/papers/meyeretal.pdf>. Acesso em: 20.jul.2007

MONTGOMERY, D. C.; RUGER, G. C. (1999). Estatística aplicada e probabilidade para engenheiros. Tradução de Verônica Calado. 2.ed. Rio de Janeiro: LTC.

MOSES, F. (1977) Structural system reliability and optimization. Computers \& Structures, v.7, n.2, p.283-290, Abr. Disponível em: < http://www.sciencedirect.com>. Acesso em: 6.fev.2007.

MOSES, F. (1982). System reliability developments in structural engineering. Structural Safety, v.1, n.1, p.3-13, Jan. Disponível em: <http://www.sciencedirect.com>. Acesso em: 27.fev.2007.

MRÁZIK, A; KRIZMA, M. (1997), Probability-based design standards of structures. Structural Safety, v.19, n.2, p.219-234. Disponível em: <http://www.sciencedirect.com>. Acesso em: 31.ago.2007.

NAKIB, B.; FRANGOPOL, D. M. (1990). RBSA e RBSA-OPT: two computer programs for structural system reliability analysis and optimization. Computers \& Structures, v.36, n.1, p.13-27. Disponível em: <http://www.sciencedirect.com>. Acesso em: 5.fev.2007.

NATARAJAN, K.; SANTHAKUMAR, A. R. (1995) Reliability-based optimization of transmission line towers. Computers \& Structures, v.55, n.3, p.387-403, Mai. Disponível em: <http://www.sciencedirect.com>. Acesso em: 6.fev.2007.

NEAL, B. G. (1977). The Plastic Methods of Structural Analysis. 3rd. Ed., London: Chapman and Hall.

NECHET, D. (2002) Ocorrência de tornados no Brasil. Revista Brasileira de Meteorologia, v.26, n.2, Ago.

PEYROT, A. H.; DAGHER, H. J. (1984). Reliability-based design of transmission lines. Journal of Structural Engineering, v.110, n.11, p.2758-2777, Nov.

RACKWITZ, R.; FIESSLER, B. (1978). Structural Reliability Under Combined Load Sequences. Computers \& Structures, v.9, n.5, p.489-494. Nov.

RAVINDRA, M. K.; LIND, N. C. (1973). Theory of structural code optimization. Journal of the Structural Division, ASCE, v.99, n.ST7, p.1541-1553.

RUBINSTEIN, R. Y. (1981). Simulation and the Monte Carlo method. New York: John Wiley \& Sons.

SARMA, K. C.; ADELI, H. (1998). Cost optimization of concrete structures. Journal of Structural Engineering, v.124, n.5, p.570-578, Mai. Disponível em: < http://scitation.aip.org/getpdf/servlet/GetPDFServlet?filetype=pdf\&id=JSENDH000124000005 $000570000001 \&$ idtype=cvips\&prog=normal>. Acesso em: 13.dez.2006.

SARMA, K. C.; ADELI, H. (2000). Cost optimization of steel structures. Engineering Optimization, v.32, n.6, p.777-802. 
SARMA, K. C.; ADELI, H. (2002). Life-cycle cost optimization of steel structures. International Journal for Numerical Methods in Engineering, v.55, n.12, p.1451-1462, Dez.

SAVORY, E. et al. (2001). Modeling of tornado and microburst-induced wind loading and failure of a lattice transmission tower. Engineering Structures, v.23, n.4, p.365-375, Abr. Disponível em: <http://www.sciencedirect.com>. Acesso em: 15.jul.2007.

SCHAEFER, J. T.; KELLY, D. L.; ABBEY, R. F. (1986). A minimum assumption tornadohazard probability model. Journal of Climate and Applied Meteorology, v.25, p.19341945. Disponível em: <http://ams.allenpress.com>. Acesso em: 20.jul.2007.

SILVA DIAS, N. A. F.; GRAMMELSBACHER, E. A. (1991). A possível ocorrência de tornado em São Paulo no dia 26 de abril de 1991: um estudo de caso. Revista Brasileira de Meteorologia, v.6, n.2, p.513-522, 1991.

SOLTANI, M.; COROTIS, R. B. (1988). Failure cost design of structural systems. Structural Safety, v.5, n.4, p.239-252, Dez. Disponível em: <http://www.sciencedirect.com>. Acesso em: 16.nov.2006.

SORIANO, H. L. (2003). Método de Elementos Finitos em Análise de Estruturas. São Paulo: Editora da Universidade de São Paulo.

SRIVIDYA, A.; RANGANATHAN, R. (1995) Reliability based optimal design of reinforced concrete frames. Computers \& Structures, v.57, n.4, p.651-661, Nov. Disponível em: <http://www.sciencedirect.com>. Acesso em: 5.fev.2007.

SURAHMAN, A.; ROJIANI, K. B. (1983). Reliability based optimum design of concrete frames. Journal of Structural Engineering, ASCE, v.109, n.3, p.741-757, Mar.

THOFT-CHRISTENSEN, P.; MUROTSU, Y. (1986). Application of Structural Systems Reliability Theory. Berlin: Springer-Verlag.

VANDERPLAATS, G. N. (1984). Numerical Optimization Techniques for Engineering Design: With Applications. New York: McGraw-Hill.

VANMARCKE, E. H. (1971). Matrix formulation of reliability analysis and reliability-based design. Computers \& Structures, v.3, n.4, p.757-770, Jul. Disponível em: <http://www.sciencedirect.com>. Acesso em: 8.fev.2007.

VESILIND, P. J. (2004) Chasing Tornadoes. National Geographic, p. 2-37, Abr. Disponível em: http://magma.nationalgeographic.com/ngm/0404/feature1/index.html. Acesso em: 15.out.2007.

WEN, Y. K. (2001), Reliability and performance-based design. Structural Safety, v.23, n.4, p.407-428, Out. Disponível em: <http://www.sciencedirect.com>. Acesso em: 15.jul.2007. 


\section{Apêndice A: RiskOPT - MANUAL DE UTILIZAÇÃO}

\section{A.1 Estrutura do programa}

Para completo esclarecimento do programa de otimização de risco estrutural desenvolvido neste trabalho e já descrito no Capítulo 5, descrevem-se no presente apêndice as etapas a serem seguidas para a correta utilização do programa, além de exemplos dos arquivos que devem ser modificados e/ou criados.

O fluxograma da Figura A.1 abaixo mostra a independência entre os 3 módulos de análise (otimização, confiabilidade e mecânico), e como eles se comunicam para realizar a otimização de risco estrutural baseada em confiabilidade.

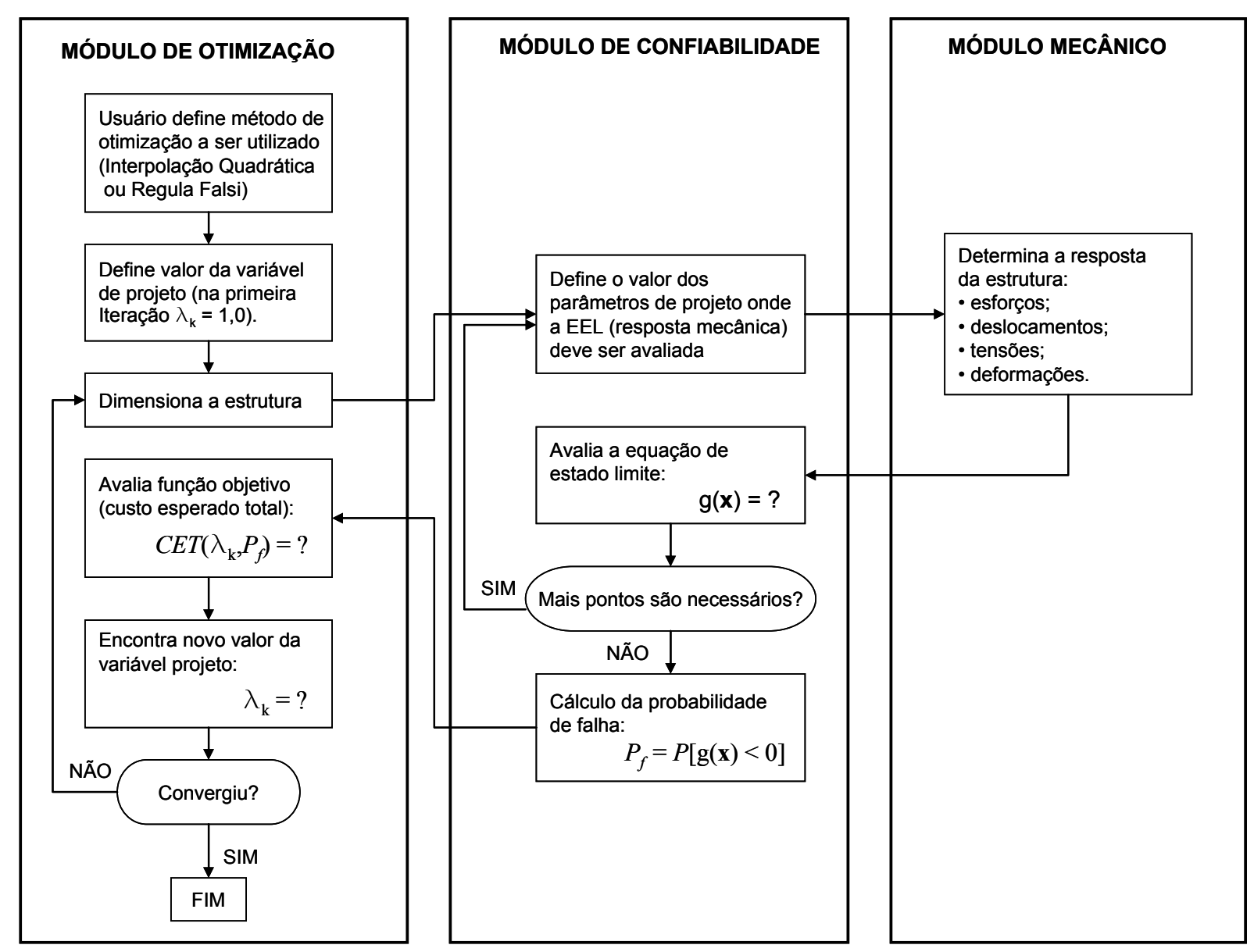

Figura A.1: Interação entre os módulos de otimização, confiabilidade e mecânico 


\section{A.2 Entrada de dados do StRAnD}

Para iniciar a utilização do RiskOPT na otimização de uma estrutura, o usuário deve primeiro editar o arquivo de entrada de dados do problema de confiabilidade a ser resolvido paralelamente com a otimização, pelo programa StRAnD: 0 arquivo de texto STRAND_INPUT.TXT. Conforme o manual do usuário do StRAnD (BECK, 2007):

"A entrada de dados é feita através de arquivo texto, em um formato livre onde os diferentes itens são identificados através de palavras chave. Essas palavras iniciam sempre por um asterisco $\left({ }^{*}\right)$. A linha imediatamente posterior à palavra chave deve conter a informação à que se refere a palavra chave. Nas demais linhas, comentários são inseridos livremente. Em geral, esses comentários se referem à informação fornecida no campo anterior."

A seguir apresenta-se, como exemplo, o arquivo de entrada de dados utilizado no problema 6.5 - Pórtico Plano.

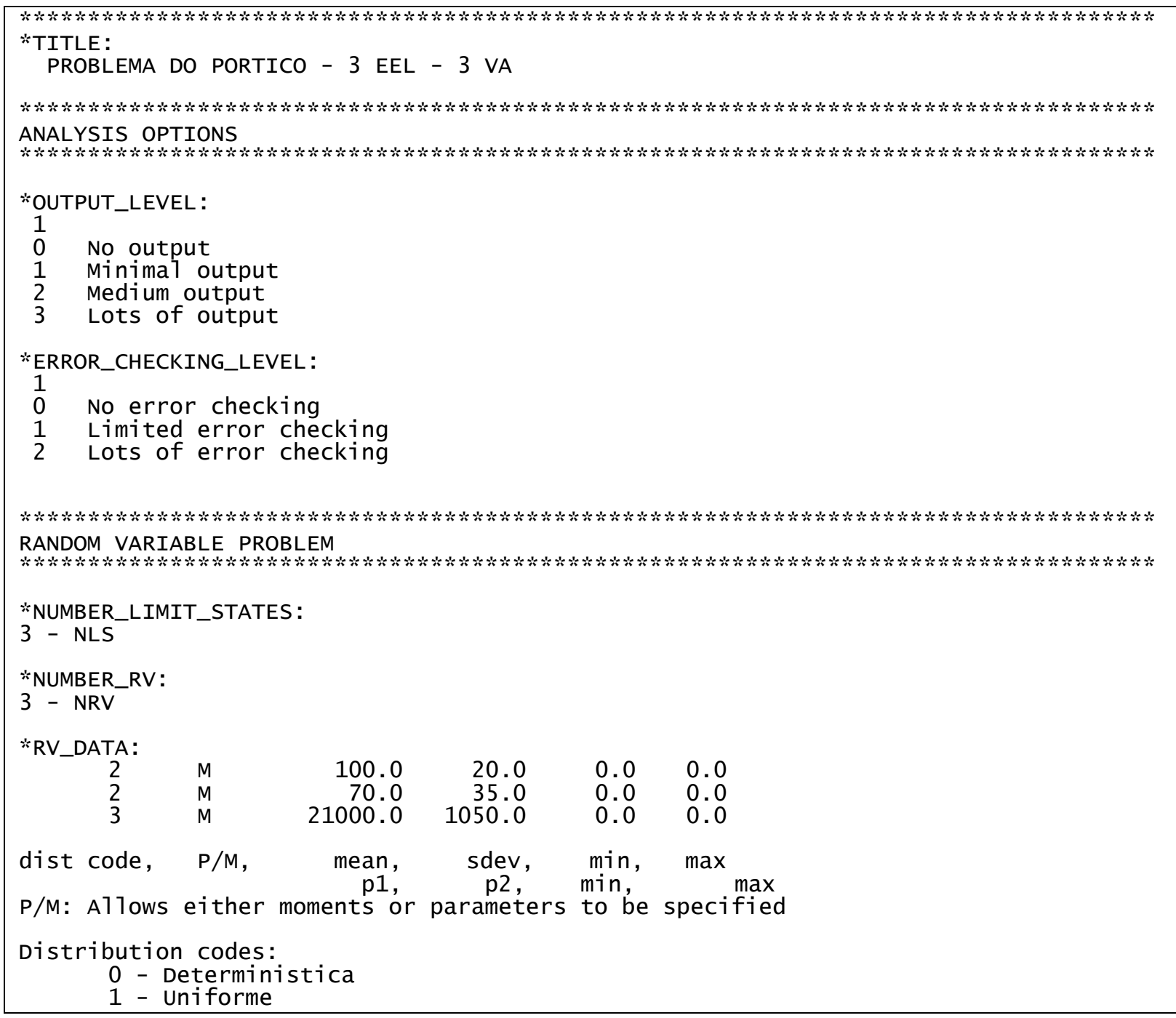




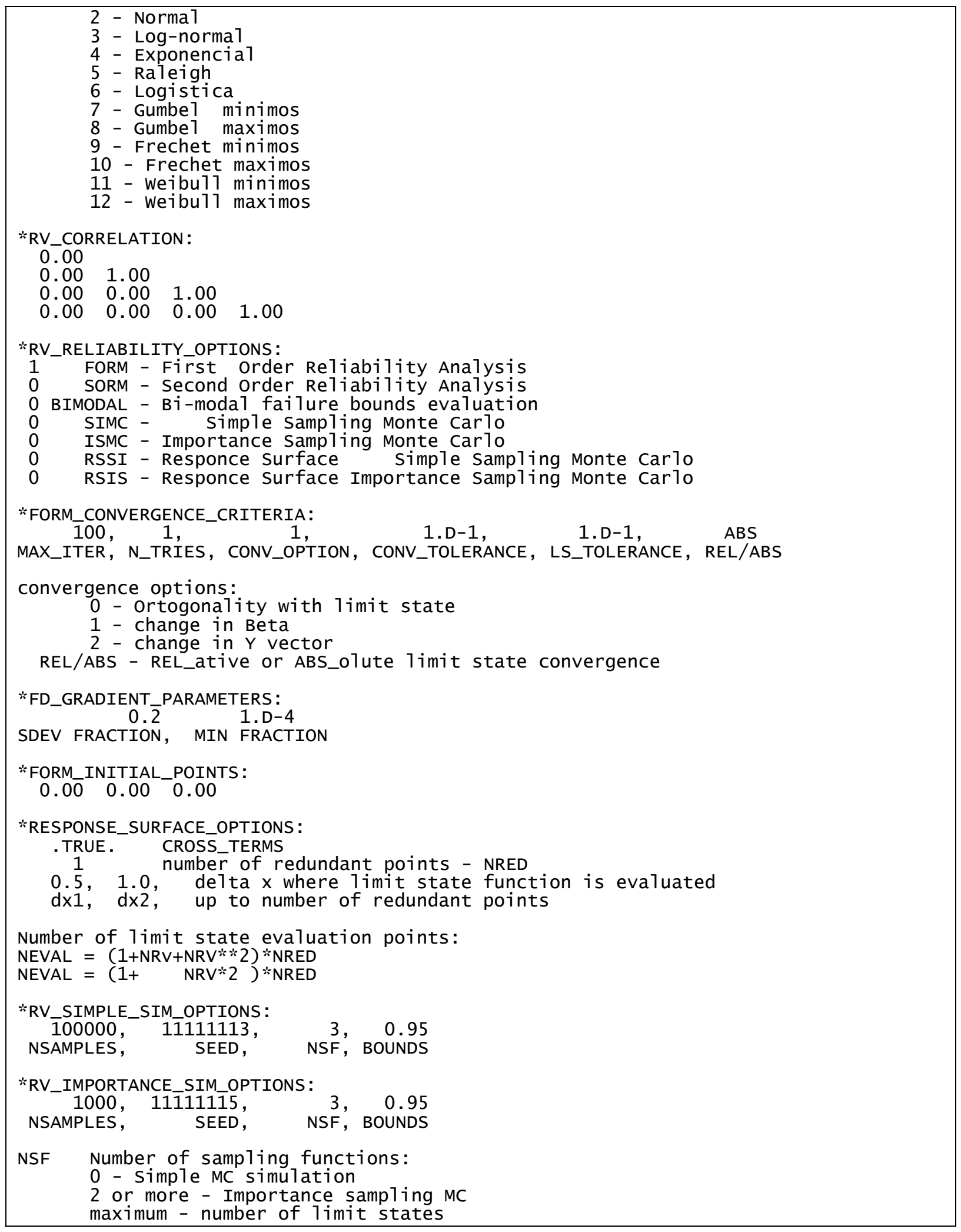




\section{A.3 Equações de Estado Limite}

O próximo passo é a edição das equações de estado limite. A equação de estado limite de determinado problema deve ser programada na rotina Fortran LIMIT_STATE_FUNCTION.F90. Esta rotina deve ser compilada para a criação da versão executável do programa.

Quando a equação de estado limite é analítica, esta é programada diretamente na função LIMIT_STATE_FUNCTION(.). Neste caso, o gradiente da equação também pode ser determinado analiticamente e programado na função gradiente LIMIT_STATE_GRADIENT(.). No entanto, para que o programa StRAnD reconheça que há gradiente analítico disponível, é necessário definir a variável de controle de gradiente como:

LSC\%ANAL_GRAD $=$.TRUE.

Quando a equação de estado limite é determinada pela solução de um modelo mecânico numérico (e.g., elementos finitos), a chamada ao programa que fornece a resposta mecânica deve acontecer dentro da função LIMIT_STATE_FUNCTION(.), através do comando FEMODEL(). Neste caso, o gradiente é avaliado por diferenças finitas. A variável de controle assume seu valor padrão dado por:

LSC\%ANAL_GRAD $=$. FALSE.

A subrotina FEMODEL() devolve os resultados obtidos pelo programa de elementos finitos Ansys num vetor de variáveis chamado ANSYS_RESULT().

Abaixo se apresenta a rotina LIMIT_STATE_FUNCTION.F90 editada para o problema 6.5. Os itens em verde são comentários e, portanto, são linhas que não são executadas pelo programa. Perceba que a função FEMODEL() está comentada pois o problema 6.5 não tem EEL numérica, não sendo necessária a utilização do Ansys. As palavras em azul são palavras reservadas da linguagem de programação Fortran. Para esse problema o gradiente das EEL também foi programado (LSC\%ANAL_GRAD = .TRUE.). 


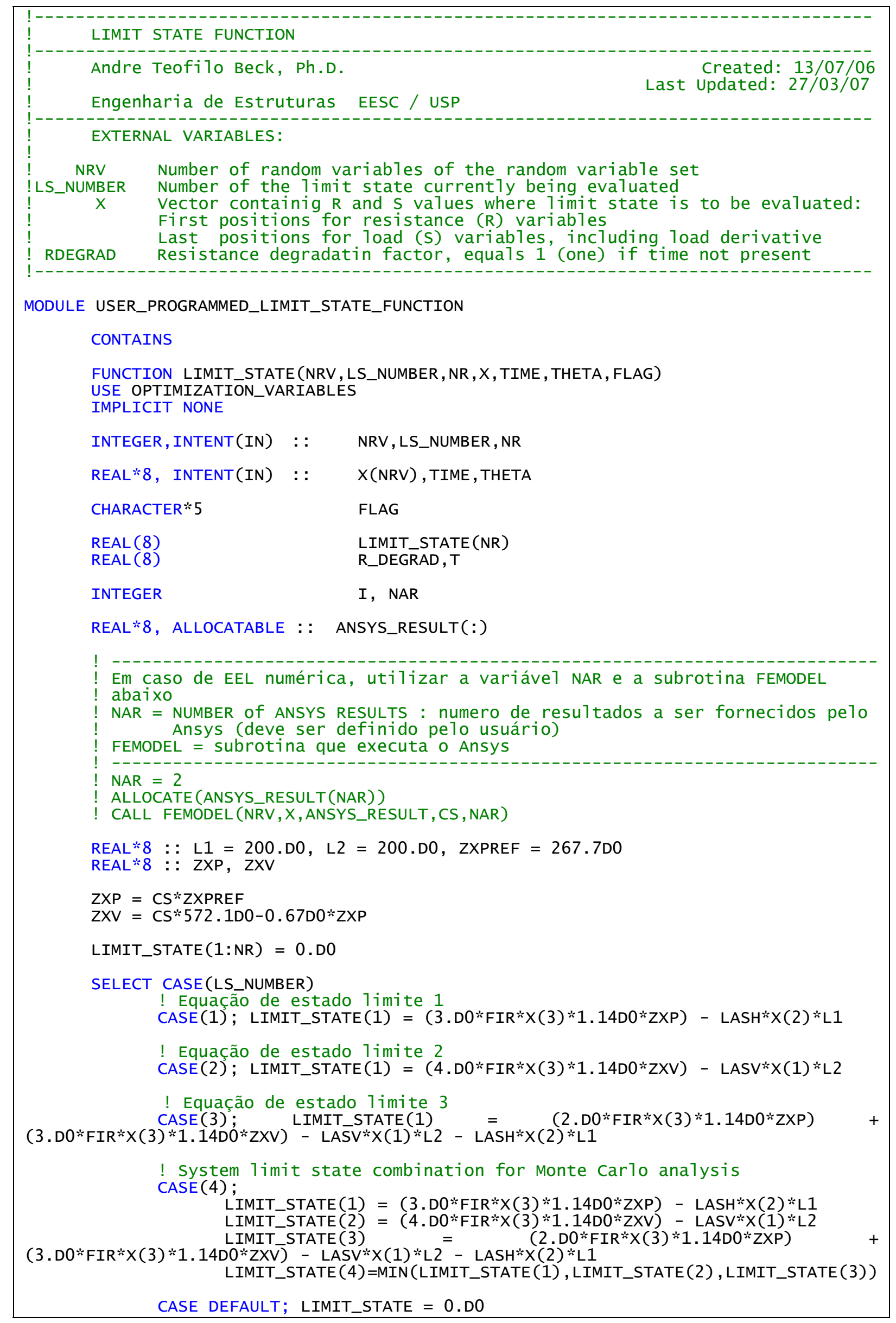




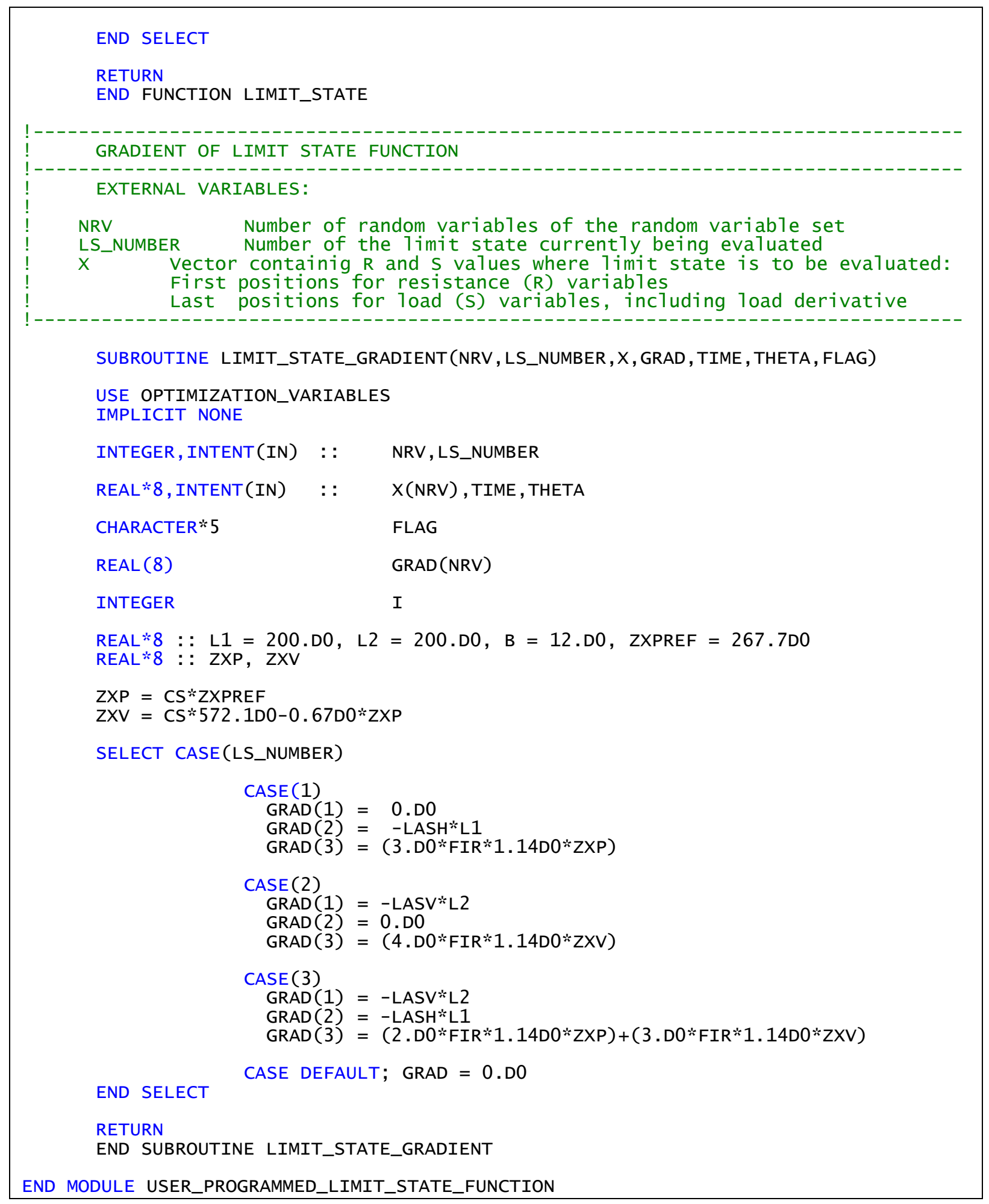

\section{A.4 Funções Custo}

O próximo passo na definição de um problema é a programação das funções custo, que o usuário deve fazer no módulo COST_FUNCTIONS.F90. Segue abaixo tal módulo, definido 
para o problema 6.5. Abaixo do comentário "Variáveis do problema" o usuário pode definir variáveis particulares para o problema em questão, que serão utilizadas para compor as funções custo.

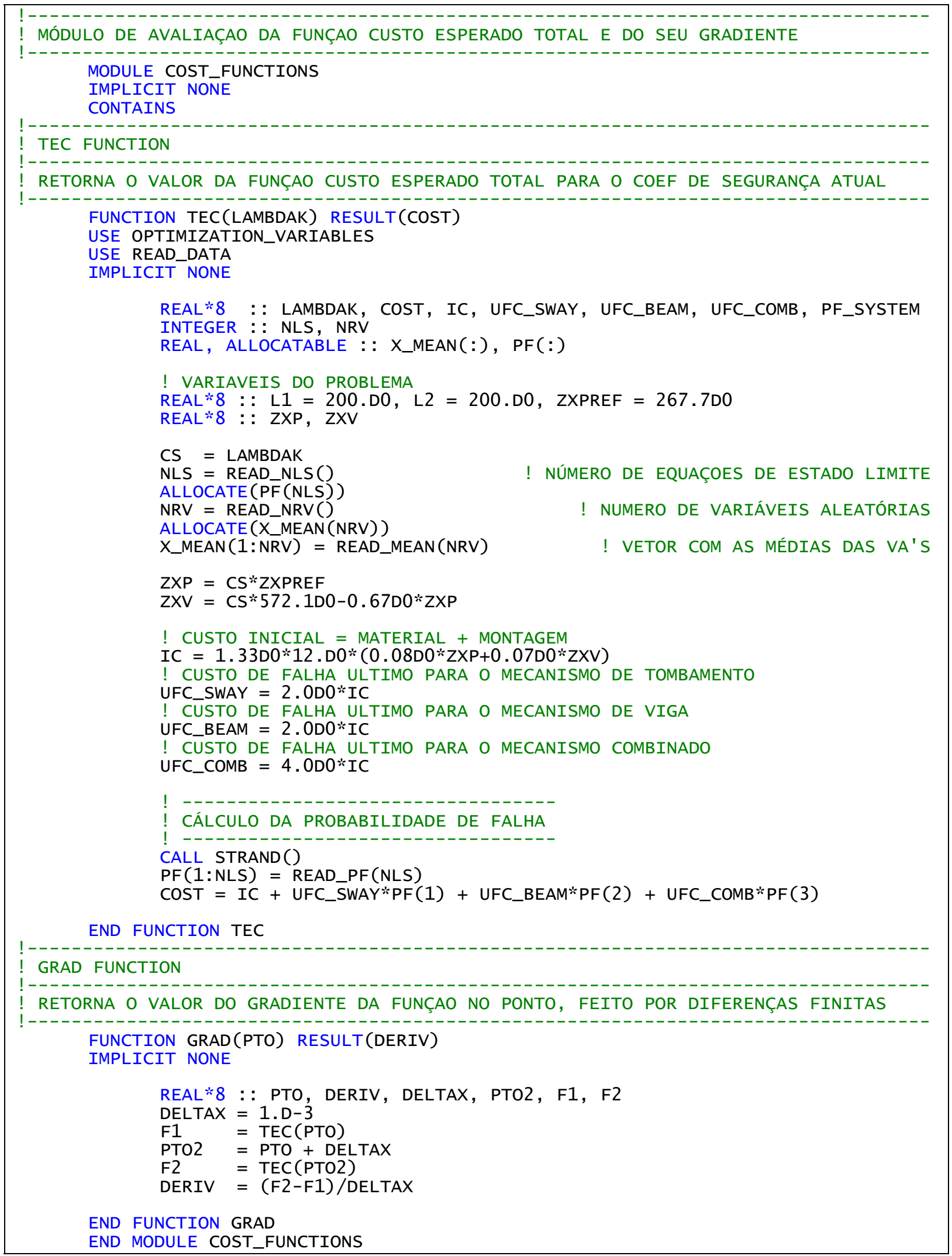




\section{A.5 Utilização do Módulo Mecânico: entrada de dados do Ansys}

Quando o problema possui EEL numéricas faz-se necessária a utilização do Ansys para determinar as respostas da estrutura (e.g., esforços, deslocamentos, tensões, deformações). Para tal, é necessária a criação do modelo mecânico em um arquivo de texto com os comandos do Ansys: o arquivo ANSYS_INPUT.LOG. No fim desse arquivo define-se as variáveis de resposta que devem ser impressas no arquivo de saída de dados do Ansys, o Dados-file.txt.

A seguir apresenta-se o arquivo de entrada de dados do Ansys para o problema 6.6 Torre Tridimensional. Note que no final do arquivo foi criada a variável "UY1", que é o deslocamento do nó 1 na direção $\mathrm{Y}$, impressa no arquivo de saída. As frases iniciadas por um "C" maiúsculo ou as que estão escritas após um ponto de exclamação (!) são comentários, ou seja, são linhas não executadas pelo Ansys que servem apenas como orientação para quem lê o arquivo. Tais comentários estão escritos na cor verde para facilitar sua identificação. Além disso, algumas partes repetitivas do arquivo, como criação de nós e elementos, e inclusão de carregamentos nos nós, foram omitidas nesta transcrição para facilitar a leitura. Tais omissões estão indicadas pela notação “(...)”.

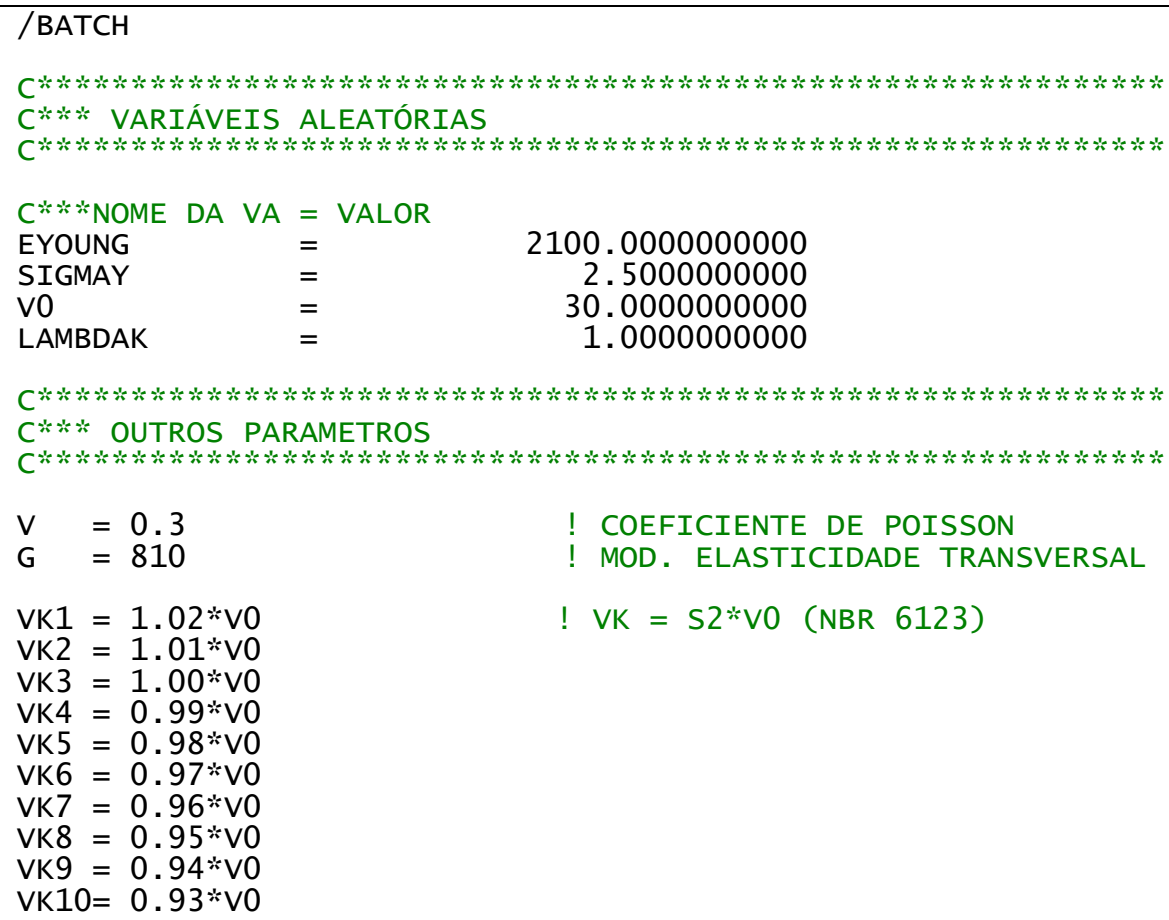




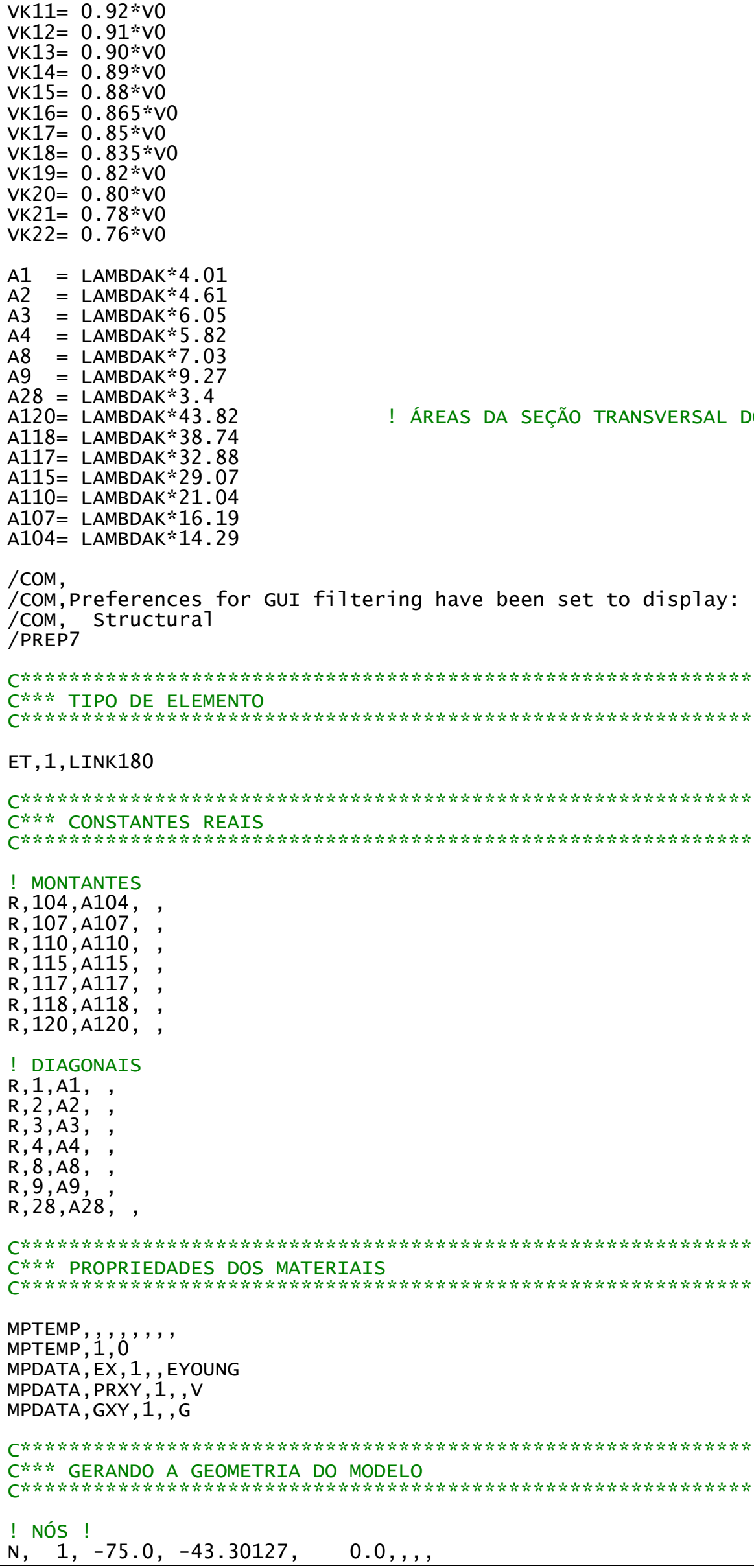




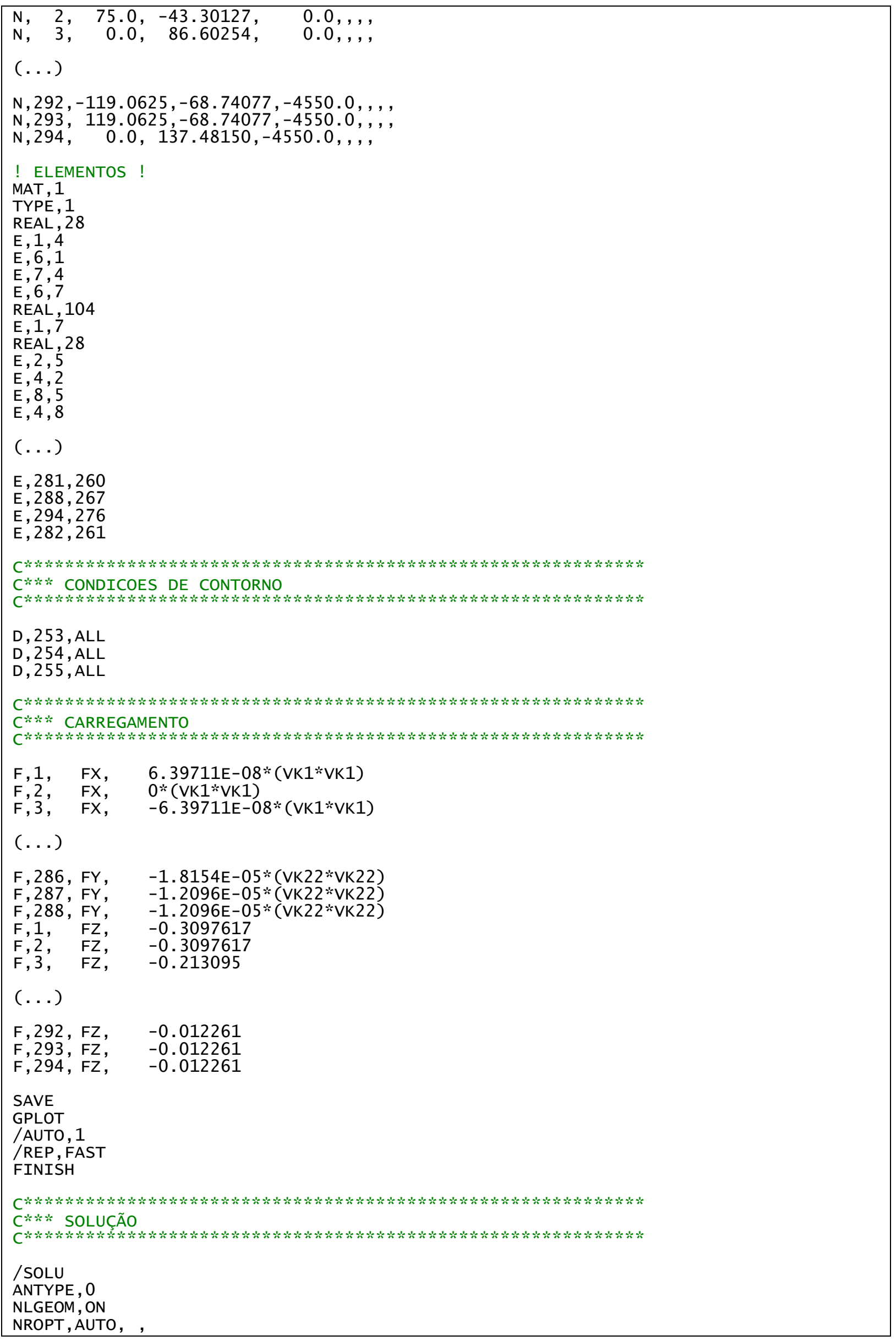




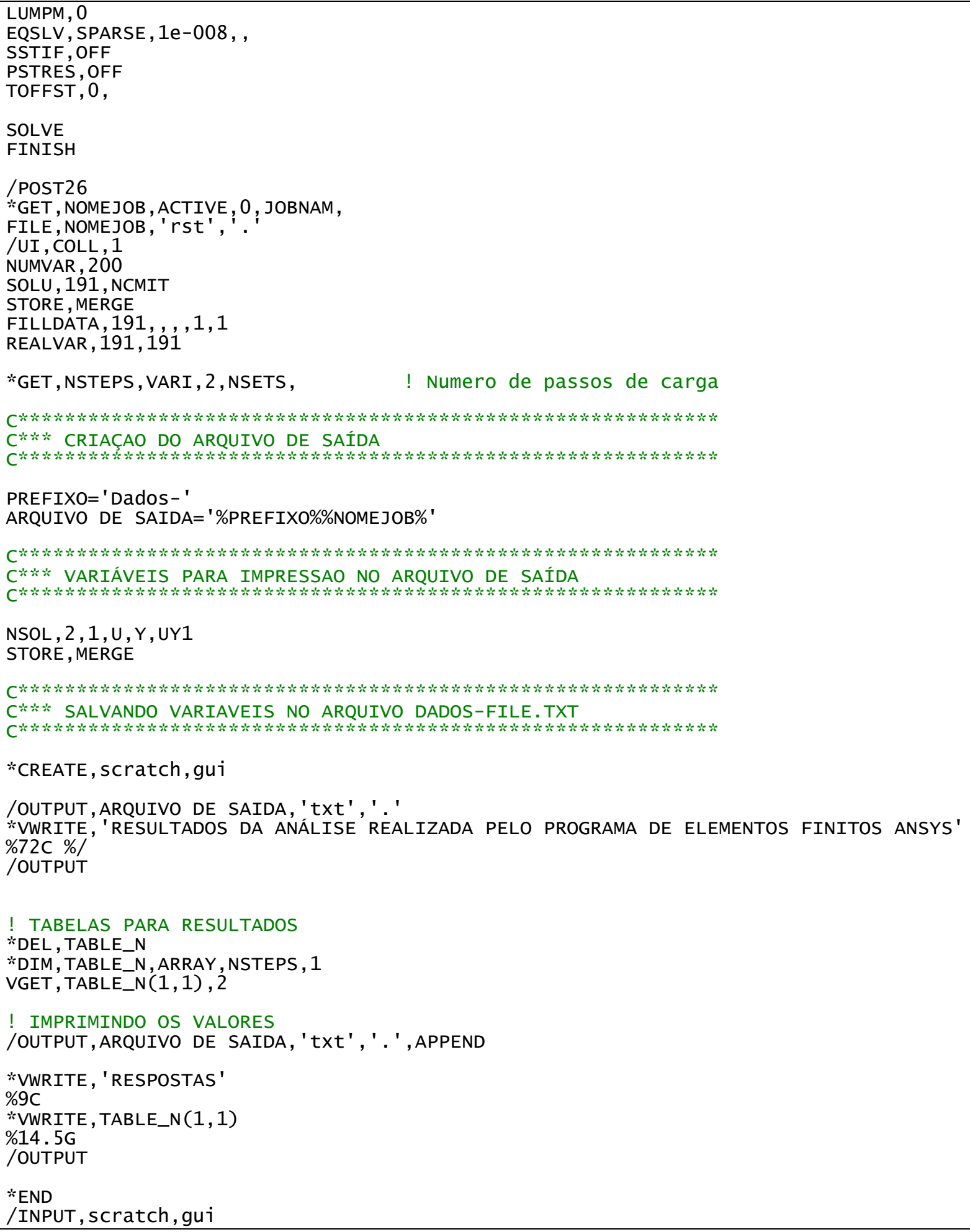

\section{A.6 Saída de dados do StRAnD}

A seguir é apresentado o arquivo de saída de dados do StRAnD, chamado STRAND_OUTPUT.TXT, para o problema 6.5 - Pórtico Plano. Esse arquivo mostra o 
arquivo de saída de execução do StRAnD para o coeficiente de segurança adicional ótimo encontrado pelo RiskOPT ( $\lambda_{k}=1,94$ ), ou seja, os resultados da probabilidade de falha mostrados no arquivo de saída referem-se ao projeto ótimo. O problema foi resolvido utilizando todos os métodos disponíveis no StRAnD: FORM, limites bi-modais, simulação de Monte Carlo simples e por importância, e método das superfície de resposta com simulação de Monte Carlo simples e por importância.

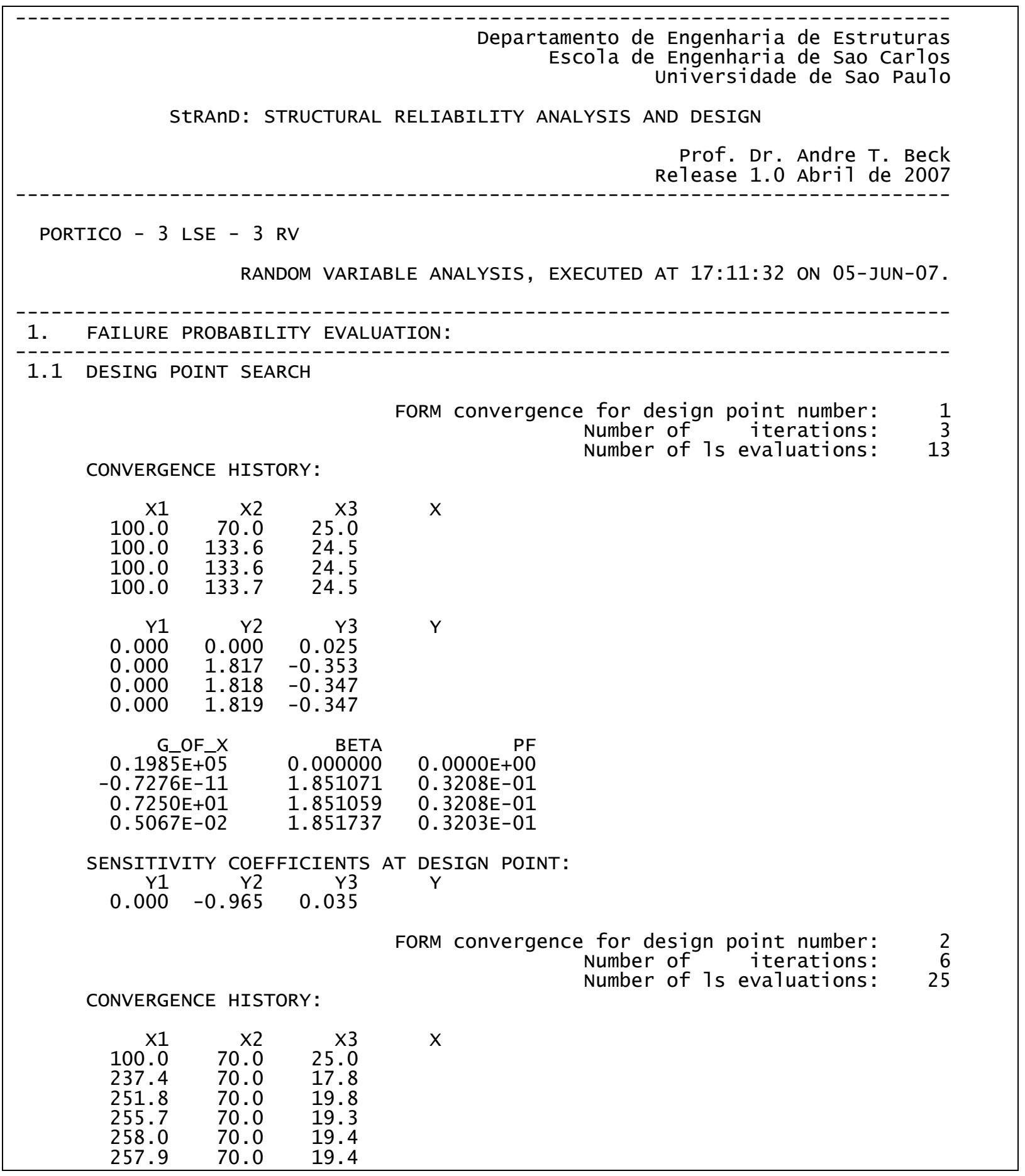




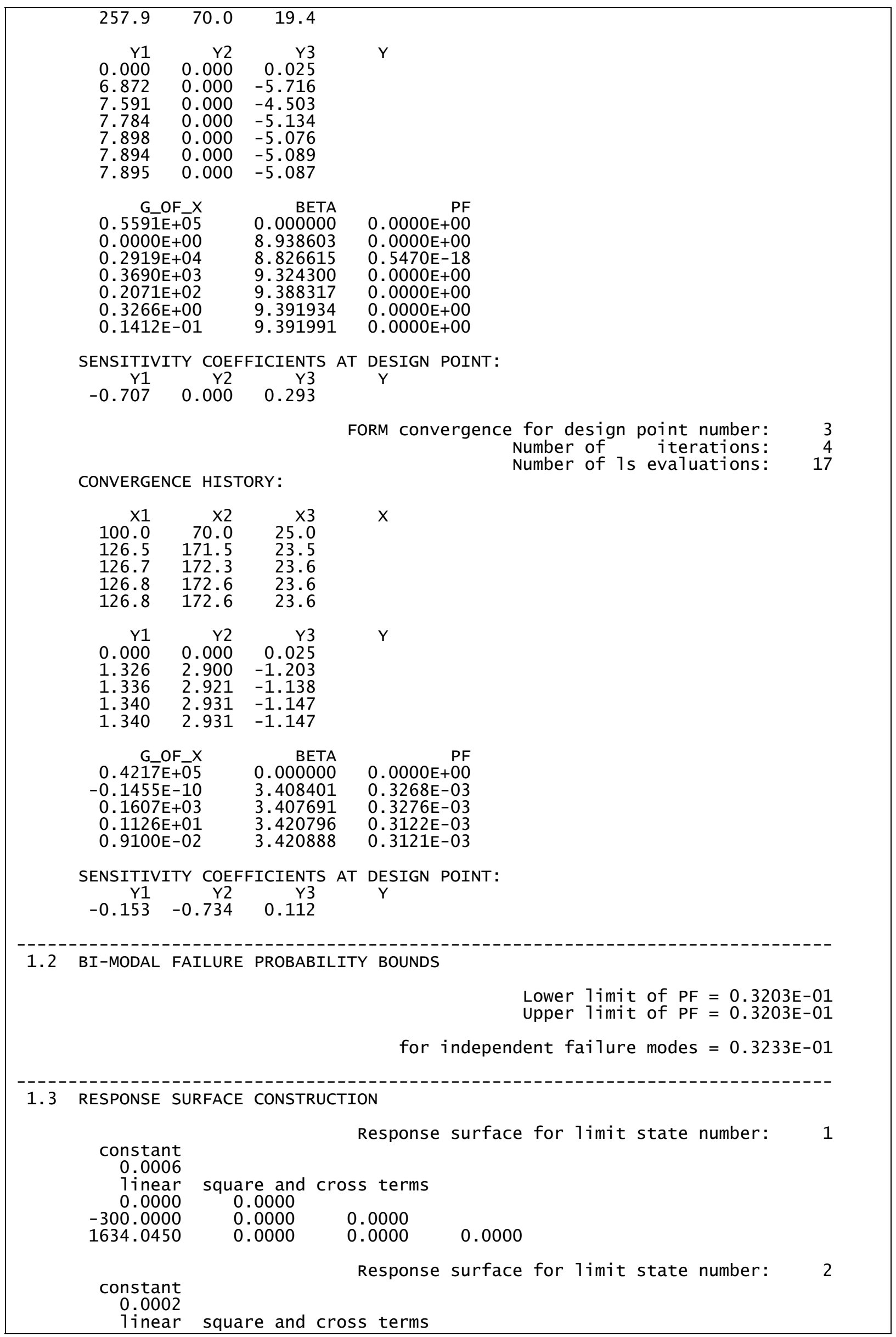




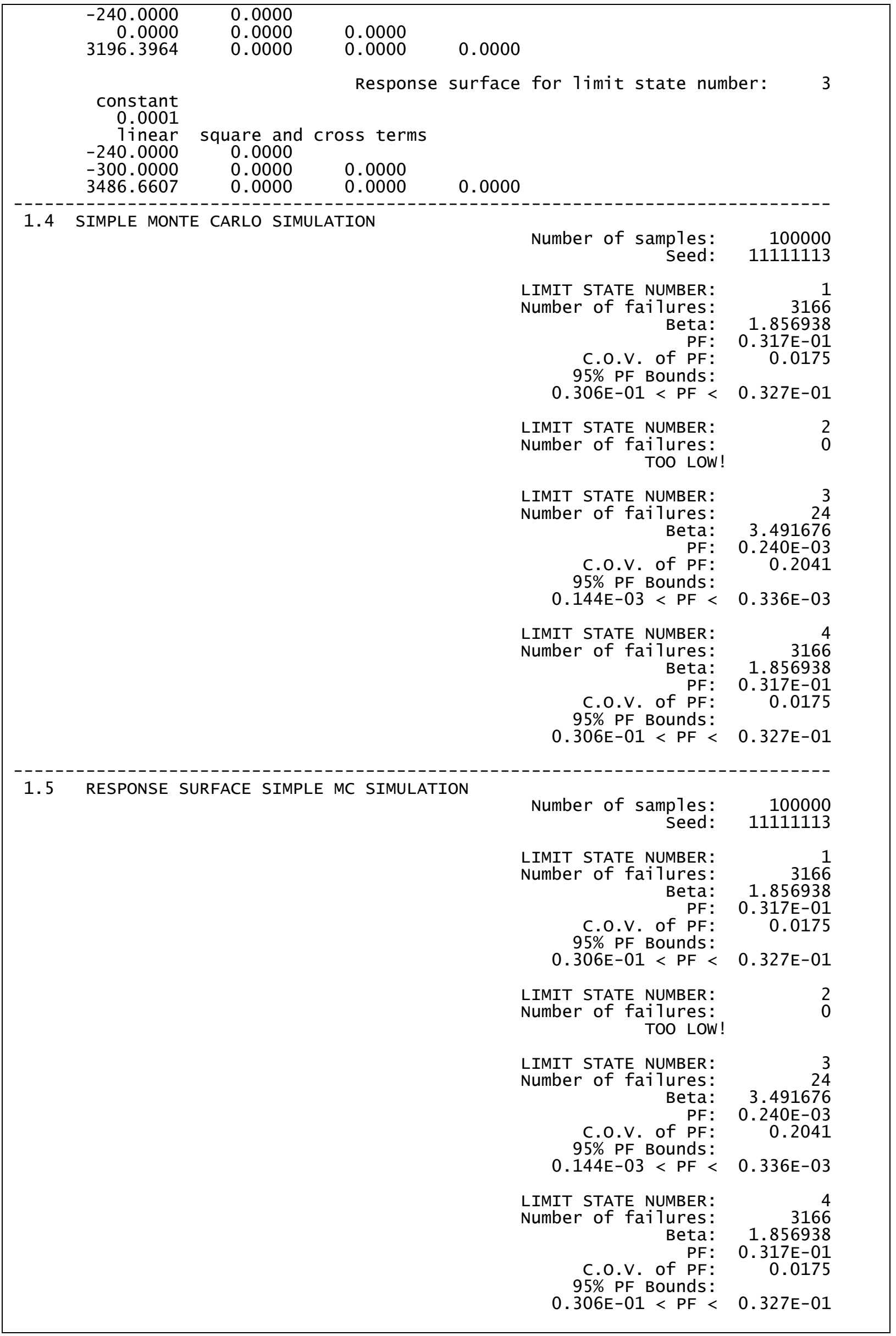




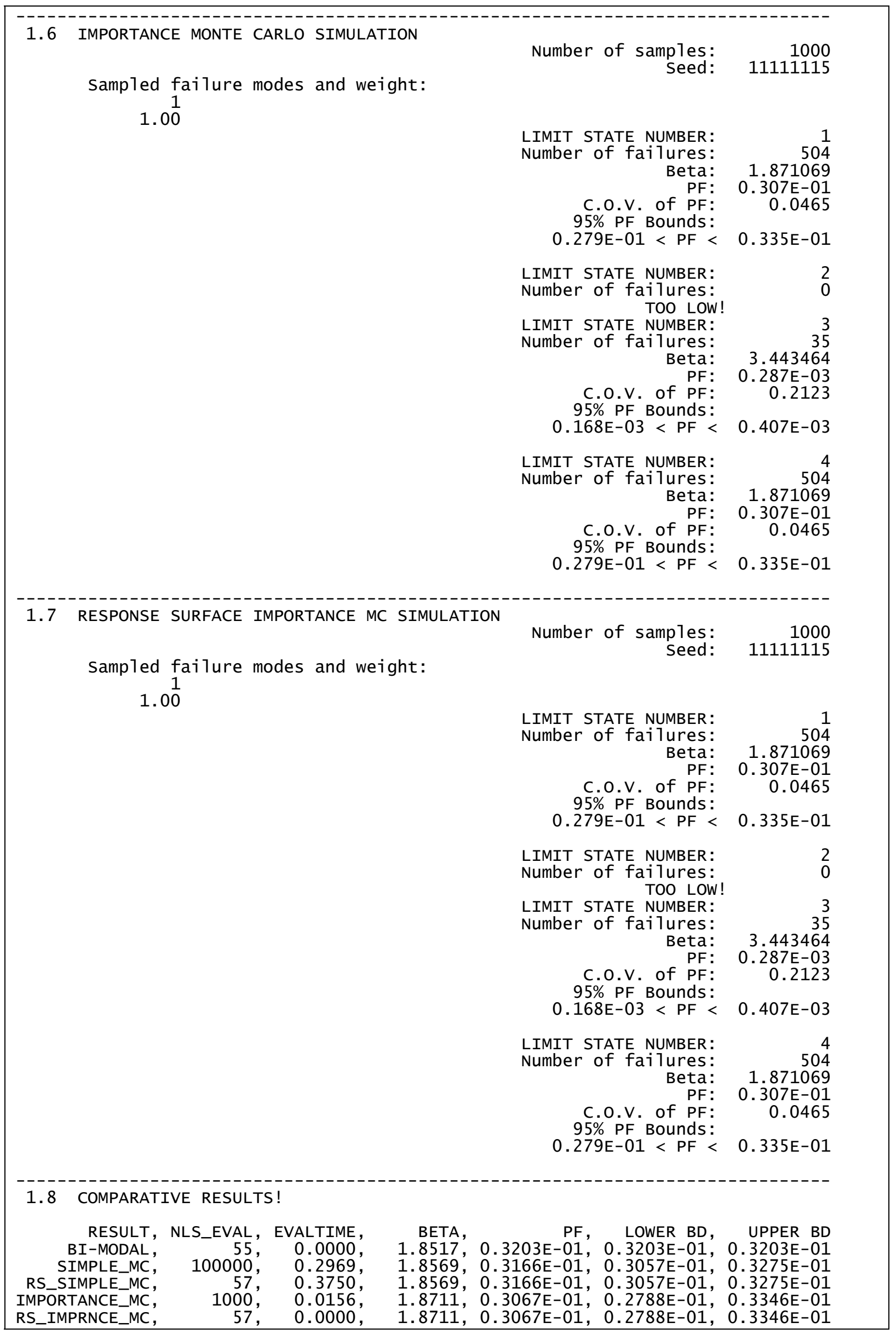




\section{A.7 Saída de dados do RiskOPT}

Apresenta-se aqui o arquivo de saída de dados do módulo de otimização RiskOPT: OPTIMIZATION_OUTPUT.TXT. Trata-se de um arquivo simples, que indica qual o algoritmo de otimização foi utilizado, o número de iterações realizadas, o ponto ótimo encontrado, e o valor da função objetivo no ponto ótimo. Abaixo está transcrito o arquivo de saída do RiskOPT para o problema 6.5 - Pórtico Plano resolvido pelo método de Interpolação Quadrática.

\section{Departamento de Engenharia de Estruturas Escola de Engenharia de Sao Carlos Universidade de Sao Paulo}

PROGRAMA DE OTIMIZAÇÃO DO RISCO ESTRUTURAL

Eng. Camila Cardozo Verzenhassi

MÉTODO UTILIZADO = INTERPOLAÇÃO QUADRÁTICA

NO. ITERAÇOES REALIZADAS = $\begin{array}{rr}\text { CET MINIMO }= & 1710.68\end{array}$ COEF SEG OTIMO $=\quad 1.9400$

\section{A.8 Resumo das etapas de utilização do RiskOPT}

Por fim, faz-se um resumo das etapas a serem seguidas para realizar-se a otimização de risco estrutural baseada em confiabilidade de uma estrutura qualquer:

1) Edição do arquivo de entrada do StRAnD, STRAND_INPUT.TXT;

2) Programação das EEL no arquivo LIMIT_STATE_FUNCTION.F90;

3) Programação das funções custo no arquivo COST_FUNCTIONS.F90;

4) Se houver EEL numérica, criação do modelo mecânico no arquivo de entrada do Ansys, ANSYS_INPUT.LOG. Caso contrário ir direto para a etapa 5;

5) Compilação do projeto FORTRAN e execução do programa. 